Portland State University

PDXScholar

$11-2-1994$

\title{
Nonlinguistic Cognitive Performance and Expressive and Receptive Language Scores in Children with Expressive Language Delay
}

Deborah Kay Warren

Portland State University

Follow this and additional works at: https://pdxscholar.library.pdx.edu/open_access_etds

Part of the Speech and Rhetorical Studies Commons

Let us know how access to this document benefits you.

\section{Recommended Citation}

Warren, Deborah Kay, "Nonlinguistic Cognitive Performance and Expressive and Receptive Language Scores in Children with Expressive Language Delay" (1994). Dissertations and Theses. Paper 4884. https://doi.org/10.15760/etd. 6760

This Thesis is brought to you for free and open access. It has been accepted for inclusion in Dissertations and Theses by an authorized administrator of PDXScholar. Please contact us if we can make this document more accessible: pdxscholar@pdx.edu. 


\section{THESIS APPROVAL}

The abstract and thesis of Deborah Kay Warren for the Master of Science in Speech Communication: Speech and Hearing Science were presented November 2, 1994, and accepted by the thesis committee and the department.

COMMITTEE APPROVALS:

Rhea Paul, Chair

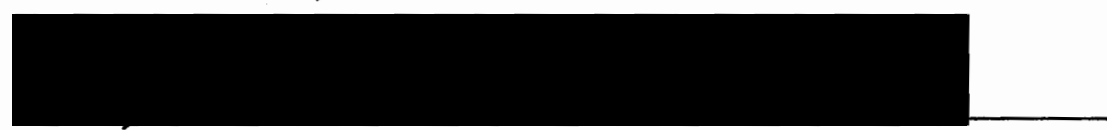

Joan McMahon

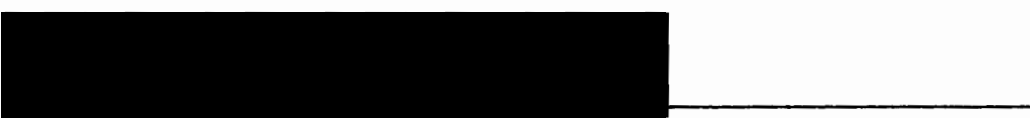

Christine Chaille

Representative of the Office of Graduate Studies

\section{DEPARTMENT APPROVAL:}

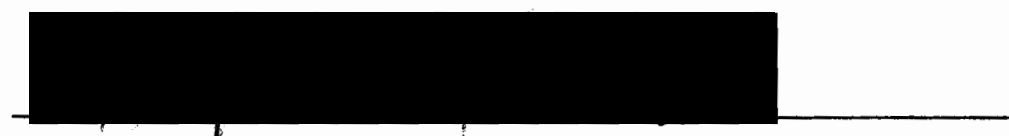

Stephen A. Kosokoff, Chair

Department of Speech Communication

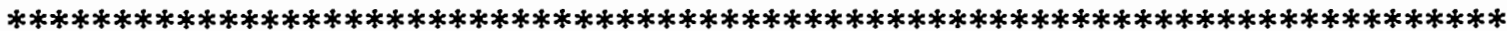

ACCEPTED FOR PORTLAND STATE UNIVERSITY BY THE LIBRARY

by

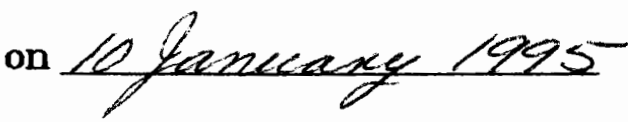




\section{ABSTRACT}

An abstract of the thesis of Deborah Kay Warren for the Master of Science in Speech Communication: Speech and Hearing Science presented November 2, 1994.

Title: Nonlinguistic Cognitive Performance and Expressive and Receptive Language Scores in Children with Expressive Language Delay.

This study was part of the Portland Language Development Project. The purpose was to establish reliability for the Goodenough Draw-A-Man Test. Additionally, nonlinguistic cognitive performance scores were correlated with scores from expressive and receptive language test scores. Finally, scores of overall cognitive function and of nonlinguistic cognitive function in children with normally developing language (NL) and with expressive language delay (ELD) were compared.

The original group size was 60 children, 30 with ELD at the age of 20 months, and 30 who were a matched control group. These subjects were reevaluated during Kindergarten. The Draw-A-Man Test was administered to assess the subjects' nonlinguistic cognitive functioning. The MoCarthy Scales of Children's Abilities (MCSA) was administered to assess the subjects' overall cognitive functioning. A fres speech sample was analyzed using the Developmental Sentence Scoring (DSS) criteria to assess expressive language skills, and the Vineland Adaptive Behavior Scales (VABS), was used to assess receptive language skills. 
Draw-A-Man Test scores were correlated with the Perceptual Performance scores and the General Cognitive Index (GCI) scores of the MSCA to establish construct and concurrent validity, respectively. No significant correlation was found between the Draw-A-Man Test scores and the Perceptual Performance scores, but there was a significant correlation between the Draw-A-Man Test scores and the GCI scores.

Draw-A-Man Test scores were correlated with the DSS scores to examine nonlinguistic cognitive skills and expressive language. Draw-A-Man scores were correlated with scores from the receptive language subtest of the VABS to examine nonlinguistic cognitive skills and receptive language. There were no significant correlations.

Draw-A-Man Test scores from the subjects with NL were compared to the scores of those with ELD, and the GCI scores from the MSCA were compared between the two groups. No significant difference was found between the two groups on their Draw-A-Man scores, but there was a significant difference between the two groups' GCI scores.

Data from this study indicated that the Draw-A-Man Test is a reliable measure for screening a child's overall cognitive performance. It is effective as a screen for children with ELD because it does not penalize them by assessing their cognitive performance via verbal language tasks. 
NONLINGUISTIC COGNITIVE PERFORMANCE AND EXPRESSIVE AND RECEPTIVE LANGUAGE SCORES IN CHILDREN WTTH EXPRESSIVE LANGUAGE DELAY

by

DEBORAH KAY WARREN

A thesis submitted in partial fulfillment of the requirements for the degree of

MASTER OF SCIENCE in

SPEECH COMMUNICATION:

SPEECH AND HEARING SCIENCE

Portland State University

1994 


\section{ACKNOWLEDGEMENTS}

My most sincere thanks to Dr. Rhea Paul, who provided her support throughout the writing of my thesis. It is difficult to find words to express what knowledge I have gained working as a research assistant over the past two years for Dr. Paul on the Portland Language Development Project. My involvement on this project not only made it possible for me to achieve my goal of becoming a practitioner in Speech and Language Pathology, but also, greatly enhanced my understanding of children with language disorders.

A huge thank you must go to Joan McMahon, my academic advisor, whose expertise in winding through the maze of graduate school requirements is unsurpassed. And thank you Joan for helping me to learn how fragile the act of communication really is.

Thanks also to Christine Chaille for adding an air of quiet assurance to my thesis defense.

My most loving thanks to my father, Bob Warren, for his help in my endeavor, and for believing in me enough to assure me, especially through the most difficult times, that I could make it through graduate school.

This work is dedicated to my loving husband, Tom Allen, and my wonderful children, Rebekah and Rachael Warren-Allen. Without their constant love and encouragement, I would not have been able to achieve this goal. Now, I only hope to have the opportunity to return their support by helping each of them to follow their dreams. 
TABLE OF CONTENTS

PAGE

ACKNOWLEDGEMENTS …...................................... iii

LIST OF TABLES ..................................................... vii

CHAPTER

I INTRODUCTION ......................................

Statement of Purpose

Definition of Terms

II REVIEW OF THE LITERATURE ............ 8

Research on Language/Cognition in Children with Normally Developing Language

Language and Cognition in Children with

Specific Language Impairment

Language and Cognition in Children Who

Are Language/Learning Disabled

Children with Slow Expressive Language

Development

Multiple Intelligences and Children with

Specific Language Impairment

The Goodenough Draw-A-Man Test /

Psychometric Data

Summary 
III METHODS AND PROCEDURES ............ 27

Subjects at Intake

Procedures at Intake

Subjects Used for Kindregarten Follow-Up

Procedures at Kindergarten Follow-Up

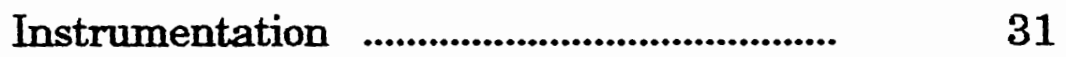

McCarthy Scales of Children's Abilities

Goodenough Draw-A-Man Test

Audio Taping

Systematic Analysis of Language Transcripts

Developmental Sentence Scoring

Vineland Adaptive Behavior Scales

Data Analysis

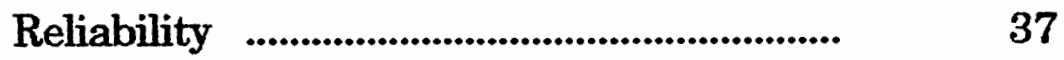

Statistical Analysis

IV RESULTS AND DISCUSSION .................. 40

Results ......................................................... 40

Discussion

V SUMMARY AND IMPLICATIONS ........... 49

Summary $\quad$......................................................... 49

Implications …............................................... 50

Research

Clinical 
REFERENCES

APPENDICES

A HUMAN SUBJECTS RESEARCH FORM 57

B QUESTIONNAIRE FOR PARENTS OF

CHILDREN 15-30 MONTHS OLD

C OREGONIAN ARTICLE 61

D LANGUAGE DEVELOPMENT SURVEY 63

E GOODENOUGH DRAW-A-MAN TEST:

SCORING CRITERIA

65

F GOODENOUGH DRAW-A-MAN TEST:

TABLE OF MENTAL AGE EQUTVALENTS

101

G MCCARTHY SCALES OF CHILDRENS

ABILITIES

H DEVELOPMENTAL SENTENCE SCORE:

SCORING CRITERIA

I DEVELOPMENTAL SENTENCE SCORE:

NORMS

J VINELAND ADAPTIVE BEHAVIOR SCALES 117

K RAW DATA

122 
LIST OF TABLES

TABLE

PAGE

1 Stanford-Binet and Draw-A-Man Correlations:

1929 to 1950

2 Wechsler and Draw-A-Man Correlations:

1950 to 1953

3 Summary of Demographic Data at Intake ..

4 Summary of Demographic Data for Kindergarten Follow-Up

5 Scores for Each Dependent Measure by Group .

6 PP/DAM and GCIDAM Correlations by Group .

7 DSS/DAM and VABS/DAM Correlations by Group

8 GCI Score Comparisons and DAM Score

Comparisons by Group

9 Data Summary 


\section{CHAPTER I}

Introduction and Statement of Purpose

\section{Introduction}

The literature discussing child language development, and disorders in child language, has entertained a variety of relationships between language and cognition. Some researchers believe that there may be a significant relationship between children's nonlinguistic cognitive performance and their expressive and/or receptive language skills at specific times during their development of language. Therefore, clinicians and special educators are in need of a quick and easy-to-administer screen of children's nonlinguistic cognitive skills that can be contrasted with measures of language production and comprehension.

The Goodenough Draw-A-Man Test (Goodenough, 1926) requires only five to ten minutes to administer and about ten minutes to score. Harris (1963) described it as designed to assess a child's ability to formulate concepts, mental proceseses in which qualities, aspecte, and relationships of objects are identified, compared, abstracted, and generalized. In child language development very simple concepts are present as symbols, or first words, are produced. Concept formation continues to develop as the child becomes more able to analyze and abstract. The reconstructions of these abstractions into symbolic form, either in drawing or in language, are considered to be the cognitive skills which relate to language acquisition.

The relationship between children's nonlinguistic cognitive skills and their expressive and receptive language skills has been explored in recent 
research. A study of the correlations between Goodenough Draw-A-Man Test scores and expressive and receptive language test scores, in children with expressive language delay (ELD) and in children with normally developing language (NL), may provide further research data in the analysis of this relationship.

Currently, children who are ELD must receive scores within the normal range on tests of overall cognitive abilities, to qualify for service, but some researchers believe that although these children may be within the range of normal on tests of overall cognitive performance, they may score lower than children with NL on tests of nonlinguistic cognitive performance. A comparison of whether children with ELD score lower on a test of overall cognitive performance than children with $\mathrm{NL}$, and a comparison of whether a group of children with ELD score lower on the Draw-A-Man Test of nonlinguistic cognitive performance than children with NL, will provide research data regarding the belief of many observers that children with ELD have difficulties with nonlinguistic cognition that affects their representational skills in language.

\section{Statement of Purpose}

This study had the following three objectives:

1. Concurrent and construct validity for the Goodenough Draw-A-Man Test will be provided by examining the correlation between the PerceptualPerformance scores from the McCarthy Scales of Children's Abilities (MSCA) (McCarthy, 1972) and the intelligence quotients derived from the Draw-AMan Test. Also, the correlation between the General Cognitive Index (GCI) of the MSCA and the intelligence quotients derived from the Draw-A-Man Test 
will be examined. These correlations will be investigated separately for the ELD and the NL groups.

2. Draw-A-Man Test scores will be compared to expressive language scores derived from Developmental Sentence Scoring (DSS) (Lee, 1974) and the receptive language scores obtained from the Vineland Adaptive Behavior Scales (VABS) (Sparrow, Balla, \& Ciccnetti, 1984) to determine if there is evidence that expressive language performance and/or receptive language performance correlates with nonlinguistic cognitive performance in children with ELD and in children with NL.

3. This study will determine if a group of children with ELD received lower scores on the GCI of the MSCA and on the Draw-A-Man Test than children with NL.

The research questions addressed in this study are:

1. Is there a significant correlation between the Perceptual-

Performance scores from the MSCA and the Draw-A-Man Test scores within a group of children with ELD?

2. Is there a significant correlation between the Perceptual-

Performance scores from the MSCA and the Draw-A-Man Test scores within a group of children with NL?

3. Is there a significant correlation between the General Cognitive Index scores from the MSCA and the Draw-A-Man Test scores within a group of children with ELD?

4. Is there a significant correlation between the General Cognitive Index scores from the MSCA and the Draw-A-Man Test scores within a group of children with NL?

5. Is there a significant correlation between the Draw-A-Man Test 
scores and the DSS scores within a group of children with ELD?

6. Is there a significant correlation between the Draw-A-Man Test scores and the DSS scores within a group of children with NL?

7. Is there a significant correlation between the Draw-A-Man Test scores and the receptive scores from the VABS within a group of children with ELD?

8. Is there a significant correlation between the Draw-A-Man Test scores_and the receptive scores from the VABS within a group of children with NL?

9. Is there a significant difference between the GCI scores from the MSCA when a group of children with ELD and a group of children with $\mathrm{NL}$ are compared?

10. Is there a significant difference between the Draw-A-Man Test scores when a group of children with ELD and a group of children with NL are compared?

The null hypothesis for questions one and two is that there will be no significant correlation between the Perceptual-Performance scores from the MSCA and the Draw-A-Man Test scores within the group of children with ELD or within the group of children with NL.

The null hypothesis for questions three and four is that there will be no significant correlation between the General Cognitive Index scores from the MSCA and the Draw-A-Man Test scores within the group of children with ELD or within the group of children with NL.

The null hypothesis for questions five, six, seven, and eight is that there will be no significant correlation between the DSS scores, the receptive scores 
from the VABS, and the Draw-A-Man Test scores within the group of children with ELD or within the group of children with NL.

The null hypothesis for questions nine and ten is that there will be no significant difference between the GCI scores from the MSCA or between the Draw-A-Man Test scores when a group of children with ELD and a group of children with NL are compared.

\section{Definition of Terms}

1. cognition: A general concept including all of the various modes of knowing; that is, perceiving, remembering, imagining, conceiving, judging, and reasoning (Nicoloski, Harryman, \& Kresheck, 1983).

2. concept formation task: Concepts are presented that have one-feature or two-feature rules that indicate concept membership; that is, novel animals that are defined by one-feature or two-feature rules (Kamhi, Catts, Koenig, \& Lewis, 1984).

3. concrete operational: One of Piaget's four broad stages of cognitive development that describes thinking as characterized by conservation, decentration, and reversibility. Logical thought is performed relative to concrete or physical operations. Items are categorized into hierarchical and seriational categories (Owens, 1992).

4. discrimination learning task: Dimensions are created with color and are varied orthogonally. The subject must infer, verbally, in which jar the same color yarn will always appear as the pattern for moving the jars is varied orthogonally (Kamhi, et al., 1984).

5. Expressive Language Delay (ELD): Children in the Portland Language Development Project were diagnosed as delayed if between the ages of 24 
and 36 months they produced less than fifty words and used no two-word combinations (Paul, 1991).

6. formal operational: One of Piaget's four broad categories of cognitive development that describes the capacity for thought of abstract concepts, complex reasoning, flexibility, and mental hypothesis testing (Owens, 1992).

7. haptic recognition: The subject blindly feels geometric forms and then selects the visual shape that corresponds (Johnston \& Ramstad, 1983).

8. horizontal and vertical axis tasks: The subject draws a line on a figure to predict the orientation of water in a tipped jar (Johnston, et al., 1983).

9. means-end: These behaviors demonstrate a subject's knowledge of various ways to achieve a goal (James, 1990).

10. nonlinguistic cognitive skills: Skills that do not require oral language, but that demonstrate a subject's knowing through nonverbal symbolic representation.

11. normal language: Children in the PLDP were designated as a control group with normally developing language if between 24 and 34 months of age they produced more than fifty words and were using two-word combinations (Paul, 1991).

12. object permanence: A subject's realization that objects have a separate, permanent existence outside of their immediate perceptual experience (James, 1990).

13. preoperational: One of Piaget's four broad categories of cognitive development characterized by further development of symbolic function; that is, language, physical problem solving, and categorization. Thinking 
is characterized by centration, irreversibility, and egocentricity (Owens 1992).

14. sensorimotor period: From birth to two years of age, children learn about their environment through their senses (seeing, smelling, hearing, touching, tasting) and through motor experiences (James, 1990).

15. symbolic play: A child's ability to make one object represent another during play (James, 1990). 


\section{CHAPTER II}

\section{Review of the Literature}

During the last twenty years, the field of Speech-Language Pathology has been exposed to a variety of theories attempting to determine the global relationship between language and cognition. These theories have provided rich and thought-provoking arguments in the literature as described by Rice and Kemper (1994). Potential relationships that exist between language and cognition are: (a) Language has its origin in cognition; (b) Some of language has its origin in some of cognition; (c) Language and cognition interweave, but originate from different sources; (d) Language and cognition interweave, and both originate from shared common sources; (e) Language and cognition are separate, and both originate from different sources; (f) Cognition has its origin in language; and (g) Some of cognition has its origin in some of language.

However, most discussions regarding the relationship between cognition and language use a Piagetian framework. Gleason (1989) describes Piaget as a "cognitive interactionist." Piaget believed that cognitive changes in the child were the basis for communicative intent. Linguistic structures emerge as a direct result of the interaction between the child's level of cognition and his/her linguistic and non-linguistic environment. According to Gelman \& Byrnes (1991), Piaget viewed language as a window onto the relationship of language and cognition. He noted three milestones along the continuum of a child's cognitive development in which language "may" play an important role. The first milestone takes place when a child acquires "object permanence" and 
transcends from the sensorimotor period, in which actions and perceptions are based solely in the here and now, to representational intelligence, during which time the emergence of language occurs and the child is able to understand that objects exist which are not immediately apparent in the here and now. These objects can be recalled from memory or imagined in the future. At this stage the child is beginning to use linguistic symbols as his/her first words to name objects that may or may not be in the immediate environment. Additionally, as the child learns that people typically act on the things in their environment, word combinations appear in the form of agentaction, and eventually in the form of agent-action-object. A cognitive awareness of these relationships in his/her environment provide a basis for early syntactical structures.

The second milestone occurs when a child moves from preoperational thinking to concrete operational thinking. During this time, children are thought to develop a "logic of classes" in which the child is able to organize elements within a class based on their relative subordinate or superordinate relationship within that class. Additionally, the child develops a "logic of relations", at this time, allowing comparisons within classes to be made. Appropriate language in accord with this level of thinking is assimilated as this transition occurs.

Finally, the third milestone is the transition from concrete operational thought to formal operational thought. Language at this time represents such propositional concepts as "if...then" and "either...or". However, Piaget believed that without symbolic expression the milestones described above would remain interpersonal and that symbolic expression is a social obligation 
required to elaborate one's thoughts. In this sense, language and thought are a reciprocal action.

Rice (1983) describes the 1970's and 1980's as a time when many investigators were conducting studies in an attempt to answer the language vs. cognition question. Some believed that language problems stemmed from a general problem with mental representation. Others believed that language problems were related to difficulties in auditory processing and to memory deficits. Studies, usually incorporating Piagetian-type cognitive tasks, were undertaken to determine the role of cognition in language impairment and remediation, but results have been equivocal. Out of these studies, several hypotheses have grown: The Cognition Hypothesis claims that cognition underlies language acquisition. This hypothesis has its basis in Piaget's theory that language is one of several representational skills that children master and that cognition is a necessary base for language development because it provides the meanings necessary for a child to decode and encode words and, eventually, sentences. However, when investigators compared Piagetian tasks such as object permanence, means-end, or symbolic play with language production, the cognitive knowledge that was theorized to be the base for language did not always precede the expression of language. Although related cognitive and linguistic thought appeared to emerge at the same time, they did not emerge in a set order. Sometimes the language was apparent first and sometimes the cognition was apparent first.

From these observations, the Local Homologies Hypothesis evolved as a modification of the Cognition Hypothesis. This hypothesis continues to accept the basis of cognition underlying language, but not in a global sense. Instead, 
cognition is believed to underlie language only at specific times during language and cognitive development.

Additionally, some investigators argued that language may directly influence cognition, thus came the Interaction Hypothesis. Perhaps language assists the mapping of thought and the stabilizing of cognition. We use language, after all, to teach thinking.

Finally, the Weak Cognition Hypothesis argues that cognition may supply necessary meaning, but that does not account for all aspects of language development. Mismatches occur as children acquire more difficult means of expressing the same thought, or as they acquire word meanings based on an association between words rather than simply as a referent for an action or object. Also, mismatches occur as children who are cognitively challenged achieve linguistic levels of functioning that are higher than their cognitive levels of functioning.

Rice (1983) concludes her overview of the ongoing controversy over the relationship between cognition and language by stating that the relationship appears to "...vary as a function of age, linguistic abilities in question, and the type of cognition involved. If that is the case, then any attempt to characterize the relationship in global terms is misdirected" (p.354).

According to Thal (1991), the Local Homology Hypothesis is the most widely accepted at this time. It makes no attempt at establishing a global relationship between language and cognition, but rather attempts to identify specific non-linguistic cognitive skills and how they may relate to specific language skills as they occur in a child's early development. There is no claim that one cognitive skill must precede a certain language skill, only that correlations exist at specific times during a child's development. 
Research on Language/Cognition in Children with Normally Developing Language

Studies examining the relationship between language and non-linguistic cognitive skills in children with normally developing language (NL) have been conducted to evaluate the correlations that may exist between specific stages of language acquisition and non-linguistic cognitive abilities. A study by Gopnik and Meltzoff (1986) found that nineteen children with NL acquired disappearance words a few weeks prior to their solving complex Object Permanence tasks and they acquired success/failure words a few weeks prior to solving complex Means/Ends tasks. A closer look at these results shows that simple Object Permanence tasks and Means/Ends tasks were solved just before, or concurrently, as the children acquired the appropriate semantic representation of their accomplishments. Within a few weeks of the emergence of these linguistic concepts, the more complex Object Permanence and Means/End tasks were solved. Not only is there an apparent relationship between language and cognition as demonstrated by this study, but the relationship is interwoven. Cognitive concepts may precede and/or co-occur along with some linguistic development and some linguistic development may assist a child's cognitive achievements.

Symbolic Skills. A study conducted by Kelly and Dale (1989) intended to evaluate the symbolic representational skills that co-occur with nonproductive syntax and with productive syntax. They looked at twenty children with NL and how No Word Users, Single Word Users, Nonproductive Syntax Users, and Productive Syntax Users performed when tested on tasks of Object Permanence, Means/End, Play, and Imitation. Kelly and Dale observed that, as hypothesized in earlier studies, there are relationships between specific 
linguistic skills and cognitive abilities. In example, the Single Word Users scored significantly higher than the No Word Users in the assessment of their Symbolic Play schemes. The Nonproductive Syntax Users exhibited significantly more advanced Imitation and Play skills than the Single Word Users and the Single Word Users did not achieve levels 4 or 5 of Play, but the Productive Syntax Users did.

It is difficult, however, to draw concrete conclusions from studies that have been done to explore the relationship between non-linguistic cognitive skills and language development because often findings are equivocal. Rice (1983) states that some research has found that Piagetian tasks such as Object Permanence, Means/End, and Symbolic Play do not always establish the same co-occurrence of non-linguistic cognitive abilities and expressive language skills. Kelly and Dale's (1989) observations indicated that some of their subjects reached developmental language milestones before they achieved the related cognitive milestones. They conclude, as does the Local Homologies Hypothesis, that there are specific non-linguistic cognitive skills that relate to a child's language development, but one must be cautious in drawing conclusions regarding a global relationship.

\section{Language and Cognition in Children with Specific Language Impairment}

Tallal (1988) states that during the 1970's and 1980's it has been a common practice to consider children who are language impaired (LI) as having normal nonlinguistic intelligence and normal overall cognitive capacity. There is much research, however, that indicates that children who are LI do have difficulties with nonlinguistic cognitive skills. Tallal outlines some of the areas in which research indicates they are having difficulties as: means/ends 
tasks; drawing conclusions from events in which the information is processed visually; classification; thought requiring visual imagery, including: haptic recognition, seriation, and mental rotations; formulating rules and hypotheses; and both short term memory processing and short term memory capacity.

Tallal (1988) further elaborates that some researchers believe that children who are LI may not simply have deficits in their ability to use language, but that this inability to represent their thought in language is a symptom of their general inability in a variety of representational tasks. Perhaps children who are slow to begin talking, who have fewer words in their developing lexicon than children with normally developing language, and who use fewer semantic relationships to express their ideas are exhibiting their deficiencies in representation, linguistically.

Language and Cognition in Children who are Language/Learning Disabled

Whitmire and Stone (1991) studied 15 children who were diagnosed as language-learning disabled (LLD) and 15 children with normal achievement. Scores from the Test of Language Development-P (TOLD-P) were correlated with the children's' performance on imagery tasks. There was a significant relationship between the degree of language disability as assessed by the TOLD-P and the children's performance on two of the three imagery tasks. Additionally, their abilities with regard to imagery appeared to be more significantly related to their performance in the realm of semantics than syntax. They argue, based on their findings, that there may be a specific link between visual imagery, such as is required in the formulation of nonlinguistic concepts, and vocabulary acquisition. 
Powell and Germani (1993) administered the Clinical Evaluation of Language Fundamentals-Revised (CELF-R), the Test of Nonverbal Intelligence (TONI), and the Vineland Adaptive Behavior Scales (VABS) to 53 school-aged children who had been diagnosed with communication disorders to determine correlations that may exist between these children's language skills, both expressive and receptive, their nonlinguistic performance, and their adaptive behaviors. All test scores were in the "below average" to "well below average" range. Moderate correlations were found across the test battery. The moderately high correlation between the CELF-R scores and the TONI scores indicate that the type of skills needed to solve the nonlinguistic problems presented by the TONI may be similar to those required to solve the linguistic problems presented in the CELF-R. Although Powell et al. urge caution in the interpretation of their findings, they are among a group of researchers who disagree with the common practice of determining a child's eligibility for service based on normal cognitive capacity and below normal linguistic performance. Instead, these researchers argue in favor of a "qualitative differences model" of service delivery.

Representational Skills. Researchers have hypothesized that children who are LI have deficiencies in representation and symbolism. Kambi (1981) studied ten children who were LI and their performance on six nonstandardized, cognitive Piagetian tasks that assessed nonlinguistic, symbolic skills and the concepts of class, number, and order. Their results were compared to two groups of ten children each with NL: one group that was matched for mental age (MA) and the other that was matched for mean length of utterance (MLU). Performance on the haptic recognition task was significantly different between the children who were LI and the controls 
matched for MA, indicating that the children with LI have deficient nonlinguistic symbolic skills.

Johnston and Ramstad (1983) examined the performance of seven children diagnosed as LI on a series of Piagetian tasks. Their results, also, demonstrated that although these children were assessed as having normal range IQs, they had significant difficulty with tasks requiring the child "to anticipate and imagine physical states across transformations, such as the Horizontal and Vertical Axis Tasks or Haptic Recognition Tasks" (p 52.).

Kamhi, Catts, Koenig, and Lewis (1984) conclude that performance on nonlinguistic cognitive tasks does not always adequately determine the functioning in other cognitive domains of the child who is LI. They used a discrimination learning task and a concept formation task to assess the hypothesis-testing abilities, and a haptic recognition task to test the nonlinguistic symbolic performance of ten children who were LI and ten children with NL. The children who were LI performed significantly more poorly on the haptic recognition task and a portion of the discrimination learning task as compared to the control group. Additionally, there was a strong correlation between performance on the haptic recognition task and the Peabody Picture Vocabulary Test. Kamhi et al. speculate that their results may indicate that there is a stronger relationship between nonlinguistic symbolic deficits and receptive language skills than expressive language skills.

\section{Children with Slow Expressive Language Development}

Some researchers are currently studying children with expressive specific language impairment (SLI-E). These children score within the normal range on tests of intelligence and have receptive language skills that are age 
appropriate, but their expressive language is significantly delayed. In their study, Rescorla and Goosens (1992) examined the symbolic play activities of these children. Symbolic play activities provide a window on a child's representational capabilities. Piagetian theory maintains that play and language develop along side one another, and several studies have been done during the previous two decades to establish the relationship between play and expressive language.

In their study, Rescorla and Goosens (1992) found that the children with SLI-E used more functional, conventional play schemes than the matched children with NL. The children with NL used more complex play behaviors. Additionally, the children with SLI-E exhibited fewer types of play incorporating sequences and symbolism when compared to the children with $\mathrm{NL}$, who used objects for other than their real purpose and used pantomime and pretend activities significantly more often than the children with SLI-E.

They are cautious, however, in drawing general conclusions from their results. They hypothesize that the delays may be "stylistic" and therefore representative of individual differences in developmental patterns. The delays may represent a slower maturation of symbol use which supports some researchers observations that children with SLI-E simply fall at the low end of normal in their abilities to use language and symbolism. And finally, the delays may represent a problem in access or retrieval. Since these children demonstrate normal language comprehension, they may lack the ability to quickly and adequately access or retrieve their stored information. 
Multiple Intelligences and Children with Specific Language Impairment

Leonard (1991) questions the notion of the "Specifically Language Impaired" (SLI) child as being disordered. He argues that in our culture, language skills and logical-mathematical skills are often used to assess a child's level of intelligence because of their supreme importance in our educational system. Leonard hypothesizes that perhaps children who are diagnosed as SLI are simply products of the same types of variations in genetic make-up and environmental influences that cause some children to be musical and others to be lacking in musical ability.

Secondly, Leonard clarifies his hypothesis from earlier research which states that children with SLI fall in the low-end of normal on standardized tests. He states that these children appear to exhibit atypical progress as their language develops. They may score 1 year below age level in certain language acquisition skills and 1 1/2 years below age level in other language acquisition skills. He again uses the analogy of the child with musical abilities as compared to the child lacking in musical abilities. We do not consider a child lacking in musical abilities disordered because various musical skills are determined to fall below the musical skills of the musically inclined child. Instead, these differences may represent the "individual differences" in rate of learning, style of learning, skill level achieved, aptitude, and environmental input that every person exhibits as they learn a skill.

Finally, Leonard comments on other researchers' observations that children who are diagnosed as SLI exhibit deficits in areas of nonlinguistic symbolic representation which are believed, by some, to cause the child's language deficits. He questions whether these deficits cause the child's 
language deficits or are rather a part of their general inaptitude in symbolic representation, whether it be linguistic or nonlinguistic.

The implication of this argument according to Leonard is not that children who are SLI should not receive treatment. Instead, he suggests that training in an area in which a person has below average skills can, often, be beneficial to the individual as a whole, especially in regards to language because of its wide-spread cultural implications. He states his disagreement, however, with researchers who seem determined to establish that children who are SLI have a damaged system. Instead, he hypothesizes that these children may simply fall "at the very low end of the normal distribution in ability" (p. 68).

Much research has been done to go beyond the quantitative measures of cognitive capacity and nonlinguistic performance in children who are LI to look at specific qualitative differences in their processing. These studies have attempted to look at the relationship between linguistic and nonlinguistic skills, rather than simply to measure quantitative outcomes. Restrepo, Swisher, Plante, and Vance (1992) tested 20 children with SLI and 20 controls with NL using experimental language-learning measures, experimental nonlinguistic measures, and linguistic and nonlinguistic norm-referenced tests. Each group was introduced to novel vocabulary words, first, via a story format, next through a game format, and finally post tests were administered to assess the children's verbal expression of these forms. The same format (story, game, post test) was used to introduce each group to novel bound morphemes and to assess their verbal expression of the forms. Other variables included a Rule Induction task to assess the subjects' ability to induce rules non-verbally; the Snail-Trail Measure to assess spatial rotation 
skills; the Grammatic Closure subtest of the Ilinois Test of Psycholinguistic Abilities (ITPA-GC) to assess the subjects' expressive bound morpheme level; The Peabody Picture Vocabulary Test-Revised (PPVT-R) to assess the subjects' receptive vocabulary; and the Leiter International Performance Scale (LIPS) to assess general nonlinguistic performance. Results indicated that there were qualitative differences in performance between the children who were SLI and those with NL when scores from the seven variables were analyzed. Scores on the Rule Induction task and the bound morpheme task differed significantly between groups indicating that qualitative differences occur not only in the language system, but in the nonlinguistic cognitive system, as well. Studies that have compared children who are SLI and those with NL, only quantitatively, have concluded that children with SLI are within the low range of normal. However, Restrepo et al. conclude that children who are SLI exhibit atypical linguistic and nonlinguistic cognitive strengths and weaknesses as well as unique relationships between linguistic and nonlinguistic skills, indicating that their cognitive systems are qualitatively different, not low normal.

Dale and Cole (1991) discuss SLI from the perspective of "individual differences". The acquisition of difficult language skills, such as the use of bound morphemes, has been observed by researchers looking at both children diagnosed as SLI and children who have developed precocious language systems. In both of these groups, uneven patterns of bound morpheme use was observed, indicating that "individual differences" are present in both groups as they acquire elements of a particular language domain.

Dale and Cole believe that there has been a tendency to overlook "individual differences" in regards to the relationship between language and 
nonlinguistic skills due to the strong influence of the Cognitive Hypothesis, which assumes that a child must have cognitive skills within the normal range in order for remediation to be effective in the area of language skills. In an earlier study, Cole, Dale, and Mills (1990) studied two groups of children: one group whose language skills were below average and whose cognitive skills were matched to their language skills, and another group whose language skills were also below average, but whose cognitive skills were above their language skills. Both groups received intervention for a year and both groups benefited from the intervention. They conclude that these findings support Leonard's view that language delay is a variation in an intact system rather than the result of a damaged system. Additionally, they argue in favor of movement away from a medical treatment model in which assessment emphasizes the determination of an underlying cause for the disorder and treatment evolves from a differential diagnosis. Instead, they support movement toward the use of an educational model of language facilitation in which emphasis is on "individual differences, developmental causality, criterion-referenced assessment, and direct 'treatment' of deficits...[in] natural locations (home, classroom) and interactive styles of treatment, including communication and collaboration with parents in the design and implementation of intervention" (p. 83).

Aram (1991) sees the group of children who are language impaired that fall into the low-end of normal range as being only a subgroup of those with SLI. She believes that an understanding of causality will have clinical implications in regards to treatment methods. In example, we cannot treat all children with SLI as if they are at the low-end of normal and assume that they will eventually acquire language skills as their normal peers do if there is a 
causal factor that does not allow them to learn as a child with NL. Further, she states that an understanding of cause may allow us to help in the prevention of language disorders at some time in the future.

\section{The Goodenough Draw-A-Man Test/Psychometric Data}

The abilities tapped by the Goodenough Draw-A-Man Test represent conceptual maturity. According to Harris (1963), the drawing test is most effective when used to assess children who are in Piaget's "concrete operational" stage, when they are able to distinguish themselves as agents and their goals as actions which may have an effect on outcome. During this stage children range from age five or six years to age eleven or twelve years. Children's drawings have been studied in depth by Goodenough and other researchers and developmental attributes have been assigned to the drawings.

Goodenough's analytical method of scoring has been evaluated based on the performance of children with atypical social behavior, with mental retardation, and based on the performance of children with normal or average behavior and intelligence. The scores of children with hearing impairment have been evaluated, and gender differences have been evaluated. These evaluations have established that children who are socially and emotionally maladjusted score more poorly than children who are well adjusted. The drawings of children who are maladapted have characteristics similar to those children with mental retardation. Additionally, the Goodenough Draw-A-Man Test has been found effective in the assessment of children who are hearing impaired because it does not rely on linguistic skills, which are often deficient in children with hearing impairment. Girls tend to score slightly higher than 
boys and it is hypothesized that this is due to their advanced level of maturity relative to tasks requiring eye-hand-coordination.

Correlations between the Stanford-Binet and the Draw-A-Man fell between .41 and .65 in studies of normal children and disordered children between 1929 and 1950 (see Table 1). Correlations between the Wechsler Intelligence Scale for Children and the Draw-A-Man were slightly higher when considering the Perceptual Subtest (P) as compared to the Verbal Subtest (V) (see Table 2).

Current construct and concurrent validity for the Goodenough Draw-AMan Test can be obtained for normal children and for children with ELD by, first, comparing each groups scores on the Draw-A-Man with the PerceptualPerformance subtest from the MSCA, which measure children's nonlinguistic cognitive performance. Second, the scores obtained from the General Cognitive Index of the MSCA, for both the children who are ELD and who have $\mathrm{NL}$, will be compared to determine if there is a greater correlation between the Draw-A-Man and overall cognitive performance or nonlinguistic cognitive performance. 
Table 1

Stanford-Binet and Draw-A-Man Correlations-1929 to 1950

Study

Group

Correlation

Yepson (1929) 37 boys with mental retardation, ages

.60

nine to eighteen years

Williams (1935) 100 subnormal to gifted children, ages

.65

three to fifteen years

Havinghurst \& 70 normal children, ten-year-olds

.50

Janke (1944)

McHugh (1945) 90 normal children, kindergarten aged

Johnson, Ellerd, \& all mentally subnormal, epileptic, \& brain

Lahey (1950)

damaged children in a state hospital

Table 2

Wechsler and Draw-A-Man Correlation-1950-1953

\begin{tabular}{lll}
\hline Study & Group & Correlation
\end{tabular}

Rottersman (1950) 50 normal children, six-year-olds $\quad P .43$

V .38

Ellis (1953)

psychiatric outpatients, seen annually,

P.47

from ages eight to thirteen years

V .43

Note. Annual correlations for the Ellis study were averaged over six years. 'P' refers to Perceptual and 'V' to Verbal Subtests. 


\section{Summary}

Twelve studies were discussed to explore the variety of ways in which the relationship between language and cognition have been observed. Two studies of children with NL reported that some subjects exhibited certain cognitive behaviors before a related language skill was achieved, while others exhibited certain language skills before they achieved the related cognitive milestone.

Seven of the studies explored the qualitative differences among children with language disorders as reflected by the comparison of their performance on nonlinguistic tasks and on their expressive and/or receptive language test scores. These researchers believe that the data from many other studies has been too quantitative in nature, looking only at scores of overall cognition as they compare to children's language skills. Results of these studies indicate that children with language disorders often score more poorly on nonlinguistic cognitive tasks than do their peers with NL.

One study argues that children who are SLI score lower on nonlinguistic tasks, not because they have disordered systems, but because they are demonstrating their general inaptitude for symbolic expression, be it nonlinguistic or linguistic. These children are believed to fall at the low end of normal distribution when their symbolic functioning is assessed.

Two of the studies stressed the need to consider the "individual differences" of children with language disorders. They argue that the children who are at the low end of normal distribution may not acquire language skills as their peers with NL because they may have causal factors that do not allow them to learn as the child with NL learns. 
Differences in children's nonlinguistic cognitive performance may be a diagnostic indicator for deficits in expressive and/or receptive language disorders. 
CHAPTER III

Methods and Procedures

\section{Subjects at Intake}

A total of 60 subjects were recruited for the Portland Language Development Project (PLDP) when they were between 18 and 34 months of age (Paul, 1991). The PLDP is a longitudinal study following children with expressive language delay (ELD).

Subjects were recruited from three sources:

1. Parents who took their babies in for well-baby checks at three pediatric clinics, Kaiser Permanente Beaverton, Kaiser Permanente Health Center East, and the Metropolitan Clinic, were asked to fill out questionnaires about their children's expressive language development.

2. Parents who responded to a radio broadcast, asking for children with expressive language delays, were asked to fill out the same questionnaire.

3. Parents who responded to an article in the Oregonian, asking for children with expressive language delays, filled out the same questionnaire.

At intake, 30 children were categorized with ELD. They produced fewer than 50 words by the ages of 24-34 months. This information was obtained from parents' responses to the Language Development Survey (LDS) designed by Rescorla (1989). Thirty children were selected as a control group with normally developing language (NL). They had expressive vocabularies that exceeded the above criteria.

Subjects were matched for age, socioeconomic status, (SES), race, and gender ratio. The average age of the children with ELD was 25.4 months (SD 
4.6) and the average age of the control group was 25.2 months (SD 4.0). The Hollingshead Four Factor Scale of Social Position (Meyers \& Bean, 1968) indicated that the children with ELD fell into the middle to lower-middle socioeconomic class and the control group was similar. The children with ELD had no non-white ethnic group members and $17 \%$ of the control group were from non-white ethnic minorities. The children with ELD were $76 \%$ male and the control group were $69 \%$ male.

Table 3

Summary of Demographic Data

$\begin{array}{ccccc}\text { Group } & \text { Age* } & \text { SES** } & \% \text { Non-White } & \text { \% Male } \\ \underline{\mathrm{M}} & \underline{\mathrm{SD}} & \underline{\mathrm{M}} & \underline{\mathrm{SD}} & \end{array}$

\begin{tabular}{llllllll}
\hline ELD & 30 & 25.4 & 4.6 & 2.6 & 1.4 & $0 \%$ & $76 \%$ \\
NL & 30 & 25.2 & 4.0 & 2.6 & 1.0 & $17 \%$ & $69 \%$ \\
\hline
\end{tabular}

* Age is in months.

**SES is based on the Myers \& Bean (1968) four factor scale in which 1 is the highest and 5 is the lowest rating.

\section{Procedures at Intake}

Research assistants evaluated all of the subjects who were selected. They passed a hearing screening at $25 \mathrm{dBHL}$, all had a score of 85 or better on the Bayley Scales of Infant Development (Bayley, 1969), and all passed an informal, observational screening in which components of neurological disorders or autism were ruled out. 
Subjects Used for Kindergarten Follow-Up

The current study includes 49 subjects from the PLDP who were between the ages of 5:6 and 6:6 during collection of the data used in this study. Twenty-three of the subjects who participated were from the group identified as having ELD and 26 of the subjects who participated were from the group with NL.

The groups for this study were matched for age, socioeconomic status (SES), race, and gender ratio. The average age of the ELD group for this study was 71.2 months (SD 1.93) and the average age of the control group was 71.7 months (SD 3.17). Using the Hollingshead Four Factor Scale of Social Position as an indicator, slightly more than half (13) of those children with ELD fell into the middle to lower-middle socioeconomic class and the remainder (10) were in the upper-middle class. The mean SES for this group was 2.74 (SD 1.01). The control group were split evenly: 13 fell into the middle to lower-middle socioeconomic class and 13 were in the upper-middle class. The mean SES for this group was 2.54 (SD 1.39). Four percent of the children with ELD were from non-white ethnic minorities and $8 \%$ of the control group were from non-white ethnic minorities. The children with ELD were $78 \%$ male and the control group were $69 \%$ male. Table 4 provides a summary of this demographic data. 
Table 4

Summary of Demographic Data

\begin{tabular}{lllllllll}
\hline Group & $\underline{n}$ & \multicolumn{2}{c}{ Age* } & \multicolumn{2}{c}{ SES** } & \% Non-White & $\%$ Male \\
& & $\underline{\mathrm{M}}$ & $\underline{\mathrm{SD}}$ & $\underline{\mathrm{M}}$ & $\underline{\mathrm{SD}}$ & & & \\
\hline ELD & 23 & 71.2 & 1.93 & 2.74 & 1.01 & $4 \%$ & $78 \%$ \\
$\mathrm{NL}$ & 26 & 71.7 & 3.17 & 2.54 & 1.39 & $8 \%$ & $69 \%$ \\
\hline
\end{tabular}

* Age is in months.

**SES is based on the Myers \& Bean (1968) four factor scale in which 1 is the highest and 5 is the lowest.

\section{Procedures at Kindergarten Follow-Up}

When the subjects were between 5.6 and 6.6 years of age, and attending kindergarten, they were tested, as part of the ongoing PLDP, by a licensed psychologist for overall cognitive abilities and for motor abilities using the McCarthy Scales of Children's Abilities (MSCA). The 18 subtests were administered according to the MSCA manual guidelines during a single visit to each subject's home. MSCA scoring guidelines were used.

The subjects were also evaluated as part of the PLDP longitudinal followup, during the period described above, by PLDP research assistants. This evaluation took place at Portland State University during which time a battery of tests were given.

The Goodenough Draw-A-Man Test was administered by giving the subject a piece of paper and a pencil. Verbal instructions were then given by 
the research assistant: "On this paper I want you to make a picture of a person. Make the very best picture you can. Take your time and work very carefully. Try very hard and see what a good picture you can make." All questions were answered with: "Do it whatever way you think best." The subject's drawing was scored according to the 51 point scoring protocol.

A free speech sample was recorded on audio tape while the parent and subject played with a Fisher Price doll house with toy people and furniture. The free speech sample was later transcribed and analyzed by the Systematic Analysis of Language Transcripts (SALT) (Miller \& Chapman, 1985) computer software program. Fifty utterances were chosen from the analysis to be scored according to the Developmental Sentence Scoring (DSS) protocol.

While the subjects were within the same age range, their primary caregiver was interviewed by telephone by a PLDP research assistant according to the Vineland Adaptive Behavior Scales (VABS) protocol. The subject's daily living skills that require self sufficiency and social skills, as well as gross and fine motor skills, were assessed and the interview was scored according to VABS scoring guidelines.

\section{Instrumentation}

\section{McCarthy Scales of Children's Abilities (MSCA)}

The MSCA is designed to measure the overall cognitive functioning of children between the ages of 2.5 and 8.5 years of age. It consists of 18 subtests that assess mental and motor skills. These are grouped into five scales: Verbal, Perceptual-Performance, Quantitative, Memory, and Motor. When the test is scored, the first three scales are combined to obtain the child's General Cognitive Index (GCI). All of the Memory subtests and two of 
the Motor subtests are included in the Verbal, Perceptual-Performance, and Quantitative scales. Three of the subtests of gross motor skills are not included. Thus, the GCI is comprised of 15 of the 18 subtests.

The MSCA was standardized using 50 girls and 50 boys in each of ten age levels for a total of 1,032 children. Subjects lived in four geographic areas of the country and were chosen from urban as well as rural areas. It was stratified on age, gender, race, geographic region, and father's occupation. The GCI scores and the Perceptual-Performance scores will be used for correlations and comparisons as described in the Purpose Statement of this study. Internal consistency of the GCI scores is $93 \%$ and test-retest reliability is $90 \%$ when averaged across age ranges. Internal consistency of the PerceptualPerformance scores is $84 \%$ and test-retest reliability is $79 \%$ when averaged across age ranges. Concurrent validity between the GCI scores and the Wechsler Preschool and Primary Scale of Intelligence (WPPSI) is from $62 \%$ to 71\%. The concurrent validity between the Perceptual-Performance scores and the WPPSI is between $47 \%$ to $61 \%$. Concurrent validity between the GCI scores and the Stanford-Binet Intelligence Scale is $81 \%$ and concurrent validity between the Perceptual-Performance scores and the Stanford-Binet is $70 \%$.

\section{Goodenough Draw-A-Man Test}

The Draw-A-Man Test is designed to assess the conceptual maturity of children between the ages of $3: 3$ and 13:6 via a nonverbal drawing task. Goodenough devised a 51 point scoring system. The child's drawing is given one point for each of the 51 criteria that are exhibited. The total raw score is 
then converted to a mental age. The intelligence quotient is derived by a ratio of the mental age divided by the child's chronological age.

Normative data was derived from drawings by 4,000 children in kindergartens and grades one through four in Perth Amboy, New Jersey. Test-retest reliability was $94 \%$ and split-scale reliability was $77 \%$. Concurrent validity as compared to the Stanford-Binet Mental Age Test was $75 \%$. Goodenough reported that the Draw-A-Man Test was able to predict school success, but no data were given to support this claim.

\section{Audio Taping}

The subjects' free speech sample collected by the PLDP research assistants during the kindergarten evaluation were audio taped using a Sony Dictator/Transcriber BM-88, a Sony ECM-144 Electret condenser lavaliere microphone, and Sony DC-30 cassette tapes.

\section{Systematic Analysis of Language Transcripts (SALT)}

The subjects' free speech samples were transcribed orthographically by a PLDP research assistant, with bound morphemes indicated. The free speech samples were transcribed directly into an IBM-compatible computer equipped with the SALT program. The research assistant segmented the utterances first according to intonation contours. A second analysis segmented them further into T-units. T-units were determined based on the length of pause within the subjects' utterances, often followed by the preposition "but," "and," or "because". This segmentation allowed the SALT program to compute utterance length without undue influence from run-on sentences. 


\section{Developmental Sentence Scoring (DSS)}

Developmental Sentence Scoring (DSS) is designed to assess children's free speech samples. Fifty utterances were chosen from the SALT transcript and were scored by PLDP research assistants according to the DSS scoring protocol. Each utterance must have a noun and a verb in subject-predicate relationship. There are eight syntactic categories used in the scoring of each utterance: indefinite pronouns, personal pronouns, main verbs, secondary verbs, negatives, conjunctions, interrogative reversals, and wh-questions. Each category can receive a score of from one to eight based on the complexity of the utterance. The appropriate number of points is given to each utterance based on the number of syntactic structures present in the utterance and the complexity of the structure. Additionally, each utterance receives a sentence point if it is syntactically correct by adult standards. Points for all fifty sentences are totaled and divided by fifty to obtain a DSS score which is then assigned a percentile rank. These percentile ranks will be used in the comparisons and correlations described in the Purpose Statement.

The DSS was standardized using 200 white children with five boys and five girls at each three-month interval. All of the subjects lived in Ilinois, Maryland, Michigan, and Kansas and came from homes in which standard American English was spoken. They came from middle-income families, with the exception of three of the children. The overall, internal consistency of the DSS is $\mathbf{7 1 \%}$. Split-half reliability is $\mathbf{7 3 \%}$. Construct validity was determined by analyzing the overall scoring procedure for each of the grammatical categories. As the children's ages increased, their scores for the use of spontaneous use of syntax and morphology increased systematically, 
indicating that their grammatical development is being measured by this instrument. No concurrent validity was reported.

\section{Vineland Adaptive Behavior Scales (VABS)}

The $(\mathrm{VABS})$ is a structured parent interview designed to assess a child's performance during daily activities that require self sufficiency and social skills, from birth through 18:11. Information is obtained from the caregivers in the four following areas: the Communication Domain, including Expressive, Receptive, and Writing subdomains; the Daily Living Skills Domain, including Personal, Domestic, and Community subdomains; the Socialization Domain, including Interpersonal Relationships, Play and Leisure Time, and Coping Skills subdomains; and the Motor Skills Domain, including Gross and Fine subdomains.

The VABS was standardized on 3,000 individuals who were divided into 15 age groups of 200 individuals each. The sample contained children from the four geographic regions of the United States as determined by the 1980 U.S. census. It was stratified based on age, sex, race or ethnic group, and level of parental education. Only scores from the receptive language portion of the Communication Domain will be used in the correlations described in the Purpose Statement of this study. Split-half reliability for this subtest is $84 \%$. Test-retest reliability is $99 \%$ and inter-rater reliability is $99 \%$ for the Communication Domain scores. Content validity was determined by a careful review of other adaptive behavior scales and child development. Test items were then designed to assess adaptive behavior according to the test designers' definition. Concurrent validity between the VABS and the original Vineland Social Maturity Scale (Doll, 1935, 1965) was low due to the 
expansion of the revised VABS. Additionally, concurrent validity between the VABS, the Kaufman Assessment Battery for Children (1983), and the Peabody Picture Vocabulary Test-Revised (1981) were also low because the intelligence test and the receptive language test each assess different areas than does the adaptive behavior scale. However, the Communication Domain did have higher validity with each of the previously mentioned tests than did the other domains due to the language content of all three measures.

\section{Data Analysis}

This investigator collected scores from the 49 subjects' files, who were selected for the current study, and who were assessed during the follow-up, kindergarten evaluation by the licensed psychologist. The PerceptualPerformance subtest scores and the GCI scores from the McCarthy Scales of Children's Abilities was used for the comparisons and correlations described in the Purpose Statement of this study.

Scores from the follow-up, kindergarten evaluations performed by the PLDP research assistants were collected from the 49 subjects' files selected for the current study. Scores from the following test instruments were used in the comparisons and correlations described in the Purpose Statement of this study: (a) Intelligence quotients from the Goodenough Draw-A-Man Test, (b) Expressive language scores from the Developmental Sentence Scoring protocol, and (c) Receptive language scores from the Receptive subdomain of the Vineland Adaptive Behavior Scales. 


\section{Reliability}

Ten Draw-A-Man Tests, $15 \%$ of the subjects evaluated during the kindergarten follow-up, were randomly selected and independently scored by two PLDP research assistants. Inter-rated reliability was $100 \%$ and was computed by dividing Rater \#1's score by Rater \#2's score for each Draw-AMan and averaging the results.

Ten SALT orthographic transcripts, $15 \%$ of the subjects evaluated during the kindergarten follow-up, were randomly selected and independently analyzed by a second PLDP research assistant. Rater \#2 transcribed the middle 100 words from the audio tape. Inter-rater, point-to-point reliability was $89 \%$ and was computed by dividing the number of words in agreement by 100 (McReynolds \& Kearns, 1983).

Ten DSS protocols, 15\% of the subjects evaluated during the kindergarten follow-up, were randomly selected and independently scored by two PLDP research assistants. Inter-rater reliability for overall DSS scoring was $96 \%$ and was determined by computing the difference between Rater \#1's overall score and Rater \#2's overall score, and then subtracting the difference from 100 for each DSS. Results were averaged. Inter-rater reliability in choosing the same sentences for DSS analysis was 95\%. This was computed by dividing the number of sentences in agreement between Rater \#1 and Rater \#2 by the sentences in agreement plus those in disagreement. Results were averaged. Point-to-point reliability was $93 \%$ and was computed by dividing Rater \#1's total possible points minus Rater \#2's disagreements by Rater \#1's total possible points. Results were averaged.

Seven VABS protocols, $11 \%$ of the subjects evaluated during the kindergarten follow-up, were randomly selected and independently scored by 
two PLDP research assistants. Inter-rater reliability was $98 \%$ and was determined by computing the difference between Rater \#1's scores and Rater \#2's scores for each test domain and adding these to arrive at the percent of disagreement, which was subtracted from 100 . Results were averaged.

\section{Statistical Analyses}

Descriptive statistics were used to organize the data. The mean, standard deviation, and range for each dependent variable used in the study was computed, for the group with ELD and for the control group.

The alpha level for this study was set at .05 . In order to accept or reject the null hypotheses for research questions one and two, a Pearson product moment correlation was performed to determine the correlation between the Perceptual-Performance scores from the MSCA and the scores from the DrawA-Man Test within the group of subjects with ELD. The Pearson product moment correlation was, also, performed on the Perceptual-Performance scores from the MSCA and the Draw-A-Man Test scores within the control group.

To accept or reject the null hypotheses for research questions three and four, a Pearson product moment correlation was performed to determine the correlation between the GCI scores from the MSCA and the scores from the Draw-A-Man Test within the group of subjects with ELD. The Pearson product correlation was also performed on the GCI scores from the MSCA and the Draw-A-Man Test scores within the control group.

To accept or reject the null hypotheses for research questions five and six, a Pearson product moment correlation was performed to determine the correlation between the Draw-A-Man Test scores and the DSS scores within 
the group of subjects with ELD. The Pearson product moment correlation was also performed on the Draw-A-Man Test scores and the DSS scores within the control group.

To accept or reject the null hypotheses for research questions seven and eight, a Pearson product moment correlation was performed to determine the correlation between the Draw-A-Man Test scores and the receptive scores of the VABS within the group of subjects with ELD. The Pearson product moment correlation was also performed on the Draw-A-Man Test scores and the receptive scores of the VABS within the control group.

To accept or reject the null hypotheses for research questions nine and ten, a t-test for independent measures was performed on scores from the GCI of the MSCA between the group of children with ELD and the control group. The t-test for independent measures was, also, performed on scores from the Draw-A-Man Test between the group of children with ELD and the control group. 


\section{CHAPTER IV}

Results and Discussion

Results

The purpose of this study was threefold: first to provide concurrent and construct validity for the Goodenough Draw-A-Man Test by examining correlations between the intelligence quotients derived from the Draw-A-Man Test and the Perceptual-Performance scores from MSCA, as well between the General Cognitive Index (GCI) of the MSCA and the Draw-A-Man Test. Second, Draw-A-Man Test scores were correlated with expressive language scores derived from the DSS, and receptive language scores derived from the VABS, to determine if expressive language performance and/or receptive language performance correlate with children's nonlinguistic cognitive performance. Finally, GCI scores and Draw-A-Man Test scores were compared between groups to determine if children with ELD score more poorly on tests of cognitive performance than their peers with NL.

The range, means, and standard deviations for each of the dependent measures described above were computed. These are shown in Table 5.

In this study, research questions one and two examined whether there was a significant correlation between the Perceptual-Performance scores from the MSCA and the intelligence quotients derived from the Draw-A-Man Test, within the group of children with NL and within the group of children with ELD. Research questions three and four examined whether there was a significant correlation between the GCI scores from the MSCA and the 
intelligence quotients derived from the Draw-A-Man Test, within the same two groups. (see Table 6)

Table 5

Scores for Each Dependent Measure by Group

Measure Group Mean $\quad$ SD $\quad$ Range

Draw-A-Man Test*

$\begin{array}{llll}\text { NL } & 110.7 & 16.3 & 79-148 \\ \text { ELD } & 111.8 & 20.8 & 86-165\end{array}$

Perceptual-Performance:

MSCA subtest***

$\mathrm{NL}$

60.3

9.1

42-78

$\begin{array}{llll}\mathrm{ELD} & \mathbf{5 4 . 6} & \mathbf{1 1} .1 & \mathbf{3 3}-78\end{array}$

GCI: MSCA* $^{*}$

VABS:

$\begin{array}{llll}\text { NL } & 119.2 & 12.1 & 98-140 \\ \text { ELD } & 106.7 & 15.9 & 70-133\end{array}$

$\underline{\mathrm{DSS}} * * *$

Receptive subtest**

$\begin{array}{llll}\text { NL } & 7.9 & 1.3 & 6.4-11.4 \\ \text { ELD } & 7.2 & 1.3 & 4.5-11.2\end{array}$

$\begin{array}{llll}\text { NL } & 24.5 & 0.8 & 24-26 \\ \text { ELD } & 24.0 & 0.5 & 22-25\end{array}$

* Standard Scores ** Raw Scores *** Derived Scores 
Table 6

Perceptual Performance (PP)/Draw-A-Man(DAM) and GCIDAM Correlations by Group

\begin{tabular}{lllll}
\hline Group & $\begin{array}{c}\text { Variable } \\
\text { Pairs }\end{array}$ & $\begin{array}{c}\text { Sample } \\
\text { Correlation }\end{array}$ & $\mathrm{T}$ & p-value \\
\hline NL & PP, DAM & .138 & .683 & .5012 \\
ELD & PP, DAM & .084 & .377 & .7102 \\
NL & GCI, DAM & .390 & 2.075 & $.0488^{*}$ \\
ELD & GCI, DAM & .450 & 2.254 & $.0356^{*}$ \\
\hline
\end{tabular}

* These correlations were significant at the .05 level.

There was no significant correlation between Perceptual-Performance scores from the MSCA and Draw-A-Man Test scores within either group of children. There was, however, a significant correlation between the GCI scores from the MSCA and the Draw-A-Man Test scores.

Research questions five and six examined whether there was a significant correlation between expressive language scores from the DSS and intelligence quotients derived from the Draw-A-Man Test, within both the NL. group and the ELD group.

Contrastively, research questions seven and eight examined whether there was a significant correlation between the receptive language scores from the VABS and the Draw-A-Man Test scores, within both groups. (see Table 7) 
Table 7

DSS/DAM and VABS/DAM Correlations by Group

\begin{tabular}{lcccc}
\hline Group & $\begin{array}{c}\text { Variable } \\
\text { Pairs }\end{array}$ & $\begin{array}{c}\text { Sample } \\
\text { Correlation }\end{array}$ & $\mathrm{T}$ & p-value \\
\hline NL & DSS, DAM & .105 & .517 & .6098 \\
ELD & DSS, DAM & .034 & .517 & .8808 \\
NL & VABS, DAM & .178 & .886 & .3844 \\
ELD & VABS, DAM & -.071 & -.318 & .7538 \\
& & & & \\
\hline
\end{tabular}

No significant correlation was found between these dependent measures among either the children with NL or the children with ELD.

Research question nine examined whether there was a significant difference between GCI scores from the MSCA when the scores of the children with NL were compared with the scores of the children with ELD. Contrastively, research question ten examined whether there was a significant difference between Draw-A-Man Test scores when the scores from both groups were compared. (see Table 8 ) 
Table 8

GCI Score Comparisons and DAM Score Comparisons by Group

\begin{tabular}{lllllll}
\hline Group & Measure & Mean & $\underline{\mathrm{SD}}$ & $\mathrm{df}$ & $\underline{\mathrm{t}}$ & $\mathrm{p}$-value \\
\hline NL & GCI & 119.2 & 12.1 & 40.8 & 3.077 & $.004^{*}$ \\
ELD & GCI & 106.7 & 15.9 & 40.8 & 3.007 & $.004^{*}$ \\
NL & DAM & 111.7 & 16.3 & 41.5 & -.210 & .835 \\
ELD & DAM & 111.8 & 20.8 & 41.5 & -.210 & .835
\end{tabular}

* These differences were significant at the .05 level.

In summary, the preceding data analyses indicate a significant correlation between the GCI scores of the MSCA and the Draw-A-Man Test scores among both the children with NL and those with ELD. However, no significance was found between the Perceptual-Performance scores from the MSCA and the Draw-A-Man Test scores for either group.

Additionally, the data analyses indicated no significant correlation when Draw-A-Man Test scores were correlated with expressive language scores from the DSS for either group of children. Nor was there a significant correlation between the Draw-A-Man Test scores and receptive language scores from the VABS for either the children with NL or those with ELD.

When differences between the two groups scores on the GCI of the MSCA were analyzed, a significant difference was determined. There was no significant difference between the two groups scores from the Draw-A-Man Test, however. Table 9 provides a summary of these findings. 
Table 9

Data Summary

Measures

$\begin{array}{llll}\text { Research } & \text { Statistical } & \text { ELD } & \text { NL } \\ \text { Questions } & \text { Analysis } & & \end{array}$

\begin{tabular}{clll}
\hline $1 \& 2$ & Correlations & PP/MSCA to DAM & PP/MSCA to DAM \\
$3 \& 4$ & Correlations & GCIMSCA to DAM* & GCIMSCA to DAM* \\
$5 \& 6$ & Correlations & DAM to DSS & DAM to DSS \\
$7 \& 8$ & Correlations & DAM to Recep/LABS & DAM to Recep/NABS \\
9 & Difference & GCI/MSCA* & GCIMSCA* \\
10 & Difference & DAM & DAM \\
\hline
\end{tabular}

* significant at the .05 level

\section{Discussion}

One purpose of this study was to provide concurrent and construct validity for the Draw-A-Man Test. Additionally, this study examined the relationship of nonlinguistic performance, derived from Draw-A-Man Test scores, with expressive language scores derived from the DSS, and receptive language scores derived from the VABS. This relationship was examined to provide additional data for previous, equivocal studies that have explored, generally, the relationship between language and cognition, and more specifically, the relationship between nonlinguistic cognitive performance and 
receptive and expressive language skills. Finally, this study examined the difference in scores between the children with ELD and those with NL, when their cognitive performance was assessed.

Results of this investigation did not provide a significant correlation between Draw-A-Man Test scores and the Perceptual-Performance subtest scores of the MSCA in the group with NL or in the group with ELD. Construct validity was not achieved in this manner, but this may have been due to the difference in tasks required by the Draw-A-Man and the PerceptualPerformance subtest. There was, however, a significant correlation between Draw-A-Man Test scores and the GCI scores of the MSCA in both groups. The GCI of the MSCA provides a well standardized index of general cognitive performance. Thus, this correlation provides concurrent validity for the DrawA-Man which is designed to screen children's abilities to represent abstract, cognitive concepts via a nonlinguistic representational task. Correlations for this study were .39 for the group with NL and .45 for the group with ELD. These correlations are within the same range as those from the previous validity studies described in Tables 1 and 2 . Note, specifically the studies of children in similar age ranges. The McHugh (1945) validity study administered the Stanford-Binet and Draw-A-Man Test to 90 normal, kindergarten aged children and the correlation of scores was reported as .41 . The Rottersman (1950) validity study administered the Wechsler and Draw-AMan Test to 50 normal, 6-year-old children. The correlation of scores was .43 and .38 for the Perceptual and Verbal subtests of the Wechsler, respectively. Thus, this study is able to provide current validity data that is within the range of findings from the validity studies of 45-50 years ago. However, this 
study also provides validity for using the Draw-A-Man Test to assess the nonlinguistic cognition of children with ELD.

Data from this study did not show a significant correlation between nonlinguistic performance, assessed by the Draw-A-Man Test, and either expressive language skills, assessed by the DSS, or receptive language skills, assessed by the VABS, in the group with NL or in the group with ELD. Thus, findings from this study do not provide additional conclusive data for those studies mentioned in the review of the literature that have found significant correlations between nonlinguistic performance and either expressive or receptive language skills. Instead, data from this study concurs with those studies in the review of the literature that children with ELD appear to be functioning with "qualitatively different cognitive systems." It is interesting to note in Table 5 on page 42, that the range and mean of Draw-A-Man Test scores for the children with ELD is higher (Range=86-165; Mean=111.8) than the range and mean of Draw-A-Man Test scores for the children with NL (Range=79-148; Mean=110.6). This data concurs with data from previous studies that define children with ELD as having atypical strengths and weaknesses within the spectrum of their linguistic and nonlinguistic cognitive skills.

Finally, results from this study determined that there is a significant difference between GCI scores from the MSCA when scores from the group with NL are compared to scores from the group with ELD. The mean score in the group with NL was 119.2, whereas the mean score in the group with ELD was 106.7. There was, however, no significant difference between Draw-AMan Test scores, when scores from both groups were compared. The mean score in the group with $N L$ was 110.6 , whereas the mean score in the group 
with ELD was 111.8 , slightly higher than the group with $\mathrm{NL}$ as mentioned previously. Because the GCI in comprised of some verbal tasks, those children with ELD might be expected to score in a lower range than their peers with NL. Since there appears to be no significant difference in scores between the groups with NL and with ELD when the Draw-A-Man Test scores are analyzed, it should be an excellent tool to use to screen cognitive performance, especially among those children with ELD, because it does not penalize them by using verbal tasks to assess their cognitive skills. 


\section{CHAPTER V}

Summary and Implications

\section{Summary}

The purpose of this study was to establish the validity of the Draw-AMan Test as a reliable screen of a child's nonlinguistic cognitive performance. Additionally, Draw-A-Man scores were correlated with scores from both expressive and receptive language test scores to determine if nonlinguistic cognitive performance correlates with expressive and/or receptive language skills. And finally, the scores of both children with NL and with ELD were compared to determine if there is a significant difference in how these two groups score on a test of overall cognitive function vs. a test of nonlinguistic cognitive function.

The original group size was 60 children, 30 who were diagnosed with ELD at the age of 20 months and 30 who were a matched control group with $\mathrm{NL}$ at the age of 20 months. These subjects were re-evaluated during kindergarten, at approximately six years of age. The Draw-A-Man Test was administered to assess the subjects' nonlinguistic cognitive functioning. The MSCA was administered to asses the subjects overall cognitive functioning. A free speech sample was collected and analyzed using the DSS to assess expressive language skills, and the VABS was administered to assess receptive language skills.

Draw-A-Man Test scores were correlated with the PerceptualPerformance scores and the GCI scores of the MSCA to establish construct and concurrent validity, respectively. No significant correlation was found 
between the Draw-A-Man Test scores and the Perceptual-Performance scores, but there was a significant correlation between the Draw-A-Man Test scores and the GCI scores.

Draw-A-Man Test scores were correlated to DSS scores to examine the possible relationship between nonlinguistic cognitive skills and expressive language. Additionally, Draw-A-Man scores were correlated with scores from the receptive language subtest of the VABS to examine possible correlations between nonlinguistic cognitive skills and receptive language. There were no significant correlations.

Finally, Draw-A-Man Test scores from the subjects with NL were compared to the scores of those with ELD, and the GCI scores from the MSCA were compared between the two groups, as well. No significant difference was found between the two groups on their Draw-A-Man scores, but there was a significant difference between the two groups' scores when the GCI scores were analyzed.

\section{Implications}

\section{Research}

Data from this study were inconclusive regarding the relationship between nonlinguistic cognitive performance and expressive and receptive language skills. However, some earlier studies sited in the review of the literature, such as the Whitmire and Stone (1991) study, the Powell and Germani study (1993), the Kahmi (1981) study, the Johnston and Ramstad (1983) study, and the Kahmi et al. (1984) study all found correlations between performance on a variety of nonlinguistic cognitive tasks and their subjects' expressive or receptive language skills. Although the Draw-A-Man Test scores 
did not correlate with expressive and receptive language measures when the subjects' scores in this study were examined, these results may be indicative of the Local Homologies Hypothesis, Thal (1991): there are specific nonlinguistic cognitive skills that relate to children's language development, but only at specific times during a child's development.

To further this research, observers may want to look at correlations between children's nonlinguistic cognitive task performance and expressive and receptive language measures periodically during the course of a longitudinal study. Nonlinguistic cognitive performance might be assessed via such tasks as object permanence, haptic recognition, horizontal and vertical axis tasks, means-end tasks, or symbolic play behaviors. These nonlinguistic cognitive behaviors could be correlated with expressive language measures that assess children's language from toddler stage to early school age such as Developmental Sentence Scoring (DSS), Clinical Evaluation of Language Fundamentals-Preschool (CELF-P) or Revised (CELF-R), the Preschool Language Scale-3 (PLS-3), or the Test of Early Language Development (TELD-2). Receptive language measures that assess children's language between toddler stage and early school age, and that could be correlated with nonlinguistic cognitive task performance are the PLS-3, the Test for Auditory Comprehension of Language-1985 Revised (TACL-R), and the TELD-2.

Perhaps observations could be made annually from the emergence of language through early grade school to discover where the "windows" are that indicate a direct relationship between nonlinguistic cognitive performance and language development. 


\section{Clinical}

Data from this study have indicated that the Draw-A-Man Test is a valid measure for screening a child's overall cognitive performance because a significant correlation was found between General Cognitive Index scores from the well standardized MSCA in both groups of children whose scores were examined, those with ELD and those with NL. Additionally, the Draw-A-Man Test does not penalize children with ELD, when assessing their cognitive performance, by requiring them to perform verbal language tasks as many tests of cognitive performance require. Thus, the Draw-A-Man Test is an excellent evaluation tool for the Speech-Language Pathologist. It is not as contrived as many tasks because most children enjoy drawing. It can be administered in just a few minutes and scored in five to ten minutes once the clinician becomes familiarized with the scoring protocol. It is important to note, however, that the scoring protocol does require considerable time and effort to learn, and training among clinicians using the tool is imperative in order to achieve inter-rater reliability.

More in depth research into where the "windows" may exist between nonlinguistic cognitive performance and language development as described above, could provide diagnostic indicators for the Speech-Language Pathologist. If these specific "windows" were identified, the clinician would know when to assess nonlinguistic cognitive performance, and based on test results, could include nonlinguistic cognitive tasks in therapy to enhance receptive and/or expressive language development at appropriate developmental milestones. 
References

Aram, D. M. (1991). Comments on specific language impairment as a clinical category. Language, Speech, and Hearing Services in Schools, 22, 84-87.

Bayley, N. (1969). Scales of infant mental development. New York: Psychological Corp.

Cole, K., Dale, P., \& Mills, P. (1991). Defining language delay in young children by cognitive referencing: Are we saying more than we know? Applied Psycholinguistics, 11, 291-302.

Dale, P. S. \& Cole, K. N. (1991). What's normal? Specific language impairment in an individual differences perspective. Language, Speech. and Hearing Services in Schools, 22, 80-83.

Gelman, S. A. \& Byrnes, J. P. (1991). Perspectives on language and thought. Cambridge: Cambridge University Press.

Gleason, J. B. (1989). Studying language development. In J. B. Gleason (Ed.), The development of language ( $2 n d$ ed.). Columbus: Merrill Publishing Company.

Goodenough, F. L. (1926). Measurement of intelligence by drawing. Chicago: World Book Company.

Gopnick, A. \& Meltzoff, A. N. (1986). Relations between semantic and cognitive development in the one-word stage: The specificity hypothesis. Child Development, 57, 1040-1053.

Harris, D. B. (1963). Children's drawings as measures of intellectual maturity. New York: Harcourt, Brace, \& World, Inc. James, S. L. (1990). Normal language acquisition. Austin: Pro-Ed. 
Johnston, J. R. \& Ramstad, V. (1983). Cognitive development in preadolescent language impaired children. British Journal of Disorders of Communication. 18, 49-55.

Kamhi, A. G. (1981). Nonlinguistic symbolic and conceptual abilities of language-impaired and normally developing children. Journal of Speech and Hearing Research, 24, 446-453.

Kambi, A. G., Catts, H. W., Koenig, L. A., \& Lewis, B. A. (1984).

Hypothesis-testing and nonlinguistic symbolic abilities in languageimpaired children. Journal of Speech and Hearing Disorders, 49, 169-176.

Kelly, C. A. \& Dale, P. S. (1989). Cognitive skills associated with the onset of multiword utterances. Journal of Speech and Hearing Research, 32, 645656.

Lee, L. L. (1974). Developmental sentence analysis. Evanston: Northwestern University Press.

Leonard, L. B. (1991). Specific language impairment as a clinical category. Language, Speech, and Hearing Services in the Schools, 22, 66-68.

McCarthy, D. (1972). McCarthy scales of children's abilities. Cleveland: The Psychological Corporation.

McReynolds, L. V. \& Kearns, K. P. (1983). Single-subject experimental designs in communication disorders. Baltimore: University Park Press. Meyers, J. \& Bean, L. (1968). A decade later: A follow-up of social class and mental illness. New York: Wiley.

Nicoloski, L., Harryman, E., \& Kresheck, J. (1983). Terminology of communication disorders. Baltimore: Waverly Press, Inc.

Owens, R. E. (1992). Language development: An introduction. New York: Macmillan Publishing Company. 
Paul, R. (1991). Profiles of toddlers with slow expressive language development. Topics in Language Disorders, 11, (4), 1-13.

Powell, T. W. \& Germani, M. J. (1993). Linguistic, intellectual, and adaptive behavior skills in a sample of children with communication disorders. Journal of Psychoeducational Assessment, 11, 158-172.

Rescorla, L. (1989). The language development survey: A screening tool for delayed language in toddlers. Journal of Speech and Hearing Disorders, 54, 587-599.

Rescorla, L. \& Goosens, M. (1992). Symbolic play development in toddlers with expressive specific language impairment. Journal of Speech and Hearing Research, 35, 1290-1302.

Restrepo, M. A., Swisher, L., Plante, E., \& Vance, R. (1992). Relations among verbal and nonverbal cognitive skills in normal language and specifically language-impaired. Journal of Communication Disorders, 25, 205-219.

Rice, M. L. (1983). Contemporary accounts of the cognition/language relationship: Implications for speech-language clinicians. Journal of Speech and Hearing Disorders, 48, 347-359.

Rice, M. L. \& Kemper, S. (1984). Child language and cognition. Austin: Pro-Ed, Inc.

Sparrow, S. S., Balla, D. A., \& Ciccnetti, D. V. (1984). Vineland adaptive behavior scales. Circle Pines, MN: American Guidance Service.

Tallal, P. (1988). Developmental language disorders. In J. F. Kavanaugh \& T. J. Truss Jr. (Eds.), Learning disabilities: Proceedings of the national conference. Parkton, MD: York Press. 
Thal, D. J. (1991). Language and cognition in normal and late-talking toddlers. Topics in Language Disorders, 11(4), 33-42.

Whitmire, B. M. \& Stone, C. A. (1991). Visual imagery skills and language abilities of normal and language-learning-disabled children. Learning Disability Quarterly, 14, 49-59. 
APPENDIX A

HUMAN SUBJECTS RESEARCH FORM 


\section{OFFICE OF RESEARCH AND SPONSORED PROJECTS}

DATE: - February 17, 1994

TO: Deborah Kay Warren

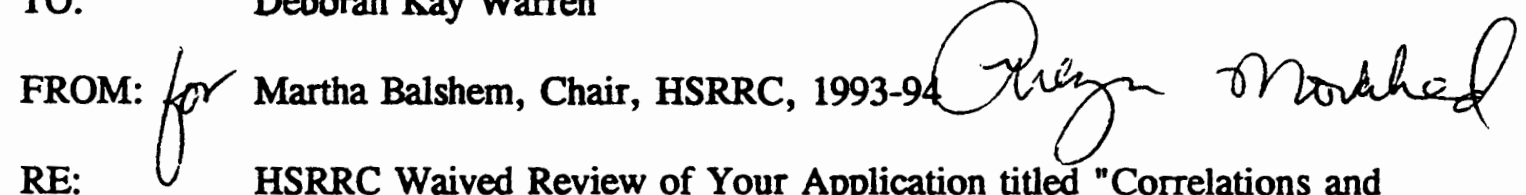
Comparisons of Three Tests of Cognitive and Language Functioning"

Your proposal is exempt from further HSRRC review, and you may proceed with the study.

Even with the exemption above, it was necessary by University policy for you to notify this Committee of the proposed research and we appreciate your timely attention to this matter. If you make changes in your research protocol, the Committee must be notified.

c. Office of Graduate Studies 
APPENDIX B

QUESTIONNAIRE FOR PARENTS OF

CHILDREN 15-30 MONTH OLD 
QUESTIONNAIRE FOR PARENTS OF CHILDREN 15-30 MONTHS OLD What is your child's:

first name? date of birth?

Mother's (or primary parent's) full name?

Mother's (or primary parent's) phone number?

Mother's occupation?

Father's occupation?

How many different words can your child say? (It's OK if the words aren't entirely clear, as long as you can understand them.)

none

less than five

5-10

$10-30$
30-50 more than 50

If your child says fewer than ten words, please list them here:

Does your child put words together to form short "sentences"? Yes. No

If yes, please give three examples here:

Would you be interested in participating in later parts of this study? Yes No 
APPENDIX C

OREGONIAN ARTICLE 


\section{Toddlers with delayed speech sought}

A Portiand State University researcher is looking for otherwise normal toddlers who begin talking late to serve as subjects in a study of delayed speech and its connection, if any, to later language problems.

Rhea Paul, a PSU assistant professor of speech communication, said the reasons for delayed speech in "late-blooming" young children and the early identification of toddlers who later will suffer chronic language delay had not been well-investigated, although perhaps 10 percent of American children may fall into those categories.

Paul is interested in studying children between the ages of 18 and 30 months in the Portland-Vancouver area who can say only five or fewer words, instead of the 50 or so most children can speak by that age. She hopes to monitor their progress in speech development for two to five years, using such tools as speech tests and videotaped play sessions with their parents, to determine whether the children are indeed late-bloomers or whether their lack of early communication skills signals the start of severe speech and language delays.

Early identification of such children may allow early intervention and prevent future speech deficits, she said.

Paul's research is funded by the Fred Meyer Charitable Trust, the American Speech, Language and Hearing Foundation, and PSU. Parents who are interested in allowing their children to participate may contact Paul through the PSU Department of Speech.

The Oregonian, Portland, Oregon 


\section{APPENDIX D}

\section{LANGUAGE DEVELOPMENT SURVEY}

Rescorla, L. (1989). The language development survey: A screening tool for delayed language in toddlers. Journal of Speech and Hearing Disorders, 54, 587-599. 


\section{Language Development Survey}

Please check off each word that your child says SPONTANEOUSLY [no: luse :misates or understands) It's okay to coune words that aren'e pronounced clearly or are in "baby talk" ("baba" for boctle)

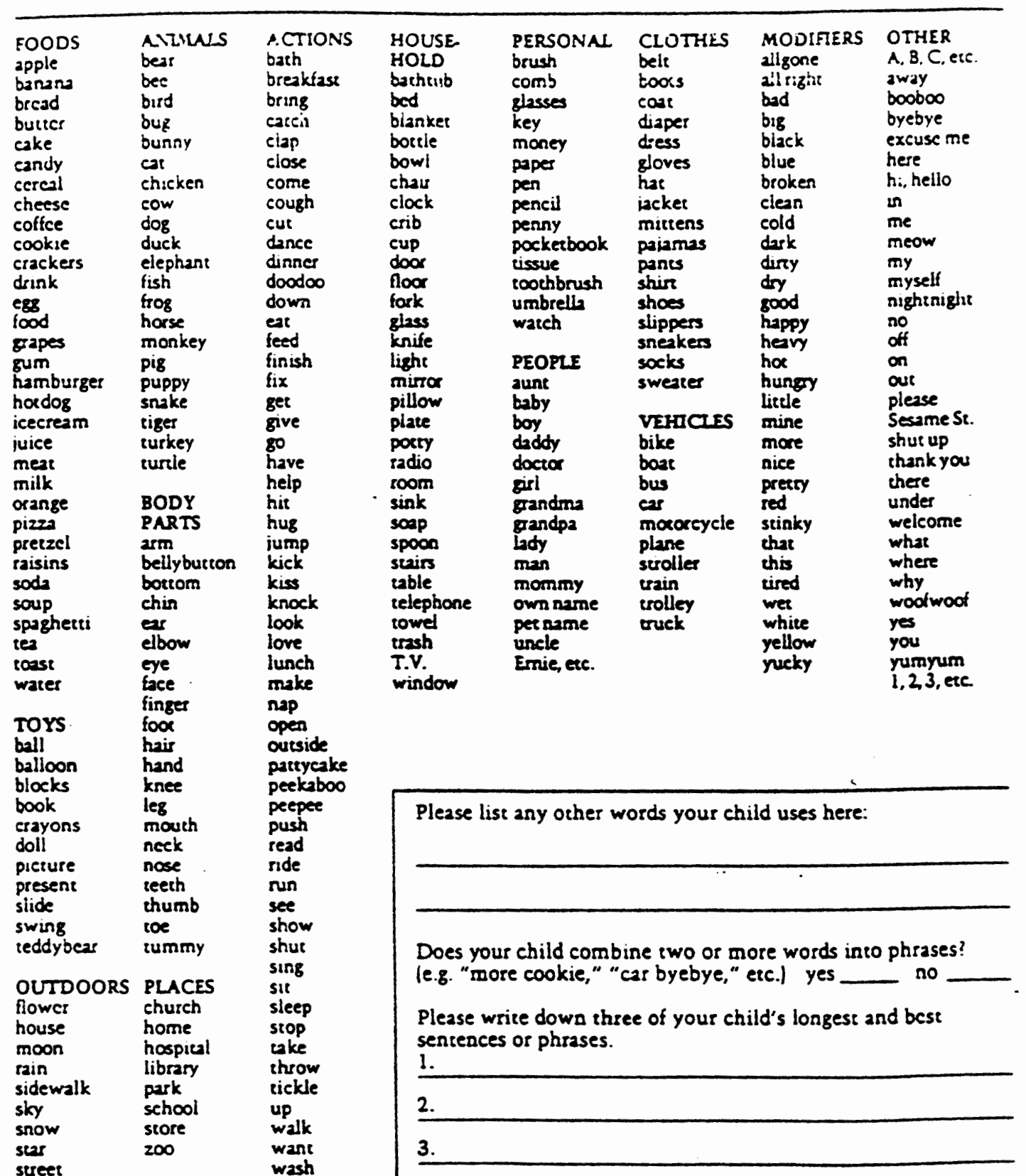




\section{APPENDIX E}

\section{GOODENOUGH DRAW-A-MAN TEST:}

SCORING CRITERIA

Goodenough, F. L. (1926). Measurement of intelligence by drawing.

Chicago: World Book Company. 


\section{CHAPTER SIX}

Test Procedere and Drrections for Scordng

TEST PROCEDURE

EAcr child should be provided with a pencil and a test blank. Crayons should not be used, but the large "beginner's" pencils may be used if the children are more accustomed to them. Before beginning, see that all books and pictures are put away, so that there will be no opportunity for copying.

The following instructions are then given:

" On these papers I want you to make a picture of a man. Make the very best picture that you can. Take your time and work very carefully. I want to see whether the boys and girls in - school can do as well as those in other schools. Try very hard and see what good pictures you can make."

As the drawings are being made, the examiner should stroll about the room to see that instructions are being followed, and encourage, by means of a little judicious praise, any one who seems to need it. In doing this it is best to avoid calling attention to the work of any individual child; rather, let the comments be of a general nature, such as, "These drawings are fine; you boys and girls are doing very well," etc. Never make adverse comments or criticism, and under no circumstances should a child's attention be called to any errors or omissions in his work, however gross they may be. Answer all questions by saying, "Do it whatever way you think is best."

The importance of avoiding every kind of suggestion cannot be overemphasized. Not only must the examiner himself refrain from all remarks which could influence the nature 
of the drawings (the only exception to this rule is noted in a following paragraph), but he must see to it that no suggestions come from the children. They should not be permitted to hold up their drawings for admiration or comment in such a way that other children may see them, or to make audible remarks about their work. - If permitted to do so, little children are very likely to accompany their performance by a running fire of description, such as, "I'm giving my man a soldier hat," "Mine's going to have a big, long pipe," etc. While it is true that these comments are most likely to have to do with appurtenances which do not affect the score, there is danger that a child who attempts to carry out such suggestions may thereby have his attention so distracted from his original concept as to cause him to forget some of the essential parts of his drawing in his interest in this new, and probably unimportant, detail.

The examiner must not, however, lose sight of this fact: It is essential for the validity of the test that each child make the best effort of which he is capable. To secure such effort, a cheerful, sympathetic attitude must be adopted throughout. The child who is bursting with eagerness to tell about his drawing must be suppressed, it is true, but never in such a way as to dampen his enthusiasm. A firm but good-natured "No one must tell about his picture now. Wait until everybody has finished," will usually dispose of such cases without affecting the general interest or disturbing the rapport which should exist between examiner and children.

There is no time limit for the test, but little children rarely take more than five or ten minutes. If one or two chitdren are slower than-the,$-i t$ best to colleet papers from those who have finished, and allow them to go on with their regular work while the slower workers are finishing.

The following special circumstances should be noted: (1) It sometimes happens that through erasure or other accident a child may spoil his drawing. In such cases he should always be given a fresh sheet and be allowed to try again. All such instances should be noted on the back of the sheet. (2) In grades above the second (rarely below), it will occasionally be found that a child has drawn a bust picture only. When it is evident that this has been the intention, a fresh paper should be given and the child told to " make the whole man." Both papers should be preserved for comparison.

\section{GENERAL INSTRUCTIONS FOR BCORING}

While the test may be given by the regular classroom teacher, it is better to make other provision for the scoring. In school systems where there is a special department to look after the tests and measurements, all scoring should be done by some member of this department. Where no such arrangement exists, a special teacher, preferably one who has had experience along this line, may learn to do the scoring. The task of learning how to score is not an especially difficult one for an intelligent person who is willing to devote the necessary time and patience to a thorough mastery of the directions given; but it cannot be emphasized too strongly that such study is imperative, if results are to be of any value. Because of the amount of time necessary to learn the scoring method, it is obviously unwise to divide the task of scoring among too many workers. The gain both in speed and accuracy which comes with practice is enormous - so much so that an experienced scorer can readily attain a speed of from forty to fifty papers an hour, although in the beginning he may not have been able to score more than five or ten an hour. The following general instructions should be noted:

1. As a preliminary exercise, the beginner should check through the scoring of the illustrative drawings shown on pages 112-161. There are two series of these drawings. 
The first series should be used as a guide for study; the second as a test exercise. The student is advised to read the directions for scoring the different points very carefully, referring, as he does so, to the drawings in Series I. He should note in each case whether a plus or minus score has been given for the point under consideration, and endeavor to fix clearly in his mind the principles which govern the scoring. If he has had little previous experience in work of this kind, it may be well for him to go over the rules a second or a third time before proceeding to any independent work. As soon as he feels that the rules have been thoroughly mastered and that the scoring of the drawings in Series $I$ is well understood, the next step is to score the drawings in Series II without reference to the standard scoring of these drawings which is given on pages 160-161. If his total error is found to be not more than one or two points, it will ordinarily be safe for him to begin regular work in scoring, provided that he proceed rather carefully at first and refer to the guide whenever there is doubt as to the scoring of any point.

2. Time will be saved and the scoring will be rendered appreciably more accurate if special drawing sheets ${ }^{1}$ with spaces for recording the scores on the separate points by their key numbers are used. After a reasonable amount of practice, these numbers will serve as sufficient cues for the scorer so that continual reference to the manual becomes unnecessary. The scoring can then be done much more rapidly, without the danger of overlooking or omitting points which is likely to result from complete reliance upon the memory. This also makes possible the rechecking of scores, point by point, a procedure which is always desirable in the beginning or when inexperienced scorers are used.

3. In practice, drawings will occasionally be found which the scorer is unable to interpret. The most common types of these bizarre drawings have been described in the text, together with notes as to their scoring. While it is not to be hoped that all the unusual forms which will be met with have been described, nevertheless, since a selection has been made from several thousand drawings made by children of widely separated localities and social antecedents, it is probable that a basis will have been afforded for the settlement of many of the ordinary difficulties. In all cases where doubt exists as to what has been intended by any particular portion of a drawing, it is well to consult the child, if this is possible, and to score the drawing in accordance with his reply, bearing in mind that special requirements as to the manner of representing any particular item must be met in these cases as well as in others.

4. All computations should be checked carefully. Age should be taken to the nearest month, scores should be transmuted into mental age equivalents by reference to the table on page 39, and the IQ found by dividing the mental age by the chronological age.

5. If, as sometimes happens with young children, more than one drawing has been made, select for the child's rating the one which makes the highest score. This will ordinarily be the first one made, since in subsequent drawings there is likely to be a slight falling off of interest and effort. In some cases, however, the second drawing shows improvement over the first, usually because of the fact that the child noticed some error or omission in his first drawing and drew the second by way of correction. In any case, the best drawing is the one to be credited. It is not permissible, in such cases, to combine parts of two drawings for the total score. If, for example, the first drawing contains arms but no trunk, and the second one trunk but no arms, it is incorrect to credit both arms and trunk unless both appear in one drawing. 
6. Erasures should always be noted. If much erasing has been done, it is probable that the child has not been correctly rated by the test and that the true mental age is higher than that indicated by the drawing. This is especially true of older children, who have reached a stage of mental development at which they regard their work with a more critical eye. Other things being equal, erasing is always a favorable sign, even though the effect may be quite detrimental to the good appearance of the drawing.

\section{RULES FOR SCORING}

\section{Class $A$}

In drawings of this class the subject cannot be recognized. The total possible score is either 0 or 1 . If the drawing consists merely of aimless, uncontrolled scribbling (Fig. 1), the score is $\mathbf{0}$. If the lines are somewhat controlled and appear to have been guided by the child to some extent, the score is 1. Drawings of this type most frequently take the form of a rough square, triangle, or circle, very crudely done. Not infrequently several of these forms are included in a single drawing (Fig. 2). If a drawing of this kind contains much detail, it is always well to call upon the child for an explanation, since occasionally it will be found that such a drawing belongs in Class B, rather than in Class A. Figure 3 is an example.

In questioning a child about his drawing, great care must be taken to avoid suggesting the expected answer. Be sure that his confidence has been gained before asking any direct questions. 'Ihen, after praising his drawing, say, "Now tell me about your picture. What are all these things you have made?" If this does not elicit a response, point to one of the items and say in an encouraging tone, "What is this?" If he is still unable to respond, or if, as is frequently the case, he calls each part in turn " a man," then the drawing should be scored as Class A; but if, on the other hand, he names the various parts in a logical fashion, it should be scored according to the rules given for Class $B$.

\section{Class $B$}

This class includes all drawings which can be recognized as attempts to represent the human figure, no matter how crude they may be. Each point is scored plus or minus. A credit of 1 is allowed for each point scored plus, and no half credits are given.

\section{Head present.}

Requirement: Any clear method of representing the head. Features alone, as in Figure 4, without any outline for the head itself, are not credited for this point.

\section{Legs present.}

Requirement: Any method of representation clearly intended to indicate the legs. The number must be correct; two in full-face drawings, either one or two in profiles.

It is always necessary to mingle a reasonable amount of common sense with what would otherwise be purely arbitrary scoring. One or two examples have been found in which only one leg was present, but a rude sketch of a crutch was included, showing clearly what the child had in mind. A more sophisticated drawing of this kind would probably show the stump of the missing leg, but it is hardly fair to expect this from a young child. On the other hand, little children sometimes draw three or more legs, or a single leg without logical explanation. These should be scored minus. A less usual occurrence is the showing of a single leg to which two feet are attached. These are scored plus.

\section{Arms present.}

Requirement: Any method of representation clearly intended to indicate arms. Fingers alone are not sufficient, 


\section{Measurement of Intelligence by Drawings}

but the point is credited if there is any space left, between the base of the fingers and that part of the body to which they are attached. The number must also be correct. See rules for preceding point.

The only real danger of incorrect scoring of this point arises from the many remarkable methods by which the arms are indicated, and the unusual points of attachment, which makes it very easy for the beginner to overlook them. Figures 0-12 are instances of this sort.

\section{4a. Trunk present.}

Requirement: Any clear indication of the trunk, whether it be by means of a straight line only (in which case, $4 b$, it should be noted, is always minus) or by some sort of twodimensional figure. In cases where there is no clear differentiation between the head and the trunk, but the features appear in the upper end of a single figure, the point is scored plus if the features do not occupy more than half the length of the figure; otherwise the score is minus, unless a cross line has been drawn to indicate the termination of the head. A single figure placed between the head and the legs is always counted as a trunk, even though its size and shape may be such as to suggest to the adult a neck rather than a trunk. This ruling is based on the responses of a number of children whose drawings showed this peculiarity, practically all of whom have, when questioned, called the item a trunk. A row of buttons extending down between the legs is scored minus for trunk but plus for clothing, unless a cross line has been drawn to show the termination of the trunk.

\section{4b. Length of trunk greater than breadth.}

Requirement: Measurement should be taken at the points of greatest length and of greatest breadth. If the two measurements are equal, or so nearly so that the difference is not readily determined by the use of a millimeter rule, the score is minus. In most instances the difference will be found great enough to be recognized at a glance, without actually measuring. Unless the trunk is shown in two dimensions, the score is minus.

\section{Shoulders definitely indicated.}

Requirement: In full-face drawings, a change in the direction of the outline of the upper part of the trunk which gives an effect of concavity rather than convexity. See Figure 5. The point is scored rather strictly. The ordinary elliptical form is never credited, and the score is always minus unless it is evident that there has been a recognition of the abrupt broadening out of the trunk below the neck which is produced by the shoulder blade and the collar bone. A perfectly square or rectangular trunk does not score, but if the corners have been rounded as in Figure 6, the point is credited. (Figure 6 represents the lowest limit for which credit may be allowed.)

In profile drawings the scoring should be somewhat more lenient than in full-face drawings, since the difficulty of representing the shoulders in an ádequate fashion is somewhat greater in the profile position. A profile drawing, in this connection, should be understood to mean one in which the trunk, as well as the head, is shown in profile. If the lines forming the outline of the upper part of the trunk diverge from each other at the base of the neck in such a way us to show the expansion of the chest, the point is credited.

\section{5 a. Attachment of arms and legs.}

Requirement: Both arms and legs attached to the trunk at any point, or arms attached to the neck, or at the junction of the head and the trunk when the neck is omitted. If the 


\section{Measurement of Intelligence by Drawings}

trunk is omitted, the score is always zero. If the legs are attached elsewhere than to the trunk, regardless of the attachment of the arms, the score is zero. If one arm or leg has been omitted, either in full-face or in profile drawings, credit may be given on the basis of the limb that is shown; but if both arms and legs are shown, and one is attached elsewhere than to the trunk, the score is zero. Arms attached to the legs score zero.

\section{5 b. Legs attached to the trunk. Arms attached to the trunk at the correct point.}

Requirement: In full-face drawings where $4 c$ is plus, the point of attachment must be exactly at the shoulders: If $4 c$ is minus, the attachment must be exactly at the point which should have been indicated as the shoulders. Score very strictly, especially in those cases where $4 c$ is minus.

In profile drawings the attachment must be indicated at a point approximately on the median line of the side trunk, at a short distance below the neck, this point coinciding with the broadening of the trunk which indicates the chest and shoulders. If, as is frequently the case, the arms extend from the line which outlines the back, or if the point of attachment reaches the base of the neck, or falls below the greatest expansion of the chest line, the point is not credited. See $5 a$ for ruling as to omitted limbs or misplacement of a single limb.

While this point and point $4 \mathrm{c}$ tend to go together, that is, one is more likely to be credited if the other is also credited, - this agreement is not absolute, and $5 b$ is more likely to be credited than is $4 \mathrm{c}$. However, success with $4 \mathrm{c}$ does not insure success with $5 b$, and care must be taken to differentiate between the two. It should be noted that $4 \mathrm{c}$ has to do only with the shape of the upper portion of the trunk, $5 b$ with the point of attachment of the limbs. If this

\section{Test Procedure and Directions for Scoring}

distinction is kept in mind, there should be no difficulty in scoring the two points independently of each other.

6 a. Neck present.

Requirement: Any clear indication of the neck as distinct from the head and the trunk. Mere juxtaposition of the head and the trunk is not credited.

6b. Outline of neck continuous with that of the head, of the trunk, or of both.

See Figures 6 and 7 for examples of success with this point. There is practically never any question as to scoring.

7 a. Eyes present:

Requirement: Either one or two eyes must be shown. Any method is satisfactory. A single indefinite feature such as is occasionally found in the drawings of very little children is given credit here, even though its significance is uncertain.

In one of the earliest revisions of the scale, the rather obvious requirement of two eyes in full-face drawings and one in profile drawings was taken as the basis for scoring. It was found, however, that erroneous results were introduced by this method, owing to the confusion which many children undergo at the time of change from the full face to the profile. Holding to the strictly correct numerical requirement means that, in many cases, a child who for several years has been succeeding with this point in his full-face drawings suddenly begins to fail with it, not because he is any less certain of the correct number of eyes, but merely because he has not learned how to express this fact when drawing the figure from another angle.

\section{7 b. Nose present.}

Requirement: Any clear method of representation. In " mixed profiles" the score is plus even though two noses are shown. 
In cases where only one feature has been shown in addition to the eyes, it is sometimes impossible to tell whether this feature has been intended for a nose or for a mouth. Since the child's score will be the same in either case, it does not greatly matter which way the point is credited. However, the percentages given for this and for the following point are for this reason subject to a slight degree of error.

\section{7 c. Mouth present.}

Requirement: Same as for the preceding point.

\section{$7 d$. Both nose and mouth shown in two dimensions; two lips} shown.

Requirement: See Figure 8 for accepted forms. In the full-face drawing any two-dimensional figure which approximates the true shape of the nose is accepted. A rough equilateral triangle is credited if in the normal position with the base downward, but not credited if the position is reversed so that it rests upon its apex. A straight line only, a dot, a circle, or a square are failures. Two dots representing the nostrils is failure here but credited for the next point.

In the full-face drawing, the mouth is credited if it is drawn in two dimensions and if the line showing the separation of the two lips is indicated. In practical scoring this is the point to be looked for first, as it is the one which most frequently determines success or failure. Both nose and mouth must conform to requirements if the point is to be credited.

In the profile drawing, the nose must show a clean differentiation both from the forehead and from the upper lip. The mouth must show either a separate modeling of the two lips, or the line indicating the mouth must be continuous with that outlining the remainder of the face. In very small drawings a reading glass or small magnifying glass is some- times convenient in determining the scoring of this point, but its use is very rarely necessary. The profile drawing is very much more likely to receive credit than is the full-face drawing.

\section{7 e. Nostrils shown.}

Requirement: Any clear method of indicating the nostrils. In profile drawings the point is credited if the line outlining the nose is extended inward upon the upper lip as in Figure 18. A complete showing of the division of the septum (Fig. 11) is not credited. If the only indication of the nose consists of two dots representing the nostrils, the score is plus for this point and also for $7 b$, but is minus for $7 d$.

\section{8 a. Hair shown.}

Requirement: Any method clearly intended to represent hair is credited.

In scoring kindergarten drawings it is sometimes hard to distinguish between hair, hat, and fingers. The following notes will be found helpful.

In a drawing which shows no other indication of arms or fingers, but in which there appear a number of straight lines projecting from either side of the head, fingers have almost invariably been intended. See Figures 16-17.

A scribbled line on the top of the head usually represents hair.

The hat can, as a rule, be distinguished by its brim. It must not be forgotten, however, that the hair in these primitive drawings is usually visible through the hat, and any unusual shading or apparent decoration on or about the hat should be observed carefully and its relation to the outline of the head noted. If it appears to follow this outline rather than that of the hat, it is most probable that hair has been intended. 
8 b. Hair present on more than the circumference of the head. Better than a scribble. Non-transparent; that is, outline of head not showing through the hair.

Figures 18, 19, and 20 are examples of success, and Figures 21 and 22 of failure, with this point. All three requirements must be met if the point is to be credited.

\section{$\theta$ a. Clothing present.}

Requirement: Any clear representation of clothing. As a rule the earliest forms consist of a row of buttons running down the center of the trunk, or of a hat (which is likely to be placed above rather than on the head), or of both. A single dot or small circle placed in the center of the trunk is practically always intended to represent the navel and should not be credited as clothing. A series of vertical or horizontal lines drawn across the trunk - more rarely on the limbs as well - is a fairly common way of indicating striped material, and should be credited as clothing.

9 b. At least two articles of clothing (as hat and trousers) non-transparent; that is, concealing the part of the body which they are supposed to cover.

In scoring this point it must be noted that a hat which is merely in contact with the top of the head but does not cover any part of it is not credited. Buttons alone, without any other indication of the coat, are not credited here.

9 c. Entire drawing free from transparencies of any sort. Both sleeves and trousers must be shown.

There is usually no difficulty in scoring. In children's drawings the sleeves do not appear until a relatively late period of development - as a rule, from two to three years after the trousers are first shown. The point is therefore a difficult one, but the correlation with school success is un- usually good. 36 per cent of the accelerated nine-yearolds succeed with it, but only 7 per cent of the average and none of the retarded group of the same age do so.

\section{9 d. At least four articles of clothing definitely indicated.}

The articles should be among those in the following list: Hat, shoes, coat, shirt, collar, necktie, belt or suspenders, trousers.

Notz. Shoes must show some detail, as laces, toe cap, or double line for the sole. Heel alone is not sufficient. Coat or shirt must show either sleeves, pockets, lapels, or distinctive shading, as spots or stripes. Buttons alone are not sufficient. Collar should not be confused with neck shown merely as insert, nor should coat lapels be counted as collar. The necktie is of ten inconspicuous and care must be taken not to overlook it, but it is not likely to be mistaken for anything else.

9 e. Costume complete without incongruities.

Requirement : A definite and recognizable kind of costume, as a business suit, a soldier's uniform, etc. Whatever the costume, it must be complete in all the essential details and there must be no confusion of any of the items, such as a sailor's hat with a business suit, etc. The scoring should be strict. The following, rules should be observed as to the number of required items :

1. The hat must always be shown if it forms an essential part of the costume, as in the case of a uniform. It need not be shown with a business suit.

2. The sleeves must always be shown. Either a coat, as indicated by pockets, etc., must be shown or an acceptable substitute therefor, such as a sports shirt (with the remainder of the costume corresponding) must be present. Both collar and necktie must be shown when these would ordinarily form a part of the costume.

3. The trousers must always be shown. 


\section{Measurement of Intelligence by Drawings}

4. The shoes must always be shown. See note under $9 d$. The only real danger of incorrect scoring of this point lies in the tendency to give credit for a large number of unimportant or non-essential details in spite of the absence of essentials. This is especially likely to be the case in the drawings representing "cowboys" and "Indians," two subjects which are extremely popular with retarded boys of nine to twelve years. One frequently finds in these drawings a great amount of detail - elaborately drawn " chaps," cartridge belts, revolvers, etc., but no sleeves. (Fringes on the arms similar to those on the trousers may not be counted as sleeves unless the cross line at the wrist, showing the termination of the sleeve, is present.)

\section{0 a. Fingers present.}

Requirement: Any clear indication of fingers, no matter what may be the method of representation. They must be shown on both hands if both hands are present, but credit is given for fingers on one hand if only one hand is shown.

Notr. Little children sometimes express the fingers in very curious ways, and the scorer must be on his guard to avoid overlooking such cases. A number of these bizarre types are shown in Figures 13-17. Sully (115) has described in detail the various methods of picturing the hand and fingers which were found in his collection, and a study of his article in this connection is well worth while. See also the note on $8 a$ which calls attention to the likelihood of confusing fingers and hair.

\section{0 b. Correct number of fingers shown.}

Requirement: Five fingers on each hand where both hands are shown; on one hand if only one hand is shown. In cases where both hands are shown but one is partially concealed, as in carrying something, credit may be given on the basis of the one hand that is entirely visible, if there is no question regarding the number of fingers on that hand and

\section{Test Procedure and Directions for Scoring 101}

the concealment of fingers on the other hand is logically demanded by the situation. This ruling must be interpreted very rigidly, however, and credit allowed only in cases in which the above conditions are unquestionably applicable.

10 c. Detail of fingers correct.

Requirement: Fingers must be shown in two dimensions, the length in all cases must be greater than the breadth, and the angle subtended by them must not be greater than 180 degrees. As in the preceding point, if one hand is not shown, credit is given on the basis of the hand that is present. All three requirements must be fulfilled if the point is to be credited.

\section{0 d. Opposition of thumb shonon.}

Requirement: A clear differentiation of the thumb from the fingers. Scoring should be very strict. The point is credited if one of the lateral digits is definitely shorter than any of the others - compare especially with the little finger - or if the angle between it and the index finger is not less than twice as great as that between any two of the other digits, or if its point of attachment to the hand is distinctly nearer to the wrist than that of the fingers. Conditions must be fulfilled on both hands if both are shown; one hand is sufficient if only one is shown.

\section{0 e. Hand shown as distinct from fingers or arm.}

See Figures 23-27 for some of the most common ways of picturing the hand. There is usually no difficulty in scoring.

A small percentage, usually of the brighter children, who have come to realize the teclnical difficulties involved in drawing the hands, avoid the issue by concealing them in some way, usually by drawing the man with his hands in his pockets. In these cases the child should be credited with 


\section{Measurement of Intelligence by Drawings}

points $10 a, 10 b$, and $10 c$; not with $10 d$, and with $10 e$ only in case the upper part of the hand is visible above the pockets. This ruling is based upon the average score made on the remainder of the drawing by children who drew the hands in this position.

11 a. Arm joint shown. Either elbow, shoulder, or both.

Requirement: If the elbow joint is taken as the basis for scoring, there must be an abrupt bend (not a curve) at approximately the middle of the arm. One arm is sufficient in this case. If the shoulder joint is taken, the arm must hang at the side in a position approximately parallel to the body axis. An arm which simply points in a downward direction does not score; there must be a curve at the point of attachment to the body, to indicate the shoulder joint. While this point is more likely to be gained if $4 c$ and $5 b$ are also credited, yet success with any one of them does not necessarily mean success with either of the others. For the sake of clearness, the distinction between these points is repeated here:

$4 c$ depends upon the shape of the upper portion of the trunk. $5 b$ depends upon the point of attachment of the arms.

$11 a$ depends upon the manner of attaching the arms, and the angle between the arms and the body axis.

Drawings are occasionally found in which the arm does not hang at the side; yet $11 a$ should obviously be credited since there is a clear indication of the shoulder joint, as when the man is reaching out to get something. Because of the marked tendency of little children to draw the arms standing stifly out from the side, it is necessary to exercise great caution in giving credit for this point unless at least one arm hangs at the side. Both arms must do so if both are shown, unless there is a logical reason for the change in position. See Figures 28-31. Note that in Figure 28, $11 a$ is credited altbough both $4 c$ and $5 b$ are failures. Compare this draw- ing with Figure 23, which represents the upper limit of failure in point 11 a. In Figure 23 the curve was determined in part by the size of the sheet of paper.

In drawings made by young or backward children, the position of the elbows and knees is sometimes indicated, without apparent recognition of their function as joints. See Figures 33-34. No credit is allowed for joints in these cases. (In Figure 34 credit has been given for the hip joint.)

11 b. Leg joint shown. Either knee, hip, or both.

Requirement: If the knee joint is taken as a basis for scoring, there must be, as in the case of the elbow, an abrupt bend at about the middle of the leg, or, as is sometimes found in very high-grade drawings, a narrowing of the leg at this point. Knee-length trousers are not sufficient. The hip joint is the one most frequently shown. If the inner lines of the two legs meet at the point of junction with the body, the point is credited. Young children usually place the legs as far apart from each other as possible

12 a. Proportion. Head.

Requirement: Area of the head not more than one half or less than one tenth that of the trunk. Score rather leniently. See Figure 32 for a series of standard forms of which the first is double the area of the second.

12 b. Proportion. Arms.

Requirement: Arms equal to the trunk in length or slightly longer, but in no case reaching to the knee. Width of arms less than that of trunk.

12 c. Proportion. 'Legs.

Requirement: Length of the legs not less than the vertical measurement of the trunk, nor greater than twice that measurement. Width of the legs less than that of the trunk. 


\section{2d. Proportion. Feet.}

Requirement: The feet and legs must be shown in two dimensions. The feet must not be "clubbed "; that is, the length of the foot must be greater than its height from sole to instep. The length of the foot must be not more than one third or less than one tenth the total length of the leg. The point is also credited in full-face drawings in which the foot is shown in perspective, as in Figure 35, provided that the foot is separated in some way from the rest of the leg in these drawings.

\section{2 e. Proportion. Two dimensions.}

Requirement: Both arms and legs shown in two dimensions. If the arms and legs are in two dimensions, the point is credited even though the hands and feet are in linear dimension only.

\section{Heel shown.}

Requirement: Any clear method of indicating the heel. See Figures 36-38 for the method most frequently found. The point is also credited in full-face drawings where the foot is shown in perspective, as in Figure 35.

\section{4 a. Motor coördination. Lines $A$.}

Requirement: All lines reasonably firm, for the most part meeting each other cleanly at points of junction, without marked tendency to cross or overlap, or to leave gaps between the ends. The degree of complexity of the drawing must be taken into account, a drawing with very few lines being scored more rigidly than one which involves much detail and frequent change in the direction of the lines. A " sketchy" drawing in which most of the outlines consist of many short lines is ordinarily credited, since this is a characteristic confined almost entirely to drawings of a rather mature type.
For the scoring of this and the other five points in this group, reference should be made to the series of specimen drawings on pages 112-161. While the scoring of these points is perhaps slightly less objective than that of most of the others in the scale, a study of the types presented should produce results which are at least as consistent as those obtained by the ordinary handwriting scale, in which essentially the same method of comparison is used.

14 b. Motor coördination. Lines $B$.

Requirement: All lines firmly drawn with correct joining. This point is based upon a much more rigid interpretation of the rules given for the scoring of the preceding point. Obviously it can never be credited unless $14 a$ is also credited.

- The score is in addition to that for $14 a$. Scoring should be very strict.

14 c. Motor coördination. Head outline.

Requirement: Outline of head without obviously unintentional irregularities. The point is credited only in those drawings in which the shape of the head has devcloped beyond the first crude circle or ellipse, so that conscious control of the movement of the hand is necessary throughout. Scoring should be rather strict.

14d. Motor coördination. Trunk outline.

Requirement: Same as for the preceding point, but here with reference to the trunk. Note that the primitive circle or ellipse does not score.

14 e. Motor coördination. Arms and legs.

Requirement: Arms and legs without irregularities as above, and without tendency to narrowing at the point of junction with the body.. Both arms and legs must be in two dimensions. 


\section{4f. Motor coördination. Features.}

Requirement: Features symmetrical in all respects. Eyes, nose, and mouth must all be shown in two dimensions. In full-face drawings the eyes must be equidistant from the nose and from the corners of the mouth, and there must be no incorrect juxtaposition with the outline of the head. The nose must be symmetrical in shape, and must be placed above the center of the mouth. Where the nose is represented by two dots, these must be equidistant from the corners of the mouth. The two sides of the mouth must be alike, and the mouth must be placed at right angles with the axis of the head. In profile drawings the eye must be regular in outline and the distance from the center of the eye to the back of the head must be not less than twice as great as the distance from the center of the eye measured forward to the edge of the nose. The nose must form an obtuse angle with the forehead, and its size must be in proportion to the other features and to the size of the head. The mouth must be regular in outline and of a size proportionate to the other features. The scoring should be strict.

The point is much more likely to be credited in profile drawings than in full-face drawings.

15 a. Ears present.

Requirement: Two in full-face drawings, one in profile. Any clear method of representation.

Care must be taken not to overlook inconspicuous or unusual methods of showing the ears. Figures $43-46$ show some of the bizarre forms under which this item may appear. In some kindergarten drawings there is danger of confusing ears and arms. It should be remembered that, as a rule, the arms are shown at an earlier age than the ears; hence in cases of doubt it is usually safer to call the unexplained feature an arm rather than an ear, unless the size and shape are such as to make the classification fairly certain. As a rule the total rating of the child will not be affected whichever way the point is credited, since a score of more than one point on either item is not usual in these primitive drawings.

\section{5 b. Ears present in correct position and proportion.}

Requirement: The vertical measurement must be greater than the horizontal measurement. In profile drawings some detail, such as a dot to represent the aural canal, must be shown. In full-face drawings such detail may or may not be present. The ears must be placed somewhere within the middle two thirds of the head (as viewed from the side) and the shell-like portion of the ear must extend toward the back of the head. For some unexplained reason, a fairly large number of children, especially of retarded boys, tend to reverse this position, making the ear extend toward the face (Fig. 46). In such drawings point $15 b$ is never credited.

\section{6 a. Eye detail. Brow, lashes, or both shown.}

Requirement: Any clear method of representation. In most instances the brow is shown by means of a curved line above the eye. In some profile drawings of a high grade it is indicated by modeling to show the supraorbital ridge. Either method is satisfactory. Lashes are almost invariably represented by means of a series of curved lines projecting from the outline of the eye.

\section{6 b. Eye detail. Pupil shown.}

There is rarely any question as to the scoring. It should be noted, however, that a dot with a curved line above it is not credited, since the dot must be considered as representing the eye itself in these cases. The pupil must be preseñt in both eyes if both are shown. 


\section{Measurement of Intelligence by Drawings}

16 c. Eye delail. Proportion.

Requirement: The horizontal measurement of the eye must be greater than the vertical measurement. This requirement must be fulfilled in both eyes if both are shown; one eye is sufficient if only one is shown. In profile drawings of a high grade, the eye is sometimes shown in perspective; that is, its shape is altered from the customary almond form to that of a sector of a circle. In all such cases the point should be credited.

\section{6 d. Eye deiail. Glance.}

Requirement: The face must be shown in profile. The eye must either be shown in perspective, as described in the preceding paragraph, or, if the ordinary almond form is retained, the pupil must be placed toward the front of the eye rather than in the center. The scoring should be strict.

\section{7 a. Both chin and forehead shown.}

In full-face drawings both the eyes and the mouth must be present, and sufficient space must be lcft above the eyes to represent the forehead, below the mouth to represent the chin. The scoring should be ratlier lenient. In profile drawings the point may also be credited when the eyes and mouth are omitted, if the outline of the face shows clearly the limits of the chin and forehead. If there is no outline to indicate the separation of the chin from the neck in full-face drawings, the point cannot be credited. See Figures 47-50 for examples of success and failure. Note also the unusual methods of showing the chin and forehead, in Figures 51-54.

The reliability of scoring is rather less for this point than for most others in the scale. A number of scoring methods have been tried in an attempt to devise a purely objective rule for determining what is to be considered "sufficient" space. Comparative vertical measurements of different kinds, and combinations of vertical and horizontal measurements, using as a basis the total size of the head, the distance from the eyes to the top of the head, distance from the eyes to the mouth, etc., were tried; but no simple standard could be devised which would make sufficient allowance for the great variations in the shape of the head and in the relationships of the several features to each other. Because of this difficulty in scoring, the point was entirely omitted from one of the earlier forms of the scale. It was re-included in the present revision because of its apparent significance in the case of kindergarten and first-grade children. There is little difference between the performance of accelerated and average children in respect to this point, but the retarded group is clearly behind the others at all age levels.

17 b. Projection of chin shown; chin clearly differentiated from lower lip.

The point is rarely credited except in profile drawings. In full-face drawings, however, it may be credited if the modeling of the chin is indicated in some way, as by a curved line below the lip.

18 a. Profile $A$.

Requirement: The head, trunk, and feet must be shown in profile without error. The trunk may not be considered as drawn in profile unless the characteristic line of buttons has been moved from the center to the side of the figure, or some other indication, such as the position of the arms, pockets, necktie, etc., shows clearly the effect of this change of position. The entire drawing may contain one, but not more than one, of the following errors:

1. One bodily transparency, as the outline of the trunk showing through the arm.

2. Legs not in profile. In a true profile at least the upper 
part of the leg which is in the background must be concealed by the one in the foreground.

3. Arms attached to the outline of the back and extending forward. This appears to be a residual effect of the manner of attachment which the child was accustomed to use in his full-face drawings.

\section{8 b. Profile $B$.}

Requirement: The figure must be shown in true profile, without error or bodily transparency, except that the shape of the eye may be ignored.

Considering the strong emphasis which previous workers have placed upon the change from the full-face to the profile drawing, it may seem that too little weight has been given to this characteristic in the present scale. It has been found, however, that while it is true that very young children practically never draw the figure in profile, an appreciable number of older ones, even among the accelerated children, continue to give the preference to the full-face position. Most of the literature on children's drawings tends to give the impression that the change to the profile position is a general rule which all children come to adopt in their drawings, but my own figures show that this is far from being the case. The proportion of profiles, when the subject is left entirely to his own choice, increases steadily until it includes about 80 or 85 per cent of all drawings; but apparently the maximum is reached at about this point. At least this is the approximate proportion found among drawings by high school students and university graduates. It has therefore seemed best not to give too much credit to the profile as such; rather, to devise a scoring plan which would tend to favor the profile position in a large number of the points considered, but which would not preclude the possibility of success with these points in the full-face drawing.
Specimen Drawinge, with Scoring Indicated

Series I 
112 Measurement of Intelligence by Drawings

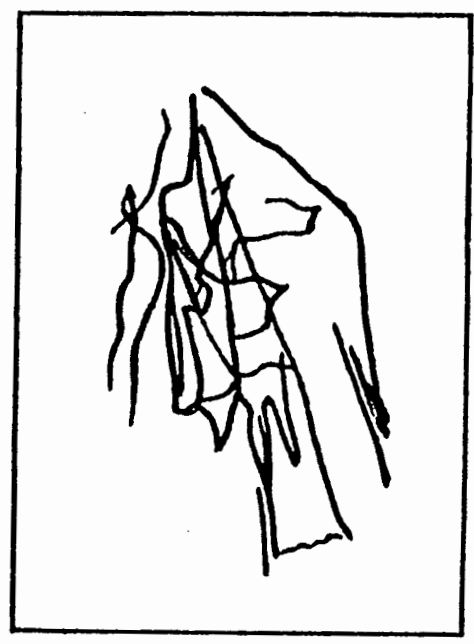

Fra. 1

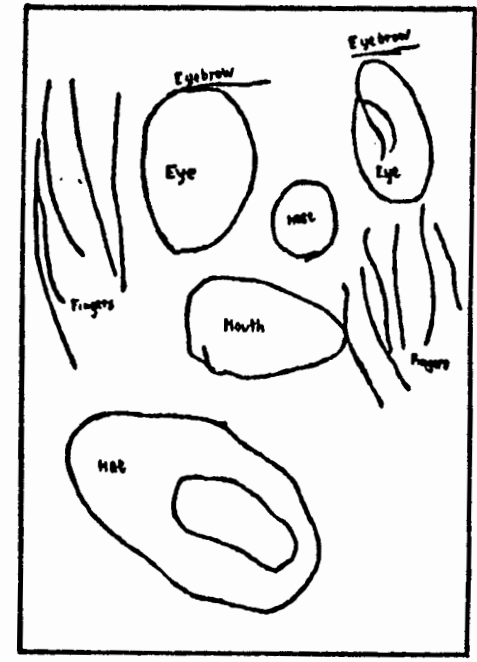

Fra. 8

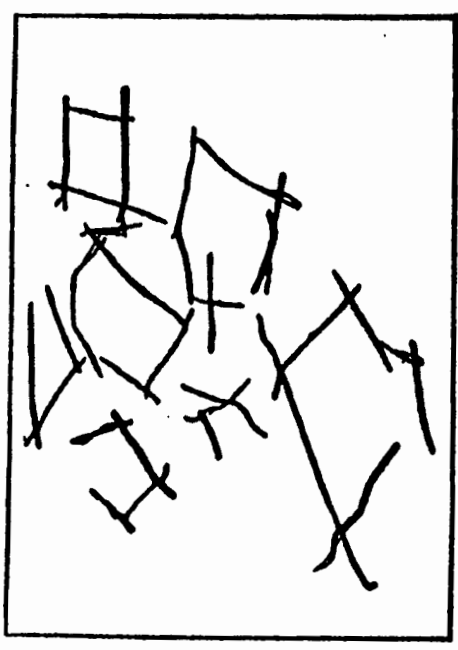

Fra. \&

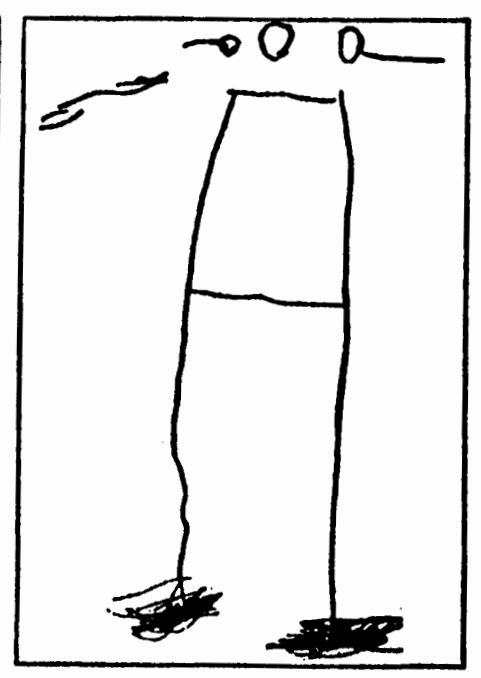

Fra. 4
Specimen Drawings, with Scoring Indicated

113

Fia. 1. Boy, Italian, age 4-2; pre-school. Score 0. (Class A.) M.A. not over 8 years. IQ 72 or less.

Frg. \&. Girl, American, age 4- 2 , kindergarten. Score 1. (Class A.) M.A. 8-9. IQ 78 .

Fra. 3. Boy, Jewish, age 4-11, kindergarten. Credits, $7 a, 7, b$, 7 c, 8 a, 10 a, $10 a_{t}$ Total score 6. M.A. 4-6. IQ 92. (This and all subsequent drawings belong to Class $B$.)

Fra. 4. Girl, American, age 5-0, kindergarten. Credits, $2,8,4 a$, $4 b, 7 a,\{b, 12 c$. Total score 7. M.A. 4-8. IQ 05 . 


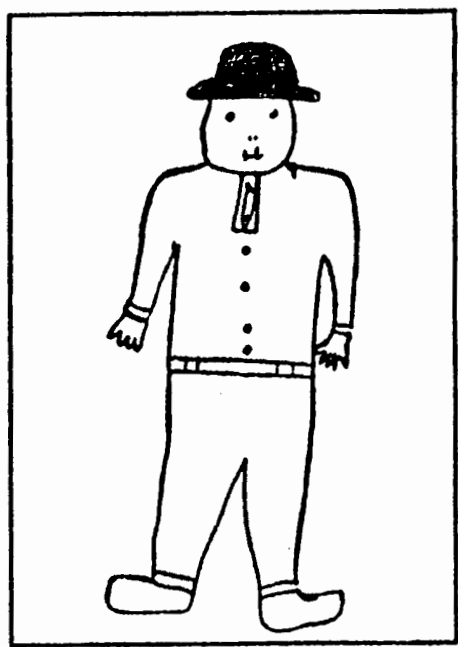

Fra. 5

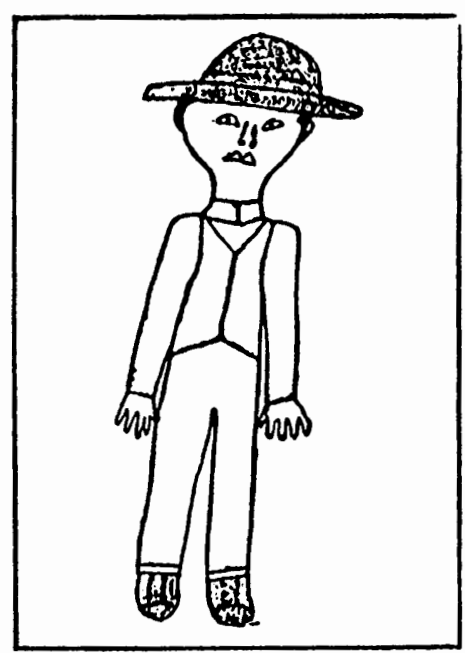

Fio. 7

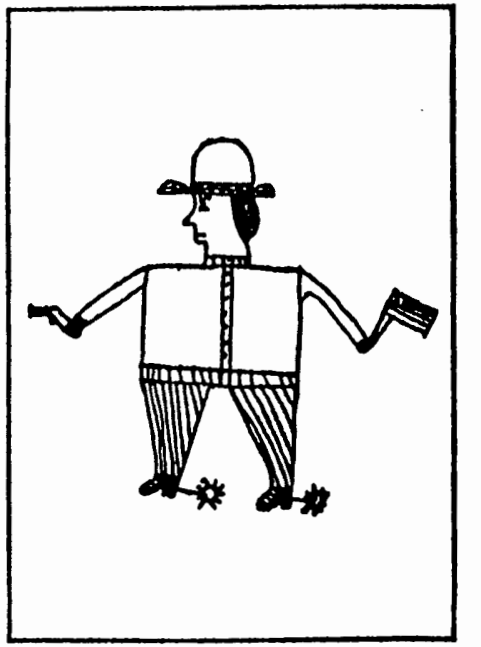

Fra. 6

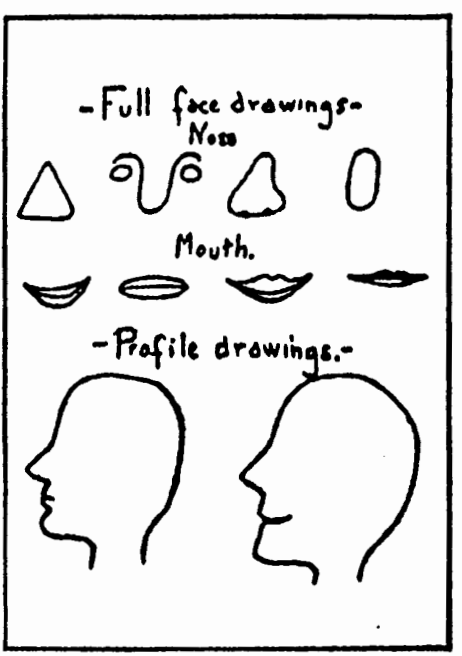

Fia. 8
Fia. 6. Girl, American, age 11-7, high third grade. Credits, 1,2 , $3,4 a, 4 b, 4 c, 5 a, b b, 7 a, 7 b, 7 c, 7 c, 9 a, 9 b, 9 d, 10 a, 10 c$, $10 e, 11 a, 11 b, 12 a, 12 e, 14 a, 14 d, 17 a$. Total score 25. M.A. 9-8. IQ 80.

Fia. 6. Boy, Negro, age 10-1, low third grade. Credits, $1,2,8$, $4 a, 4 c, 5 a, 5 b, 6 a, 6 b, 7 a, 7 b, 7 c, 7 e, 8 a, 8 b, 8 a, 8 b, 8 c$, $9 d, 10 a, 10 c, 12 a, 12 c, 12 d, 12 e, 13,14 a, 14 c, 14 f, 16 a, 17 a$. Total score 31. M.A. 10-8. IQ 107.

Fra. 7. Girl, Indian, age 12-8, fourth grade. Credits, 1, $2,3,4 a$, $4 b, 4 c, 5 a, 5 b, 6 a, 6 b, 7 a, 7 b, 7 c, 7 e, 8 a, 8 b, 19 a, 9 b, 9 c$, $9 d, 10 a, 10 b, 10 c, 10 d, 10 e, 11 a, 11 b, 12 b, 12 c, 12 d, 12 e$, 18, $14 a, 14 d, 14 e, 16 a, 16 b, 16 b, 16 c$. Total score 38. M.A. 18-8. IQ 104.

\section{Fra. 8. Accepted forms for scoring point $7 d$.}

1 In drawings of the type of Figure 7, in which practically all of the bair is covered by the hat, credit is given for point $8 \mathrm{~b}$ if the hair which is shown covers even a very small portion of the visible part of the head. 


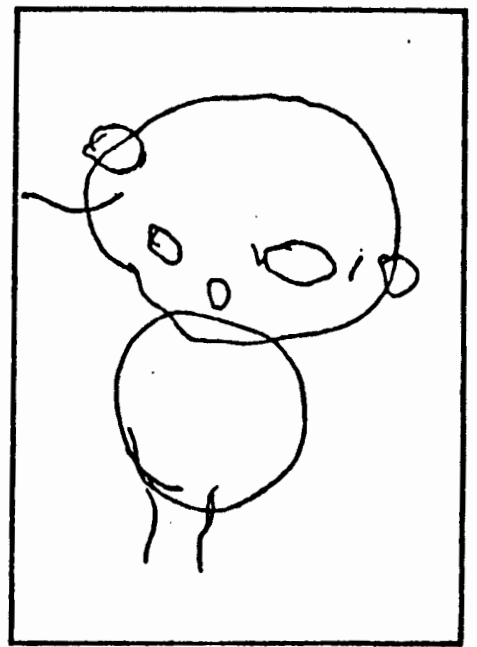

Fra. 8

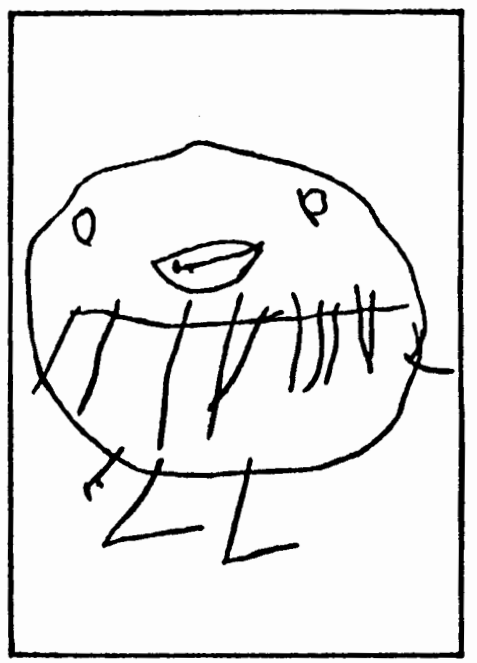

Fra. 11

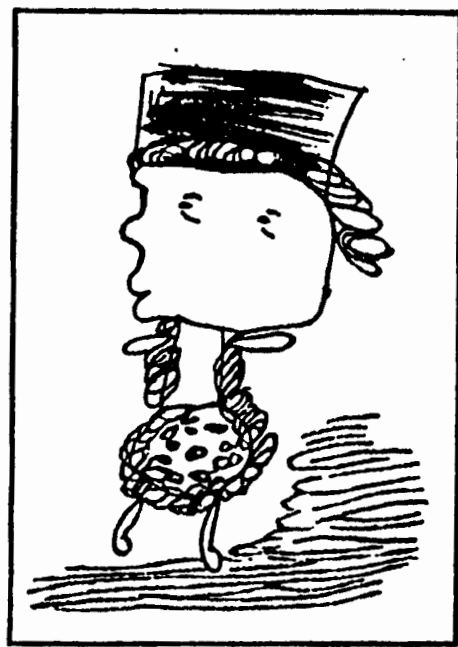

Fia. 10

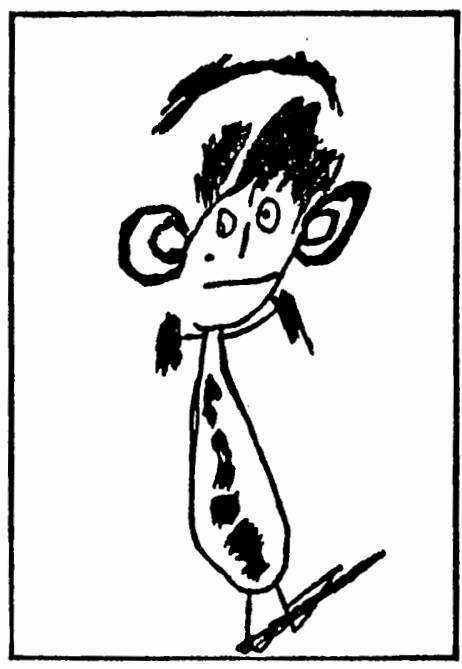

Fra. 18
Fro. 8. Girl, American, age 5-7, kindergarten. Credits, 1, 2, 3, $4 a, 4 b, 7 a, 7 b, 15 a$. Total score 8. M.A. 5-0. IQ 00 .

Fra. 10. Girl, German, age 7-6; high first grade. Credits, 1, 2, 3, $4 a, 5 a, 6 a, 7 a, 7 b, 7 c, 7 d, 8 a, 8 a, 12 e, 14 a, 16 a, 16 c$. Total score 16. M.A. 7-0. IQ 83.

Fic. 11. Girl, American, age 5-10, kindergarten. Credits, 1, 2, 8, $7 a, 7 b, 7$ c, $16 a$. Total score 7. M.A. 4-8. IQ 81. (Note the division of the septum. This is not credited as nostrils.)

Fra. 12. Boy, Jewish, age 8-11, low second grade. Credits, 1,2 , $3,4 a, 4 b, 8 a, 7 a, 7 b, 7 c, 8 a, 0 a, 10 e, 15 a, 16 b$. Total score 14. M.A. 6-6. IQ 73 . 
118 Measurement of Intelligence by Drawings

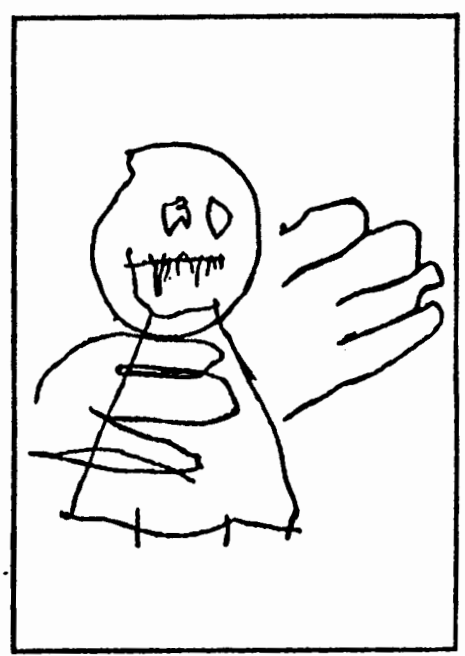

Fro. 18

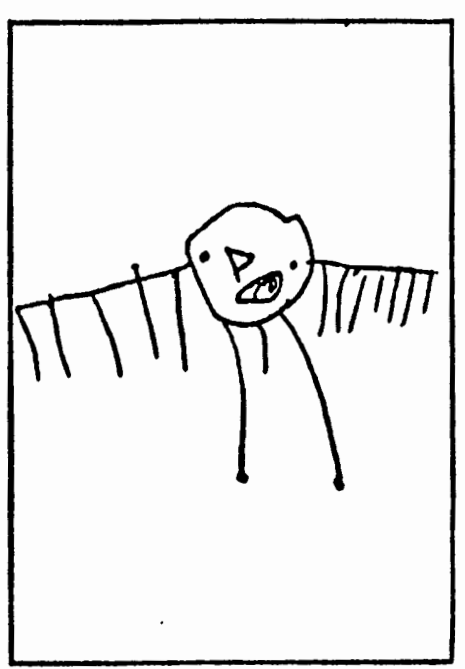

Fra. 16

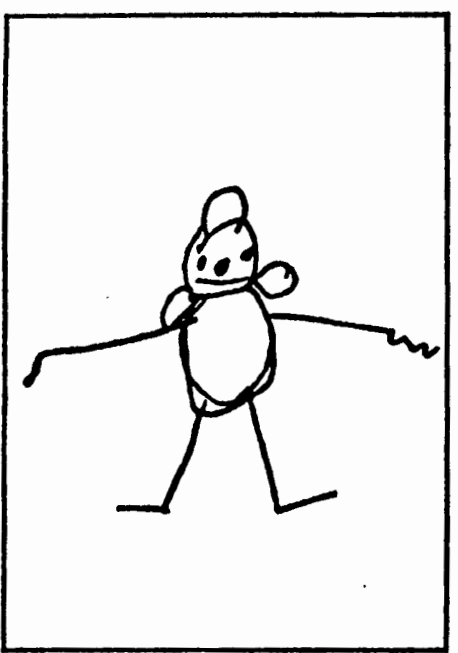

Fra. 14

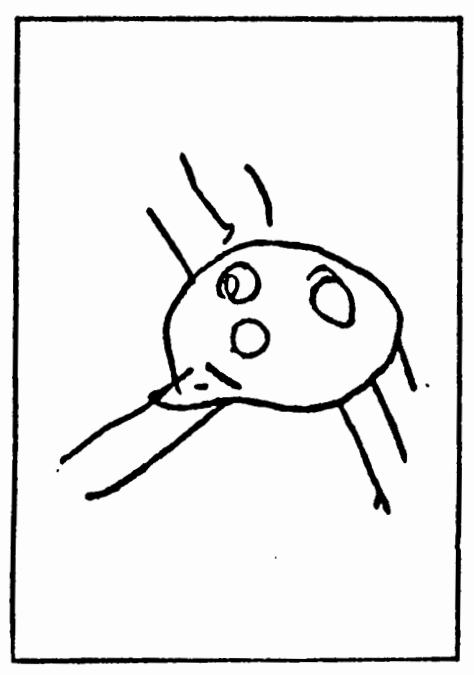

Fra. 16
Fra. 13. Boy, American, age 4-7, kindergarten. Credits, 1, 2, 3, $4 a, 6 a, 7 a, 7 c, 10 a, 10 c, 17 a$. Total score 10. M.A. 5-6. IQ 120.

Fra. 14. Boy, American, age 6-10, kindergarten. Credits, 1, 2,3 , $4 a, 4 b, 5 a, 7 a, 7 b, 7 c, 8 a, 10 a, 12 a, 12 c, 15 a, 17 a$. Total score 16. M.A. 6 6. IQ 116 .

Fra. 15. Girl, American, age 5-6, kindergarten. Credits, 1, \&, s, $7 a, 7 b, 7 c, 10 a, 17$ a. Total score 8. M.A. 6-0. IQ 81,

Fra. 16. Girl, Italian, age 6-0, pre-school. Credits, 1, $2,7 a$, $7 b, 7 c, 10 a$. Total score 6. M.A. 4-6. IQ 76. 


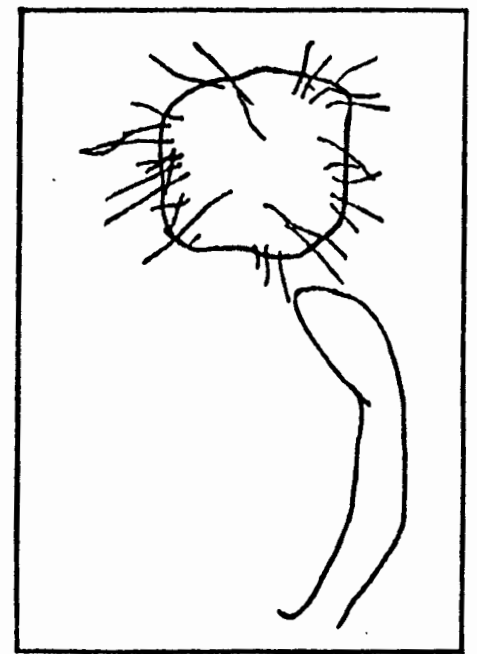

Fia. 17

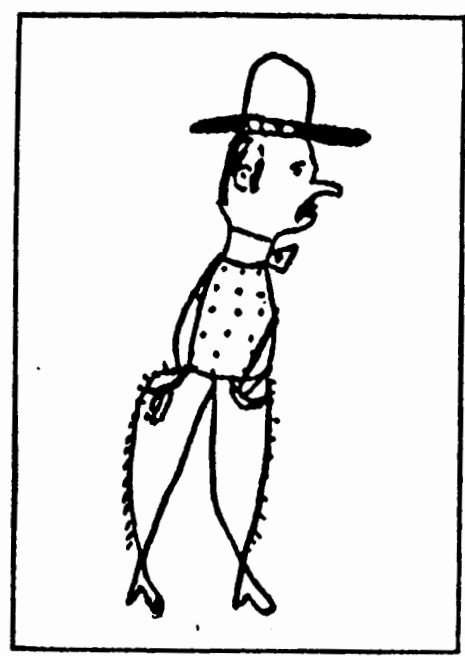

Fra. 10

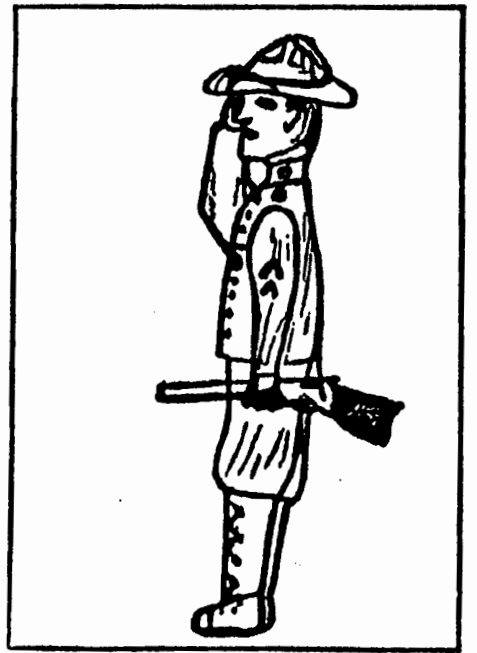

Fra. 18

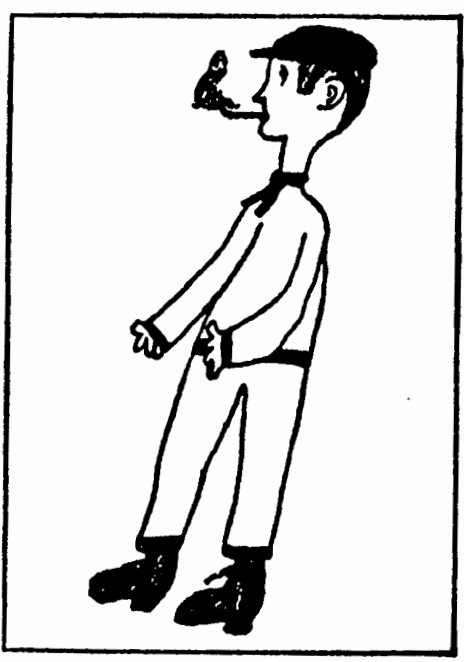

Fra. 20
Fra. 17. Boy, Jewish, age 4-0, pre-school. Credits, 1, 2,10 a. Total score 3. M.A. 3-8. IQ 94.

Fra. 18. Boy, Jewish, age 12-9, high fourth grade. Credits, 1,2 , $3,4 a, 4 b, 4 c, 5 a, 5 b, 6 a, 6 b, 7 a, 7 b, 7 c, 7 d, 7 e, 8 a, 8 b, 8 a$, $9 b, 8 c, 9 d, 9 e, 10 a, 10 b, 10 c, 10 e, 11 a, 11 b, 12 a, 12 b, 12 c$, $12 d, 12 e, 13,14 a, 14 c, 14 d, 14 e, 14 f, 15 a, 16 b, 16 c, 17 a$, $17 b, 18 a, 18 b$. Total score 46 . M.A. 19-0 or above. IQ 10 2 or above.

Fra. 19. Girl, Negro, age 12-8, high third grade. Credits, 1, 2 , 3, $4 a, 4 b, 6 a, 6 a, 6 b, 7 a, 7 b, 7 c, 8 a, 8 b, 8 a, 9 b, 9 d, 10 a$, $10 b, 10 \mathrm{c}, 11 \mathrm{a}, 11 \mathrm{~b}, 12 \mathrm{~b}, 12 \mathrm{c}, 12 \mathrm{~d}, 12 \mathrm{e}, 19,14 a, 14 f, 15 a$, $16 b, 16 a, 17 a, 17 b$. Total score 38. M.A. 11-3. IQ 92.

Fra. 20. Girl, Armenian, age 0-8, high third grade. Credits, 1 , $2,8,4 a, 4 b, 4 c, 6 a, 5 b, 6 a, 6 b, 7 a, 7 b, 7 c, 7 d, 7 e, 8 a, 8 b$, $\theta a, 8 b, 9 c, 8 d, 8 e, 10 a, 10 e, 11 a, 11 b, 12 a, 12 b, 12 c, 12 d$, $12 e, 18,14 a, 14 c, 14 f, 15 a, 16 b, 16 a, 16 b, 16 c, 16 d, 17 a$, $17 \mathrm{~b}, 18 \mathrm{a}$. Total score 44. M.A. 13-0 or above. IQ 141 or above. 


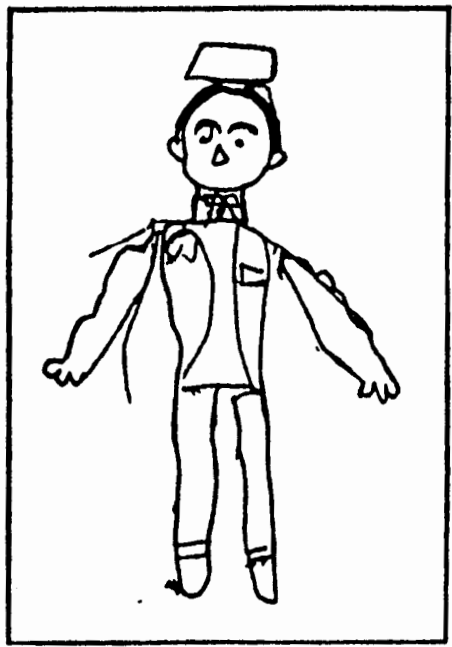

Fra. 21

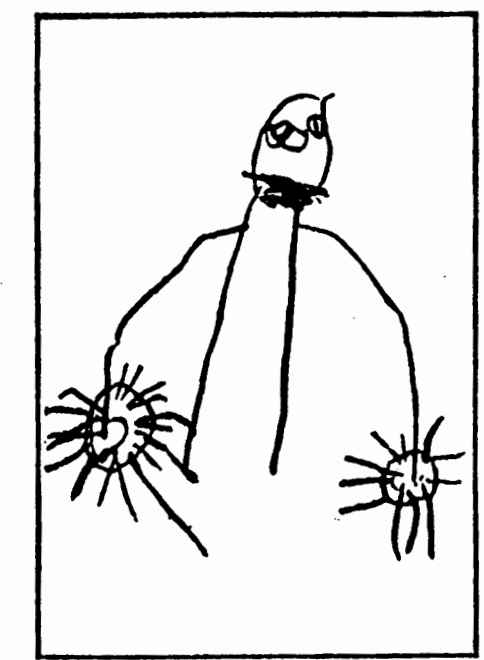

Fia. 28

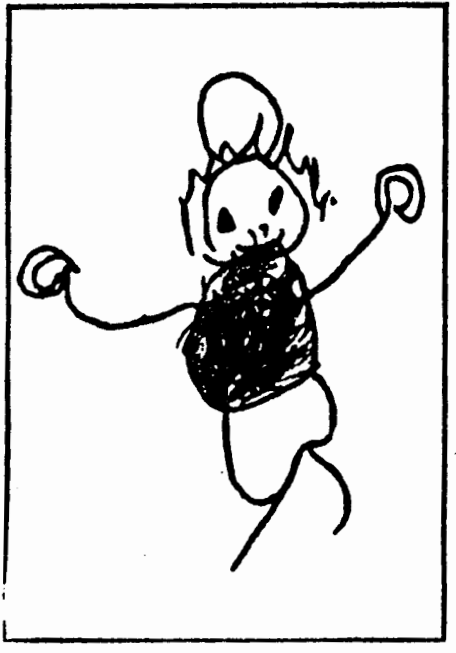

Fia. 22

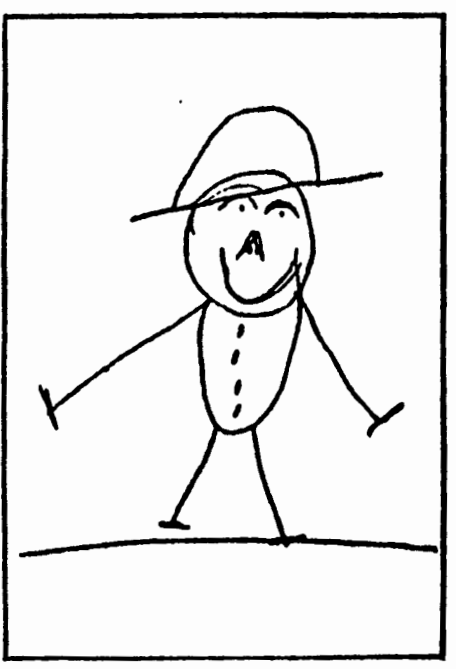

Fra. 24
Fra. 21. Girl, Negro, age 12-6, high third grade. Credits, 1,2 , $3,4 a, 4 b, 4 c, 5 a, 5 b, 6 a, 7 a, 7 b, 8 a, 8 a, 0 d, 10 a, 12 a, 12 b$, $12 c, 12 d, 12$ e, 18, 16 a, 16 a. Total score 23. M.A. 8-8. IQ 70.

Fra. 22. Girl, Jewish, age $8-\theta$, kindergarten. Credits, 1, 2,3 , $4 a, 4 b, 6 a, 7 a, 7 b, 7 c, 7 e, 8 a, 8 a, 10 e, 12 a, 12 b$. Total score 16. M.A. 6-8. IQ 117.

Fia. 23. Girl, Italian, age 4- $\theta$, kindergarten. Credits, 1, 9, 8, 7 $a$, $7 b, 7 c, 10 a, 10 \cdot e, 16 b$. Total score 9. M.A. 5-3. IQ 112 .

Fra. 24. Boy, American, age 7-11, low second grade. Credits, $1,2,8,4 a, 4 b, 5 a, 7 a, 7 b, 7 c, 7 e, 9 a, 10 e, 16 a$. Total score 13. M.A. 6-3. IQ 79 . 
124 Measurement of Intelligence by Drawings

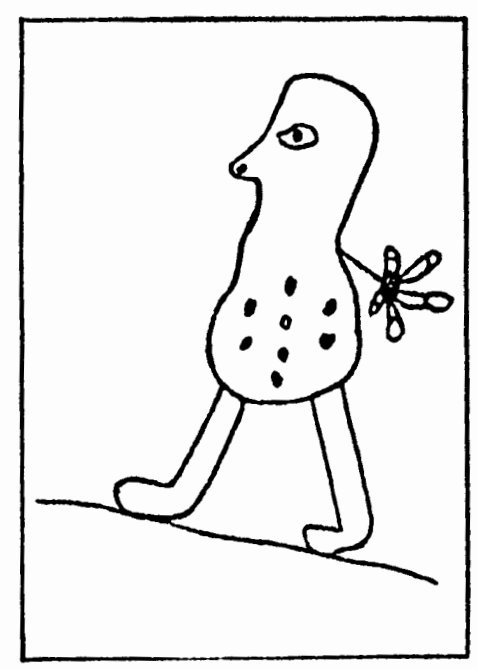

Fig. 25

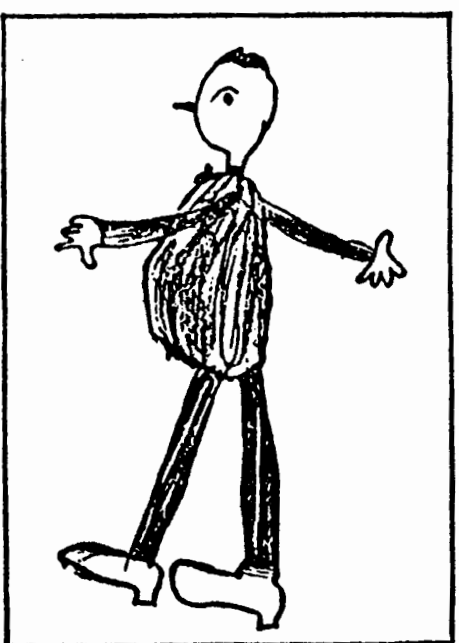

Fra. 27

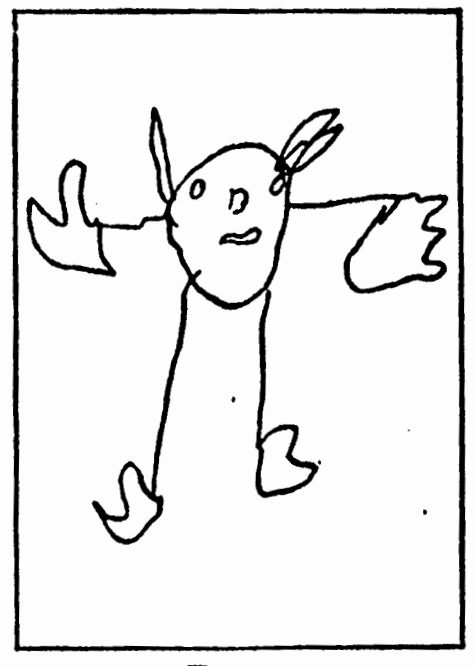

Fra. 26

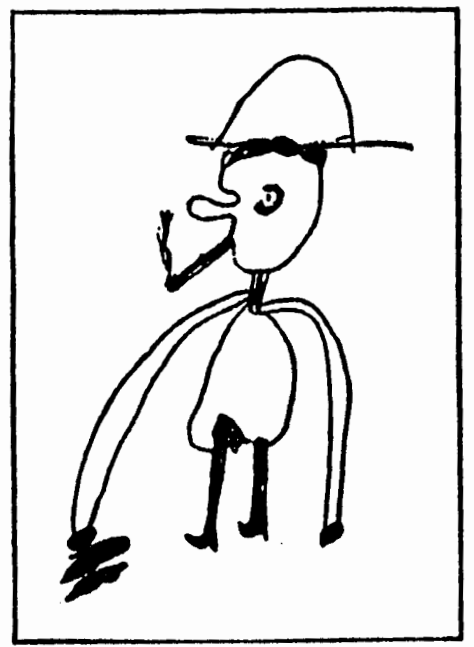

Fra. 28
Specimen Drawings, with Scoring Indicated

125

Fra. 26. Boy, Italian, age 7-2, low second grade. Credits, 1, 2, 8, $4 a, 4 b, 6 a, 7 a, 7 b, 7 e, 9 a, 10 a, 10 b, 10 e, 12 c, 14 a, 16 b$, 16 o. Total score 17. M.A. 7-3. IQ 101.

Fxa. 26. Boy, Italian, age 7-2, low first grade. Credits, 1, 2, 9, $7 a, 7 b, 7$ c, $10 a, 10 e, 15 a$. Total score 8. M.A. 5-8. IQ 78.

Fra. 27. Boy, American, age 0-6, high fourth grade. Credits, $1,2,8,4 a, 4 b, 4 c, 6 a, 6 a, 6 b, 7 a, 7 b, 8 a, 8 a, 8 b, 9 c, 10 a$, $10 b, 10 c, 10 d, 10 e, 12 a, 12 c, 12 e, 13,14 a, 10 a$ : Total score 26. M.A. 9-6. IQ 100.

Fra. 28. Boy, Polish, age 12-4, low third grade. Credits, 1, 2, 8, $4 a, 4 b, 5 a, 6 a, 6 b, 7 a, 7 b, 7 c, 8 a, 8 a, 10 e, 11 a, 12 d, 12 e$, 13, $14 a, 16 a, 17 a$. Total score 21. M.A. 8-8. IQ 67 . 


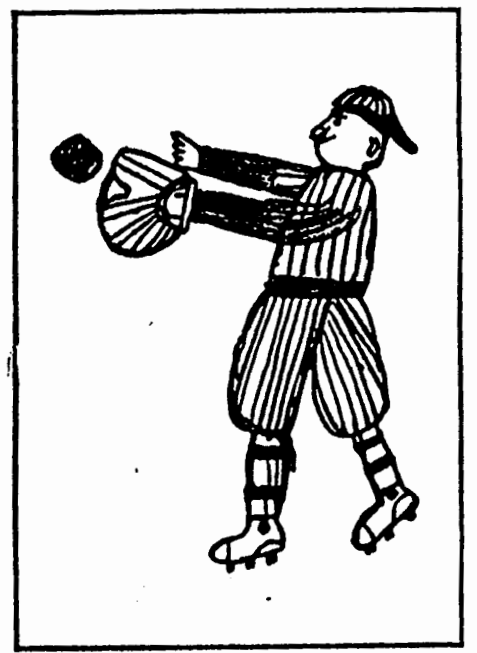

Fra. 29

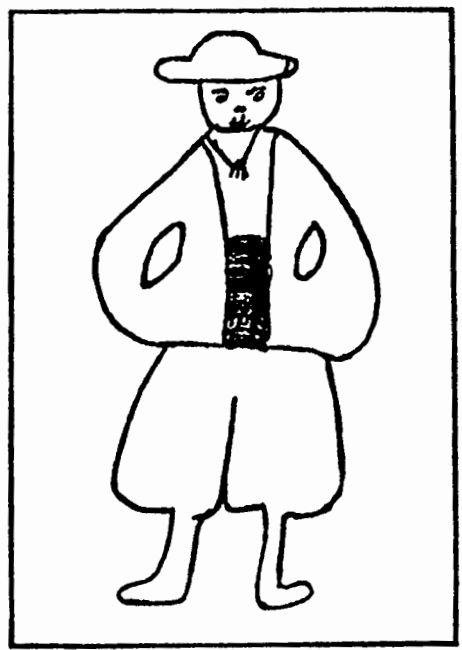

Fro. 90

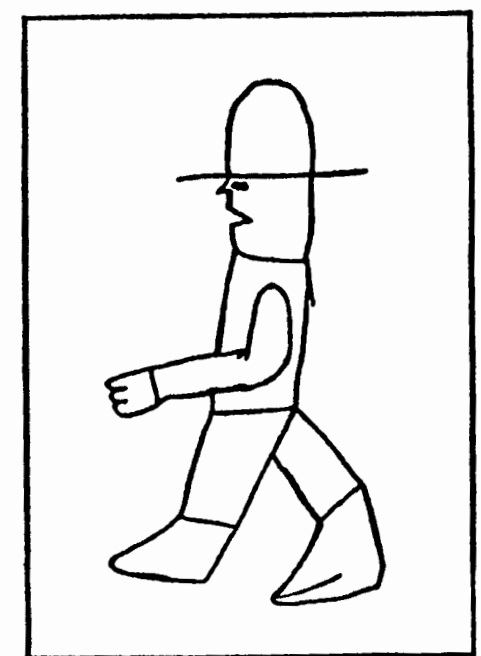

Fra. 81

Fra. 29. Boy, Negro, age 11-7, low fourth grade. Credits, 1, 2, 8, $4 a, 4 b, 4 c, 6 a, 5 b, 6 a, 0 b, 7 a, 7 b, 7 c, 7 d, 8 a, 8 b, 9 a, 8 b$, $9 d, 9 e, 10 a, 10 c, 10 e, 11 a, 11 b, 12 a, 12 b, 12 c, 12 d, 12 e$, 13, $14 a, 14 d, 14 e, 15 a, 10 a, 17 a, 18 a$. Total score 98. M.A. 12-6. IQ 108. (Note. The neck is shown only in the back, owing to the pose of the head. The hair is not clear in the photograph, but is distinct in the original drawing. The thumb shown on the glove does not score, since none is shown on the other hand. The heel is shown by projection at back of foot.)

Fra. 30. Girl, American, age 9-6, high third grade. Credits, 1, 2, 3, $4 a, 4 b, 5 a, 5 b, 7 a, 7 b, 7 c, 7 e, 8 a, 9 b, 9 d, 10 a, 10 b, 10 c$, $11 a, 11 b, 12 a, 12 b, 12 d, 12 \mathrm{e}, 14 a, 16 a, 16 \mathrm{c}$. Total score 26. M.A. O-6. IQ 100 .

Fra. 31. Boy, Chinese, age 6-7, low first grade. Credits, 1, 2, 3, $4 a, 5 a, 6 b, 7 a, 7 b, 7 c, 7 d, 9 a, 8 b, 9 c, 10 a, 10 c, 10 e, 11 a$, $11 b, 12 c, 12 e, 14 a, 16 c, 17 a, 18 a, 18 b$. Total score 26 . M.A. 9-9. IQ 141. 
128 Measurement of Intelligence by Drawings

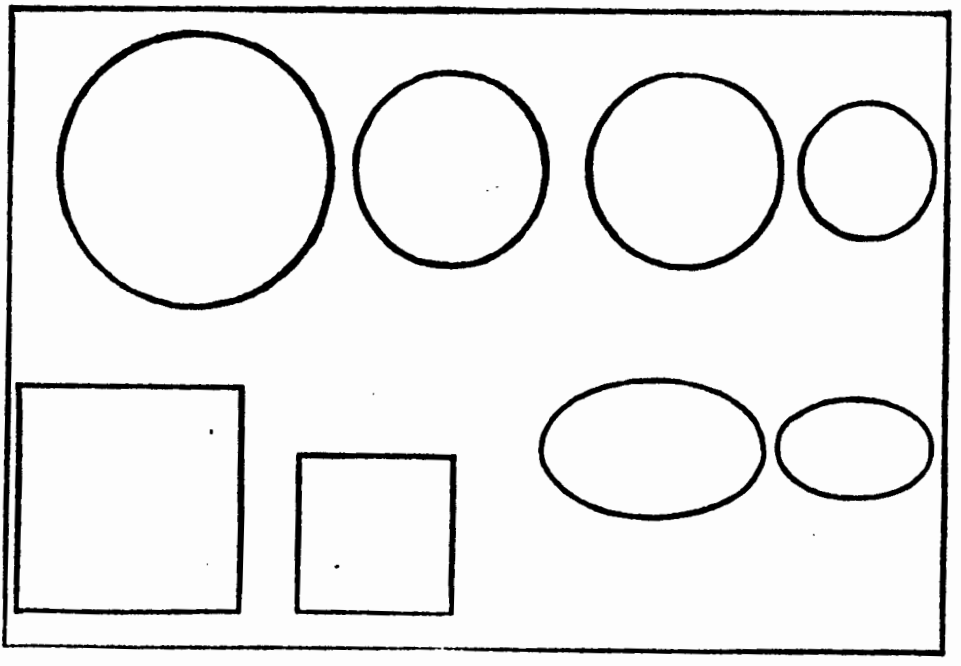

Fra. 32

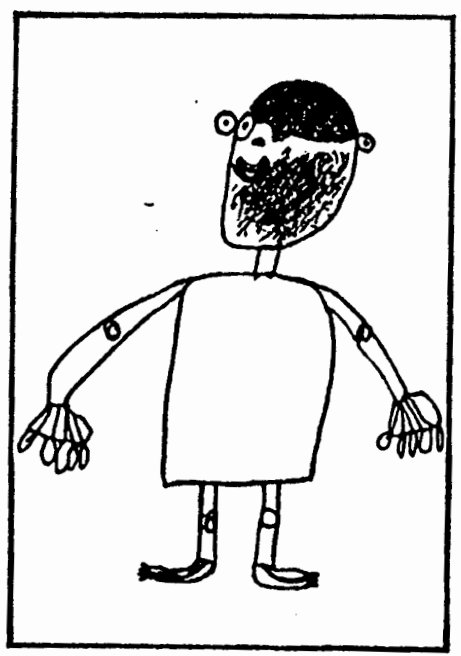

Fra. 38

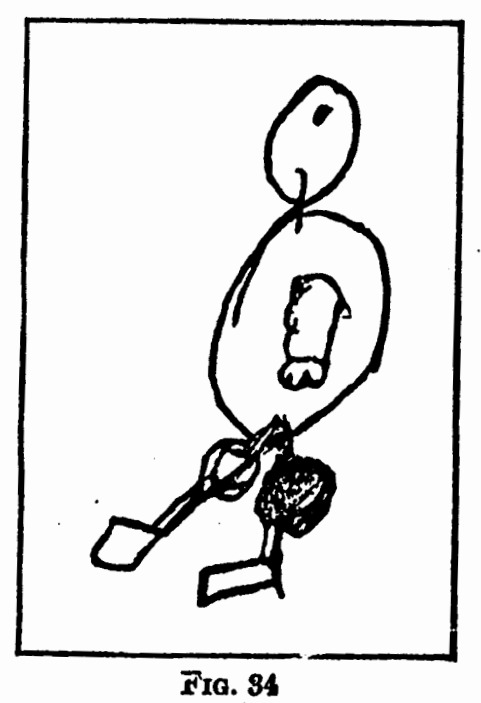

Specimen Drawings, with Scoring Indicated

129

Fra. 32. Standard forms in which the area of the second is one half of the first. For comparison in scoring point $12 a$.

Fig. 33. Boy, American, age 6-9, low second grade. Credits, $1,2,3,4 a, 4 b, 4 c, 5 a, 5 b, 6 a, 7 a, 7 b, 7 c, 8 a, 8 b, 10 a, 10 b$, $10 c, 10 e, 12 a, 12 b, 12 e, 14 a, 14 c, 15 a$. Total score 24 . M.A. 0-0. IQ 193.

Fra. 34. Girl, American, age 11-8, low second grade. Credits, $1,2,8,4 a, 4 b, 5 a, 6 a, 7 a, 8 a, 10 a, 10 e, 11 a, 11 b, 12 a, 12 e$, 18 a. Total score 16. M.A. 7-0. IQ 60. (9a is credited on basis of sleeve.) 


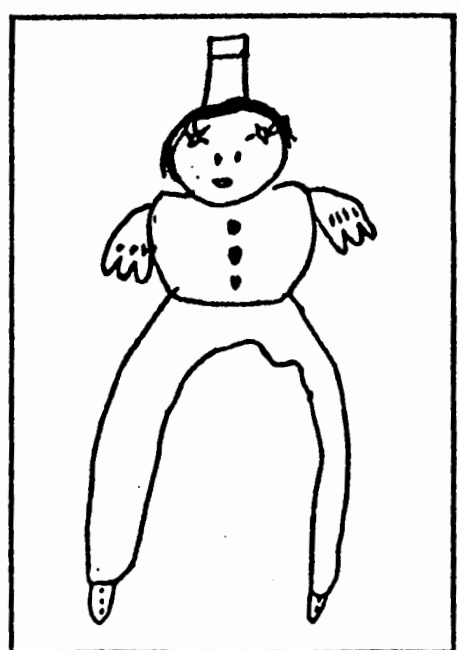

Fra. 35

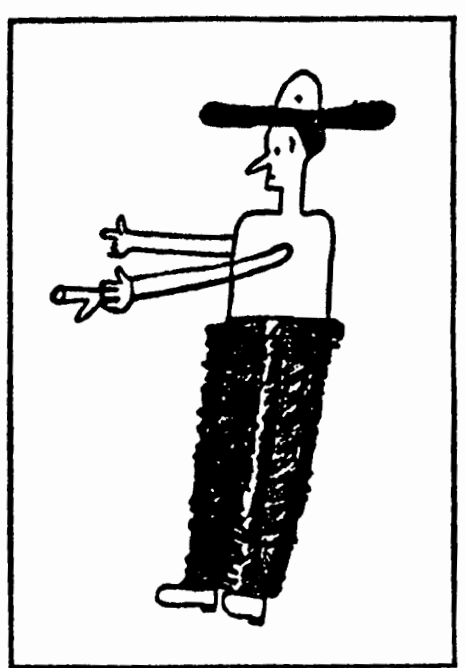

Fra. 87

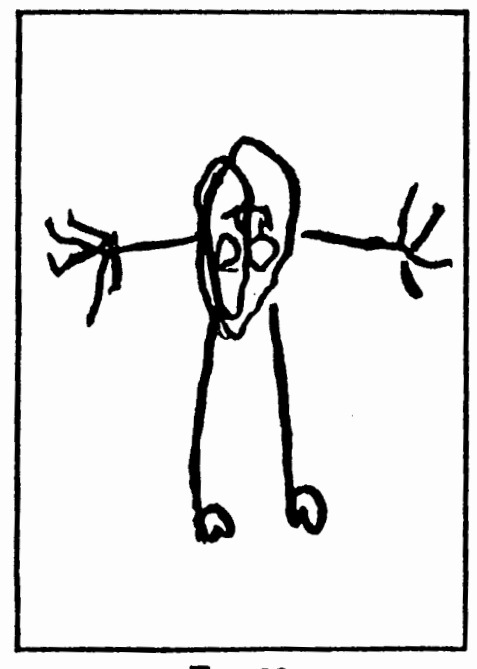

Fro. 30

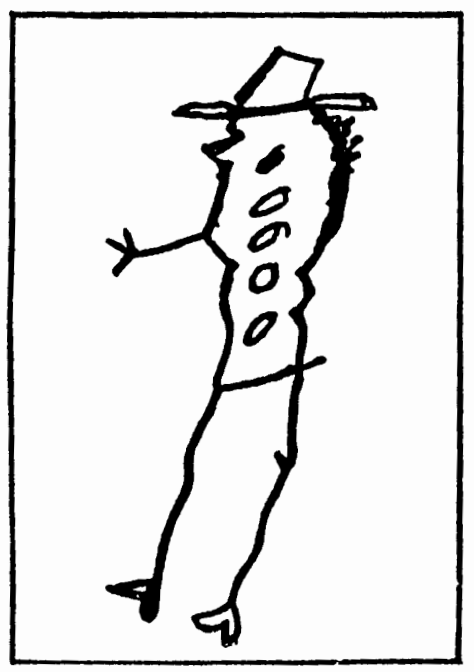

Fra. 88
Fra. 35. Girl, Scotch, age 7-0, high first grade. Credits, 1, 2, 3, $4 a, 5 a, 7 a, 7 b, 7 c, 7 e, 8 a, 9 a, 10 a, 10 c, 11 b, 12 a, 12 c, 12 d$, 12 e, 18, 16a. Total score 20. M.A. 8-0. IQ 114.

Fra. 86. Boy, Italian, age 6-7, kindergarten. Credits, 1, 2, 8, 7 a, 7 c, 10 a, 13. Total score 7. M.A. 4-8. IQ 85. (Note that the mouth, which can be identified by the teeth, is placed above the eyes. The smaller ellipse represents the face.)

Fro. 37. Boy, Negro, age 14-5, low third grade. Credits, 1, 2, 3, $4 a, 4 c, 5 a, 6 a, 6 b, 7 a, 7 b, 7 c, 8 a, 8 b, 8 a, 10 a, 10 b, 10 c$, $10 d, 10 e, 12 a, 12 b, 12 d, 12 e, 13,14 a, 14 c, 14 d, 15 a, 17 a$, 17 b. Total score 30. M.A. 10-6. IQ 71 or less. (IQ computed on basis of chronological age of 13-0.)

Fig. 38. Boy, American, age 14-7, low second grade. Credits, 1 , 2, 3,4a, $4 b, 7 a, 7 b, 8 a, 9 a, 10 a, 12 c, 13$. Total score 12 . M.A. 6-0. IQ 46. (IQ computed on basis of chronological age of 13-0.) 


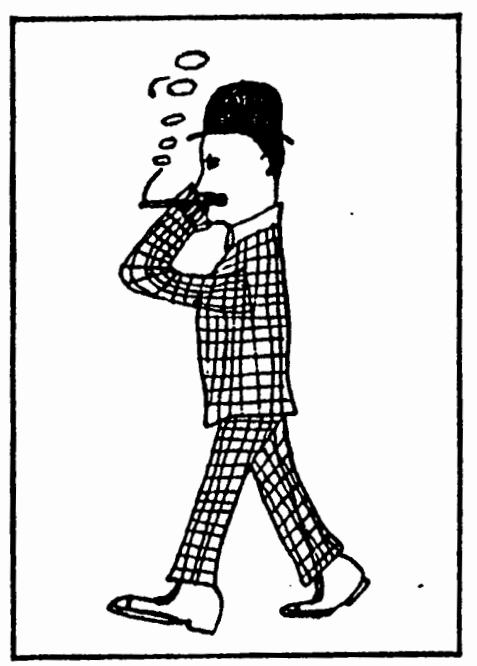

Fro. 39

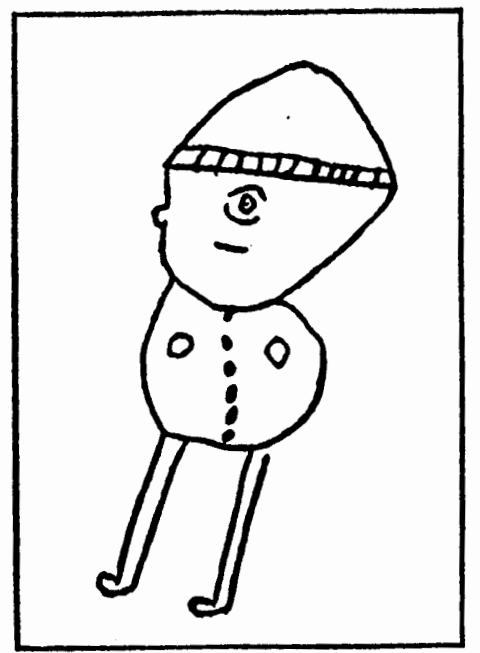

Fra. 41

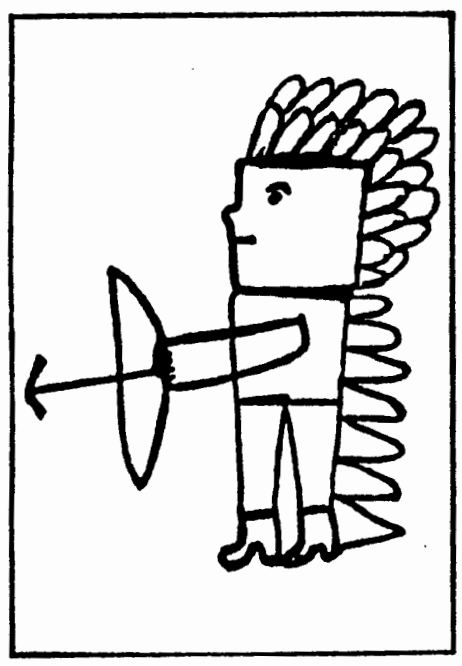

Fro. 40

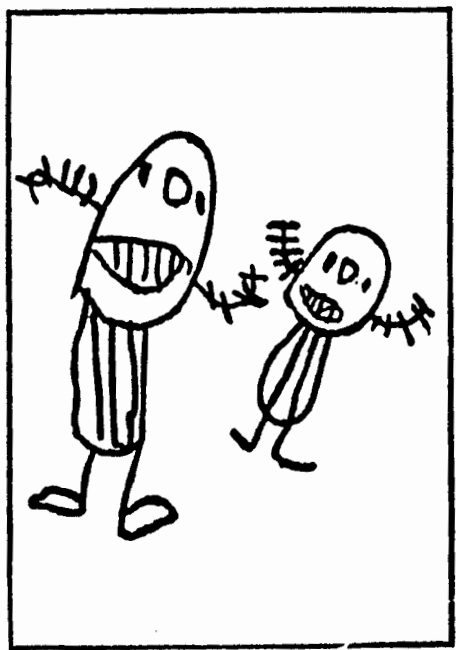

Fro. 48
Fro. 39. Boy, Armenian, age 11-2, low fifth grade. Credits, $1,2,8,4 a, 4 b, 4 c, 5 a, 5 b, 6 a, 6 b, 7 a, 7 b, 7 c, 7 d, 7 e, 8 a, 8 b$, $0 a, 8 b, 9 c, 9 d, 8 c, 10 a, 10 b, 11 a, 11 b, 12 a, 12 b, 12 c, 12 e$, $13,14 a, 14 b, 14 c, 14 d, 14 e, 14 f, 15 a, 16 a, 16 b, 16 c, 16 d, 17 a$, $17 b, 18 a, 18 b$. Total score 47 . M.A. 19-0 or above. IQ 110 or above.

Fra. 40. Boy, Negro, age 10-4, low third grade. Credits, 1, 2, 3, $4 a, 5 a, 6 a, 7 a, 7 b, 7 c, 9 a, 10 a, 10 b, 10 c, 11 b, 12 b, 12 c$, $12 d, 12 e, 13,14 a, 14 \mathrm{c}, 14 f, 16 a, 17$ a. Total score 24 . M.A. 9-0. IQ 87. (A short inserted neck is present, not clearly shown in the photograph.)

Fro. 41. Boy, American, age 0-4, low third grade. Credits, 1, 2 , $4 a, 7 a, 7 b, 7 c, 9 a, 12 c, 12 d, 14 a, 16 a, 16 b, 17 a$. Total score 13. M.A. 6-8. IQ 67.

Fra. 42. Boy, Italian, age 7-6, high first grade. Credits, 1, 2, 3, $4 a, 4 b, 7 a, 7 b, 7 c, 9 a, 10 a, 10 b$. Total score 11. M.A. 6-9. IQ 77. 


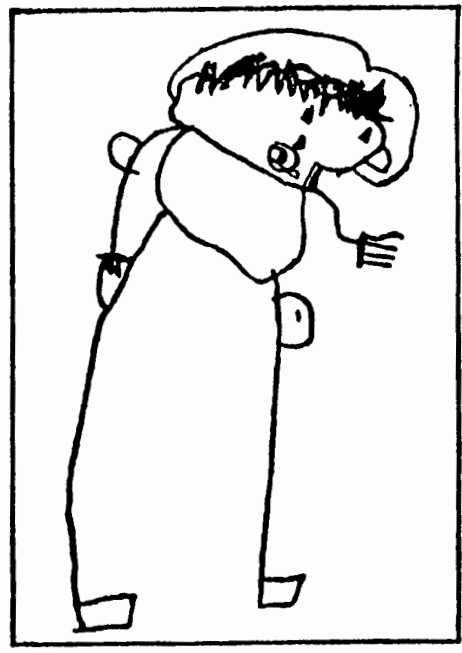

Fro. 43

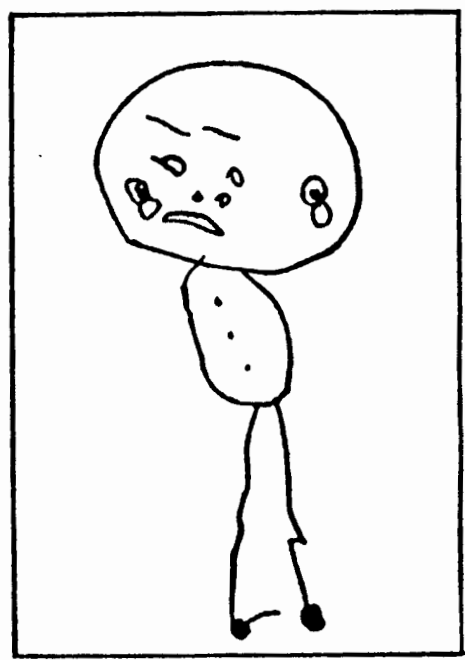

Fia. 45

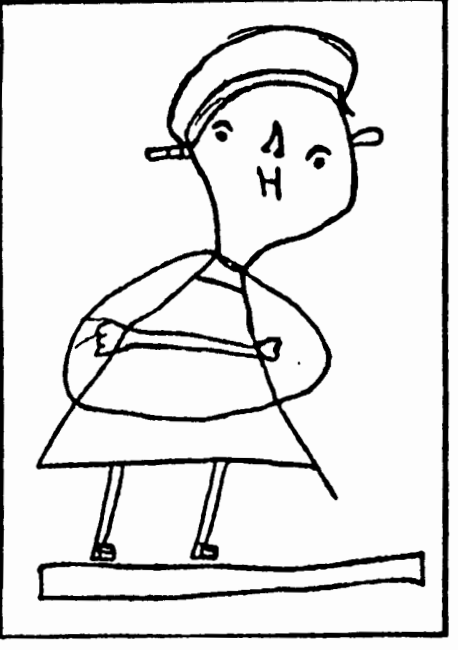

Fra. 44

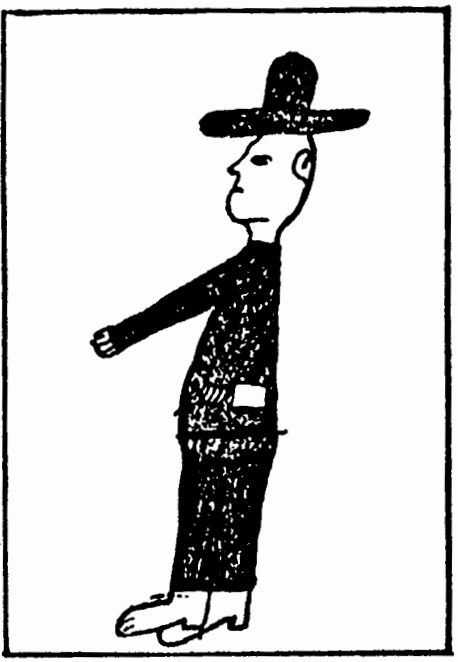

Fia. 40

Fu. 43. Boy, Italian, age 5-3, kindergarten. Credits, $1,2,3,4 a$, $5 a, 7 a, 7 b, 7 c, 8 a, 8 a, 10 a, 10 e, 12 b, 15 a$. Total score 14 . M.A. 6-6. IQ 124. (One ear is attached to the head; the other to the arm on the opposite side. The line around the head signifies the hat. Trousers' pockets but no trousers are shown. The scribbled line inside the mouth is the tongue.)

Fia. 44. Girl, Negro, age $\theta-\theta$, low third grade. Credits, $1,2,8$, $4 a, 6 a, 6 a, 6 b, 7 a, 7 b, 7 c, 7 e, 9 a, 10 a, 10 e, 12 d, 12 e, 14 a$, 16 a, 16 a. Total score 19. M.A. 7-9. IQ 79.

Fra. 45. Girl, Japanese, age 4-10, kindergarten. Credits, 1,2 , $4 a, 4 b, 7 a, 7 b, 7 c, 7 e, 9 a, 12 c, 16 a, 16 a, 17 a$. Total score . 18. M.A. 6-8. IQ 128.

Fra. 46. Boy, American, age 11-5, low fifth grade. Credits, 1,2 , $3,4 a, 4 b, 5 a, 6 b, 6 a, 6 b, 7 a, 7 b, 7 c, 7 d, 9 a, 9 b, 9 c, 9 d, 10 a$, $10 c, 11 a, 11 b, 12 a, 12 e, 13,14 a, 14 c, 14 f, 15 a, 16 b, 16 c$ $17 a, 17 b, 18 a$. Total score 39. M.A. 11-3. IQ 99. 


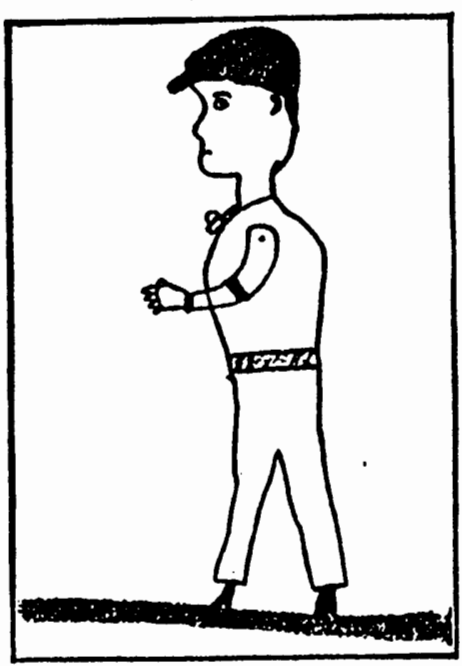

Fig. 47

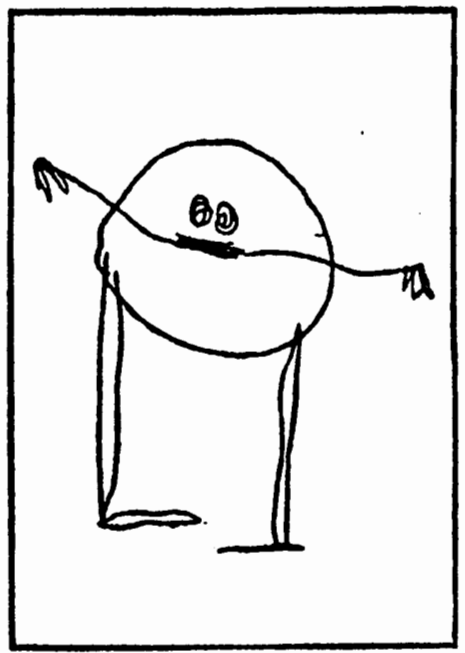

Fra. 49

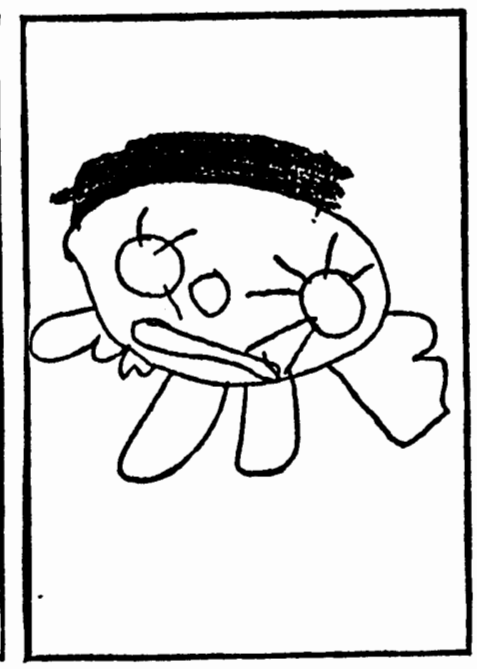

Fra. 48

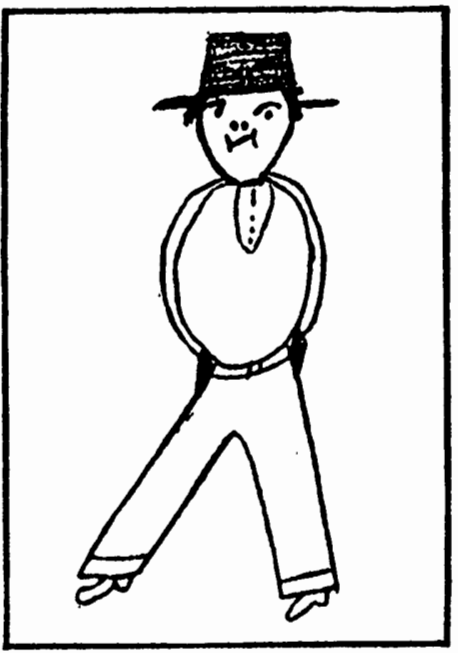

Fu. 60

Fro. 47. Girl, Indian, age 12-5, fourth grade. Credits, $1,2,3$, $4 a, 4 b, 4 c, 5 a, 5 b, 6 a, 6 b, 7 a, 7 b, 7 c, 7 d, 8 a, 8 b, 9 a, 9 b$, $9 d, 10 a, 10 b, 10 c, 10 d, 10 e, 11 b, 12 e, 13,14 a, 14 c, 14 f, 15 a$, $16 a, 16 b, 16 c, 17 a, 17 b$. Total score 36. M.A. 12-0. IQ 87.

Fia. 48. Girl, Finnish, age 4-11, kindergarten. Credits, 1, 2, 3, $7 a, 7 b, 7 c, 9 a, 10 a, 12 e, 16 a$. Total score 10 . M.A. 6-6. IQ 112.

Fro. 49. Boy, Jewish, age 4-11, pre-school. Credits, 1, 2, 3, 7 a, $7 \mathrm{c}, 10$ a, 17 a. Total score 7. M.A. 4-9. IQ 07. (Scribbling for eyes not an indication of pupil.)

Fra. 50. Girl, Negro, age 13-11, low fourth grade. Credits, 1, 2 , 3, $4 a, 4 b, 5 a, 7 a, 7 b, 7 c, 7 e, 8 a, 8 b, 9 a, 9 b, 9 c, 9 d, 10 a$, $10 b, 10 c, 11 a, 11 b, 12 a, 12 b, 12 d, 12 e, 13,14 a, 14 e, 16 a$, 17 a. Total score 30. M.A. 10-6. IQ 81. (IQ computed on basis of $13-0$.) 


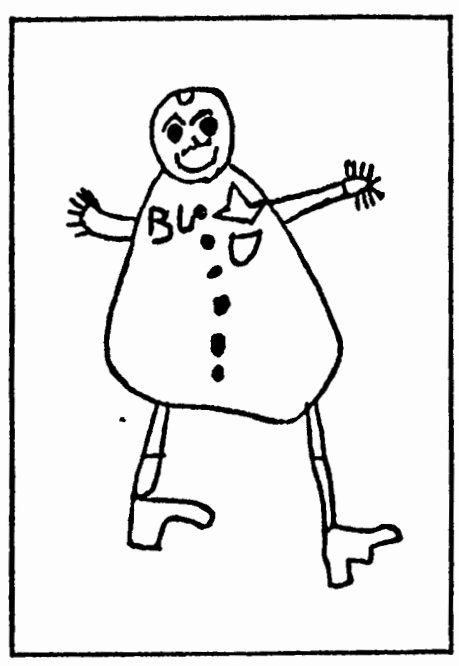

Fio. 51

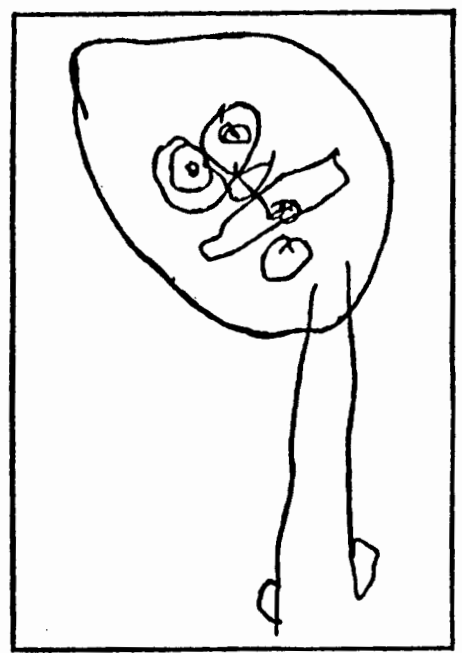

Fra. 58

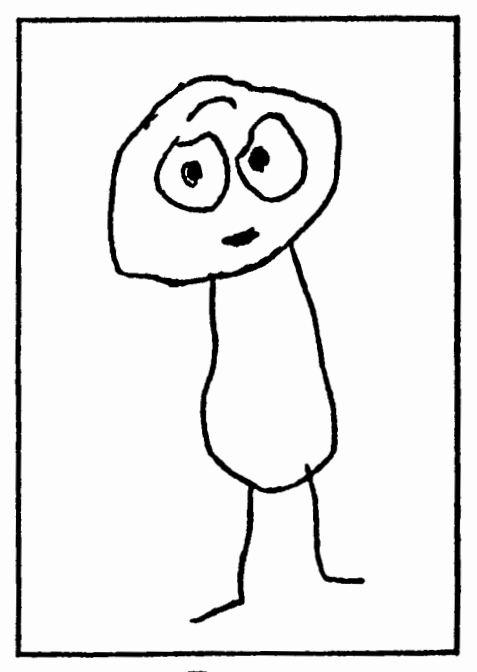

Fro. 62

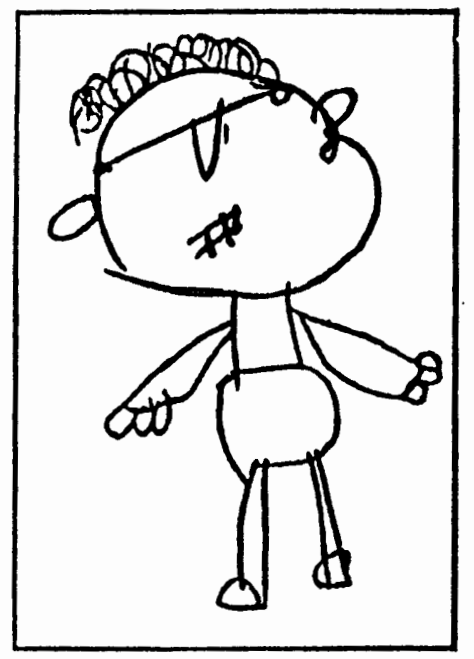

Fra. 54

Fra. 51. Boy, American, age 6-0, kindergarten. Credits, 1, 2,8 , $4 a, 5 a, 7 a, 7 b, 7 c, 7 e, 9 a, 10 a, 10 e, 12 a, 12 e, 18,14 a, 16 a$, 17 a. Total score 18. M.A. 7-6. IQ 125. (The forehead is shown by a semicircle at the top of the head.)

Fra. 52. Girl, American, age 5-8, kindergarten. Credits, 1, 2, $4 a, 4 b, 7 a, 7 c, 16 b, 17 a$. Total score 8. M.A. b-0. IQ 95 . (The forehead is shown by a line above the eyes.)

Fra. 53. Boy, Italian, age 4-9, kindergarten. Credits, 1, 2, 7 a, $7 b, 7 c, 16 b, 17 a$. Total score 7. M.A. 4-9. IQ 100. (The chin is shown by a circle below the mouth. The tongue also is shown.

Fra. 54. Girl, Jewish, age 5-8, pre-school. Credits, 1, 2, 3, $4 a$, $5 a, 6 a, 7 a, 7 b, 7 c, 8 a, 10 a, 12 b, 12 c, 12 e, 15 a, 17 a$. Total score 16. M.A. 7-0. IQ 124. (The forehead is shown by a line above the eyes.) 


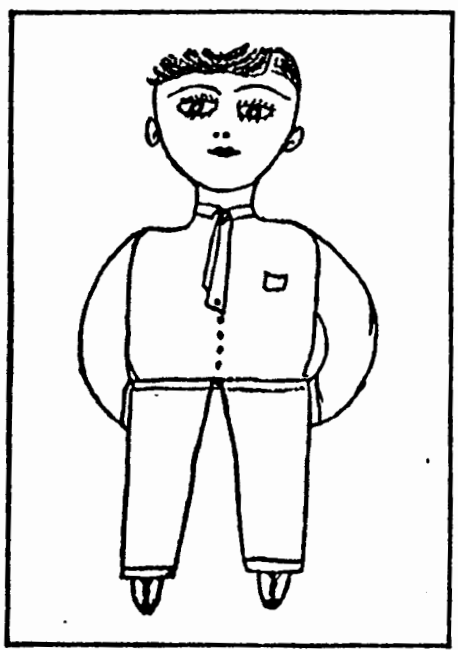

Fia. 55

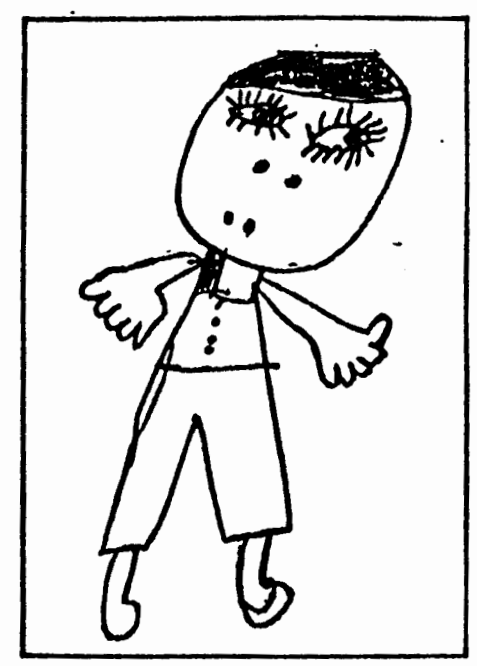

Fra. 67

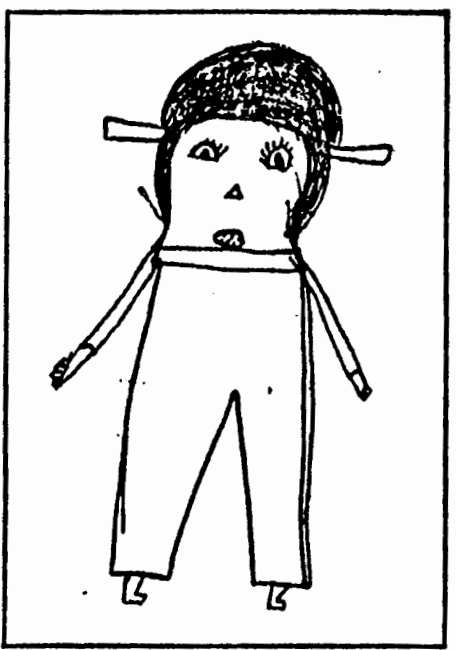

Fig. 50

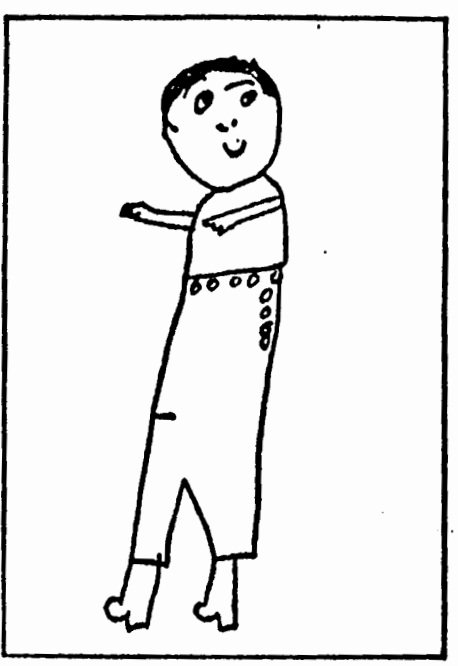

Fia. 58

Fra. 55. Girl, Egyptian, age 12-0, low fifth grade. Credits, 1, 2,3 , $4 a, 4 c, 5 a, 5 b, 6 a, 6 b, 7 a, 7 b, 7 c, 7 e, 8 a, 8 b, 9 a, 9 b, 9 c, 9 d$, $9 e, 10 a, 10 b, 10 c, 11 a, 11 b, 12 b, 12 c, 12 d, 12 e, 13,14 a, 14 c$ $14 d, 14 e, 14 f, 16 a, 16 b, 16 a, 16 b, 16 c, 17 a$. Total score 41. M.A. 13-0 or above. IQ 108 or above. Markedly "feminine" drawing. Note the large eyes, with much detail, nostrils, "cupid's bor" mouth, neatly parted hair, and laced shoes.

Fra. 56. Girl, Negro, age 10-9, high second grade. Credits, 1,2 3, 4a, $5 a, 6 a, 7 a, 7 b, 7 c, 8 a, 8 a, 9 b, 10 a, 10 c, 11 b, 12 b, 12 c$, $12 e, 14 a, 16 a, 16 b$. Score 21. M.A. 8-3. IQ 77. Markedly "feminine." It will be noted that the eyes are larger than the feet. The drawing is remarkably "static" in type.

Fra. 67. Girl, Italian, age 8-0, low second grade. Credits, $1,2,3$, $4 a, 6 a, 6 a, 7 a, 7 b, 7 c, 7 e, 8 a, 8 b, 9 a, 10 a, 10 b, 10 e, 11 b, 12 c$, $12 e, 14 a, 16 a, 16 b, 16 c$. Total score 23. M.A. 8-9. IQ 109. Markedly "feminine." Note the eye detail. The mouth as well as the nose is here shown only by two dots.

Fra. 68. Girl, Negro, age 8-2, high third grade. Credits, 1, 2, 3, $4 a, 4 b, 4 c, 5 a, 7 a, 7 b, 7 c, 7 e, 8 a, 8 b, 9 a, 10 a, 11 b, 12 a$, $12 d, 12 e, 18,14 a, 14 d, 16 a, 16 b, 10 c$. Total score 25. M.A. 0-3. IQ 113. Markedly "feminine." Note the tiny arms and short legs, the nostrils, and the eye detail. 


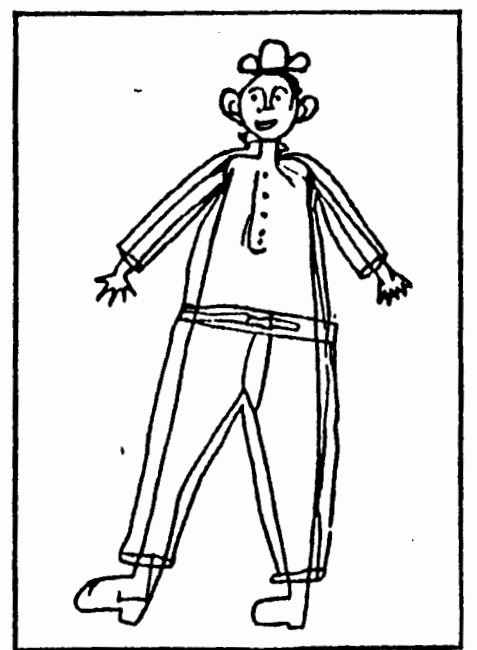

Fra. 69

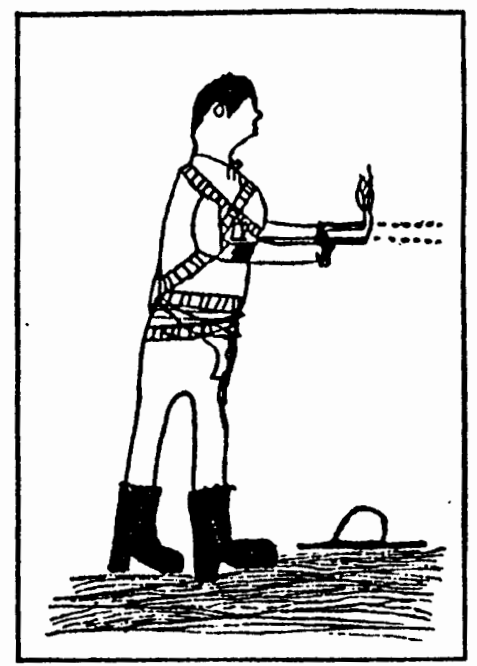

Fio. 61

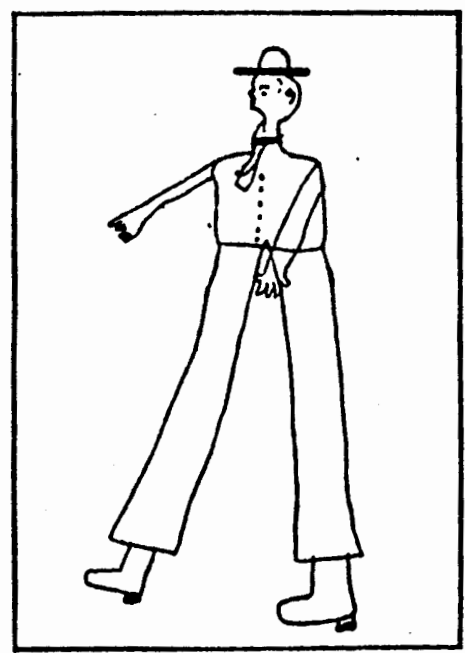

Fro. 60

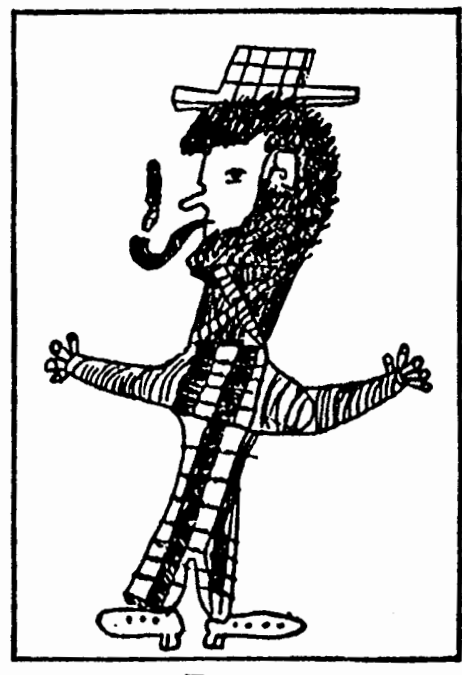

Fro. 62
Fro. 59. Boy, Negro, age 12-10, low fourth grade. Credits, $1, q_{1}$ $8,4 a, 4 b, 4 c, 5 a, 5 b, 6 a, 6 b, 7 a, 7 b, 7 c, 8 a, 9 a, 9 d, 10 a$, $10 b, 10 c, 10 e, 11 b, 12 a, 12 c, 12 d, 12 e, 13,14 a, 15 a, 15 b$, 16 a, 17 a. Total score 81. M.A. 10-8. IQ 84. Markedly "masculine." Note the small head, the eyes shown only by a dot, the transparent clothing and large feet.

Fro. 60. Boy, Negro, age 9-6, high third grade. Credits, 1, 2,3 , $4 a, 4 c, 6 a, b b, 0 a, 0 b, 7 a, 7 b, 7 c, 9 a, 9 b, 8 d, 10 a, 10 c$, $10 e, 11 b, 12 a, 12 b, 12 d, 12 e, 13,14 a, 16 a, 16 a$. Total score 27. M.A. 9-9. IQ 108. Markedly "masculine."

Fro. 61. Boy, American, age 12-9, high sixth grade. Credits, 1, $2,3,4 a, 4 b, 4 c, 5 a, 5 b, 6 a, 6 b, 7 b, 7 c, 8 a, 8 b, 8 a, 9 d, 10 a$, $11 a, 11 b, 12 a, 12 b, 12 e, 13,14 a, 14 d, 15 a, 16 a$. Total score 27. M.A. 9-9. IQ 76. The brow is shown by the supraorbital ridge, but there is no indication of the eye itself; the sleeves are not indicated. The drawing is markedly masculine in type.

Fra. 62. Boy, American, age $9-9$, high fourth grade. Credits, 1 , $\ell, 8,4 a, 4 b, 4 c, 5 a, 5 b, 6 a, 7 a, 7 b, 7 c, 7 d, 8 a, 0 a, 8 d, 10 a$, $10 c, 11 b, 12 b, 12 e, 13,14 a, 14 f, 15 a, 15 b, 16 a, 16 b, 16 c$, $17 a, 17 b$. Total score 31. M.A. 10-9. IQ 110. One of the drawings selected as showing psychopathic features in the experiment described in Chapter III. Note the "individual" characteristics, the large amount of apparently meaningless detail"verbalism" and compare the maturity of the face with the primitive drawing of the neck and trunk. This child was described by the teachers as timid, unstable, concentrates poorly. peculiar, placid, and stubborn. 
144. Measurement of Intelligence by Drawings

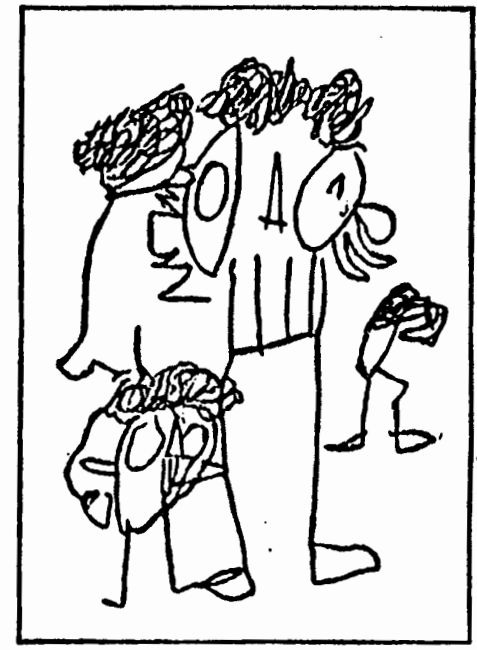

Fia. 63

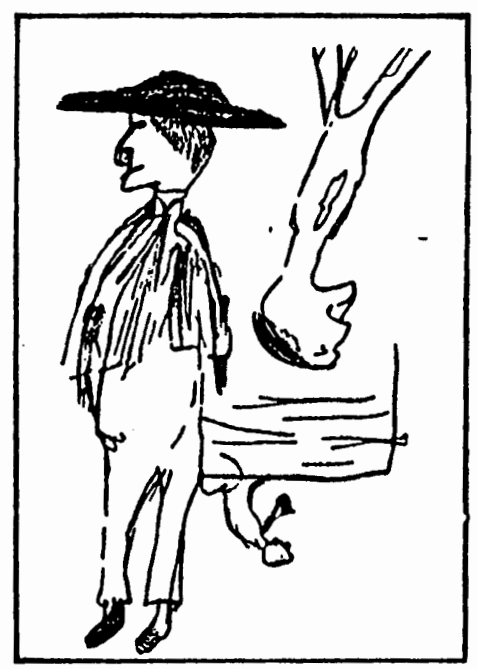

Fra. 65

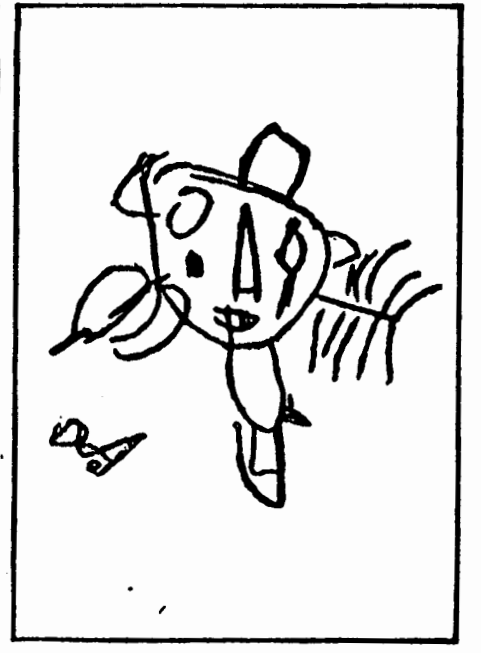

Fig. 64

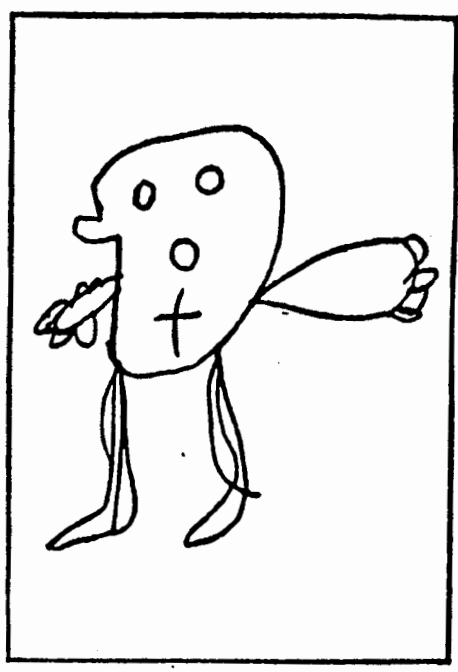

Fia. 66
Specimen Drawings, with Scoring Indicated

Fra. 63. Boy, American, age 8-2, low first grado. Credits, $2,7 a, 7 b, 7 c$ $8 a, 10 a, 16 a$. Total score 7 . M.A. 4-9. IQ 58. The child's mother is insane, and there are other cases of insanity reported in the family. Child's conduct was such that ho was twice cxcluded from school, but at the time the drawing was made he had been reinstated under the care of a very eympathetic teacher and was doing somewhat better. He was not, however, conforming to the ordinary schoolroom rules, was highly erratio and excitable, could not be kept quiet, and had made no progregs in school work beyond learning to recognize half a dozon words at sight. His Stanford-Binet IQ was 69 ; drawing IQ 58. The drawing shows a remarkablo lack of coherence; far greater than that ordinarily found even in drawings by the feeble-minded. The fingers are attached to the eyes; the legs suspended from the mouth.

Fia. 64. Girl, English, age 6-8, low firet grade. Credits, 1, 2, 3, 4a, $4 b$, $7 a, 7 b, 7 c, 9 a, 10 a, 15 a$. Total scoro 11. M.A. 5-9. IQ 86. The child has a normal heredity and is reported to havo developed normally up to the age of two and a half years, at which time she had a very severe attack of what was probably encephalitis. Upon recovery, she had lost the power of epeech (she had talked very well before her illness), seemed uneble to orient herself at all, but would walk in whatever direction she happened to be facing until she was stopped and brought back. She gradually relearned to talk but continued to be very flighty and unstable, and could not be trusted out of doors by herself. She was retained in school only a short time. The psychopathic indications in the drawing are hard to define. They consiat chicfly in an instability of line; and in much apparently meaningless detail similar to that shown in Figure 03 , although the drawing is of a much more primitive type. The two blaek dote indicate the cheeks; the circles above them aro the eyes.

Fio. 05. Boy, American, age 11-1, high fiftl grade. Credits, 1, 2, 3, 4 a, $4 b, 5 a, 5 b, 8 a, 6 b, 7 a, 7 b, 7 c, 7 d, 8 a, 8 b, 8 a, 9 d, 10 a, 10 c, 11 a$, $11 b, 12 a, 12 d, 12 e, 13,14 a, 16 b, 16 c, 17 a, 17 b$. Total score 30 . M.A. 10-6. IQ 95. Selected in the experiment deseribed in Chapter III. Note the unexplained vertical bars on the arms and the inverted fgures at the side, as well as the pronounced "verbalism" shown in the entire drawing This child was described by the teacher as "too" coura geous, apathctic, suspicious, easily depressed, active, enthusiastic "at times," geous, apathctic, suspicious, easily depressed, active, enthusiastic "at times," dreamy, unstable, flighty, oversensitive, self-conscious, concentrates poorly,
fond of companionship, peculiar, shows good common sense, modest, boastful, restless, stubborn, muscles twitch, healthy.

Fro. 66. Boy, Negro, age 6-5, low fret grade. Credits, 1, 2, 3, $7 a, 7 b$, $7 c, 9 a, 10 a, 12 e, 14 a$. Total score 10. M.A. 5-6. IQ 86. The extra lines on the legs indicate the trousers. The mouth is ohown by a cross. 


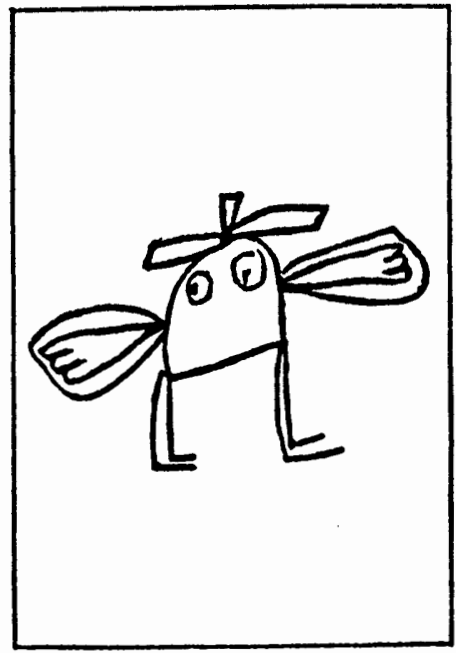

Fra. 67

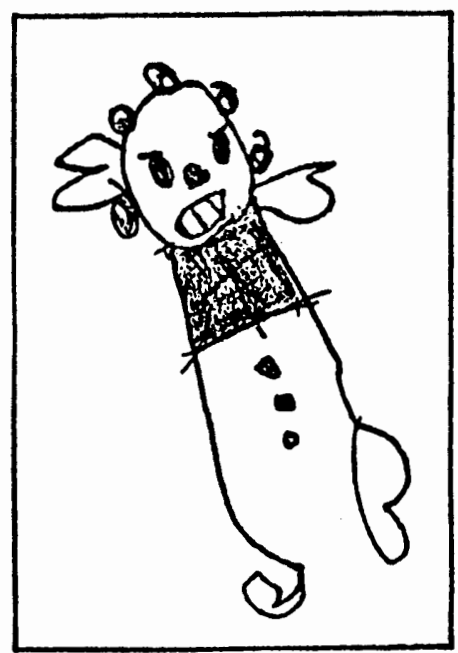

Fia. 69

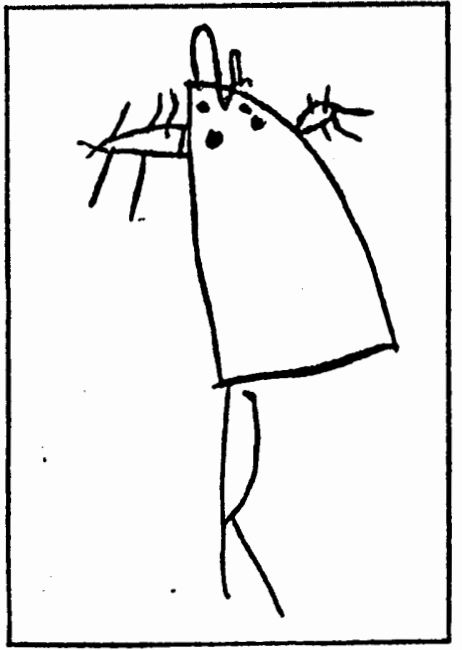

Fra. 68

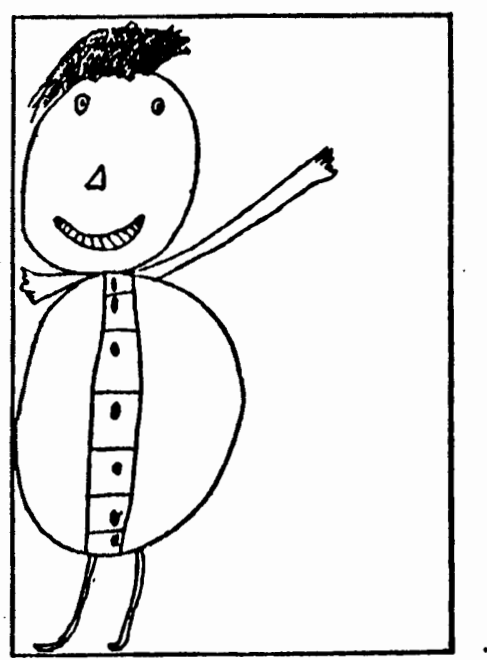

Fra. 70
Fra. 67. Girl, Negro, age 8-7, low first grade. Credits, 1, 2, 3, $7 a, 9 a, 10 a, 10 c, 12 e, 14 a, 16 b$. Total score 10. M.A. 6-6. IQ 64. The lines enclosing the arms indicate the sleeves.

Fra. 68. Girl, Negro, age 6-5, low first grade. Credits, 1, 2, 3, $4 a, 7 a, 8 a, 10 a$. Total score 7. M.A. 4-9. IQ 74. The scribbled line above the head is the hair. The two dots below the eyes are the cheeks. (Where the head and trunk are included in one figure, as in this instance, points $12 a, 12 b$, and $12 c$ automatically become zero, since it is impossible to tell where the division between head and trunk should be made.)

Fra. 09. Boy, Italian, age 0-8, low first grade. Credits, 1, 2, 3, $4 a, 7 a, 7 b, 7 c, 8 a, 8 a, 10 a, 12 c, 10 a$. Total score 12. M.A. 6-0. IQ 90. The hair is shown by the circle of little spirals surrounding the head. Note that an inverted heel such as that shown on the foot on the left is not credited for point 13.

Fia. 70. Boy, American, age 7-4, high first grade. Credits, 1,2 , $3,4 a, 4 b, 5 a, 7 a, 7 b, 7 c, 8 a, 8 a, 10 a, 10 b, 12 d, 12 c, 14 a$, $16 \mathrm{~b}$. Total score 17. M.A. 7-3. IQ 99. Lack of foresight in placing the drawing on the paper accounts for the peculiarities in this picture. Notice the short arm on the left, and the infinitesimal hat, which the child was unwilling to omit in spite of the lack of space. 


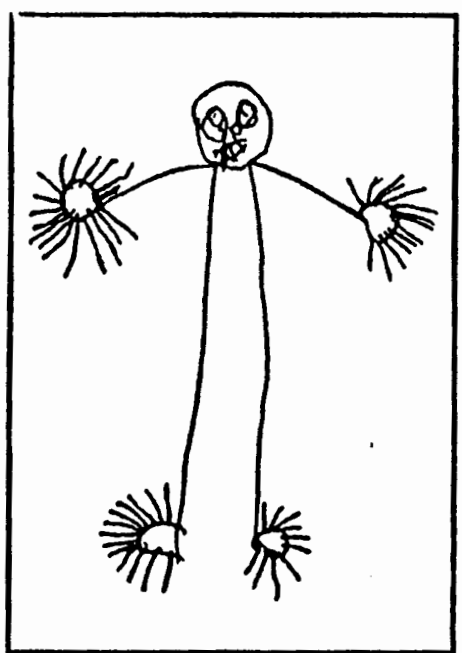

Fra. 71

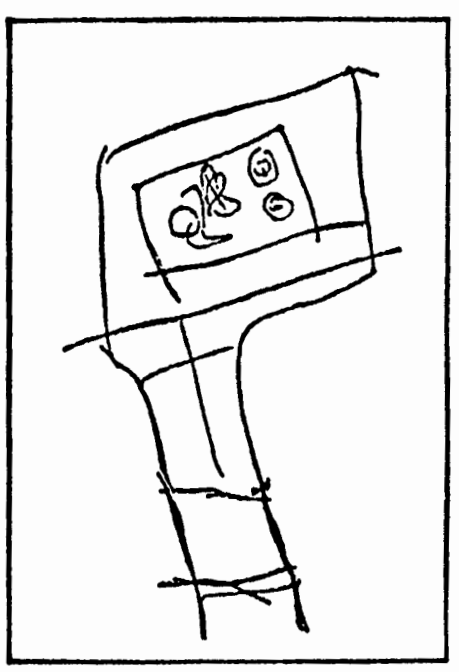

Fro. 79

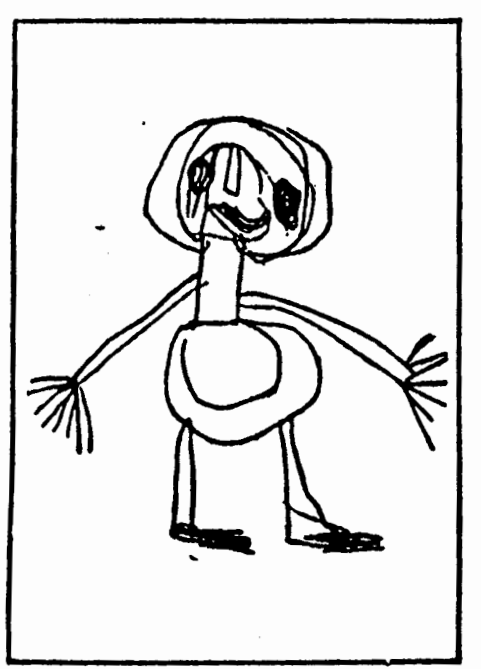

Fia. 78
Fra. 71. Girl, American, age 5-4, kindergarten. Credits, 1, 2, 3, $7 a, 7 b, 7 c, 10 a, 10$ e. Total score 8. M.A. 6-0. IQ 94. This represents approximately the upper limit of failure for point 17 a. The scribbled outline of the eye does not indicate the pupil.

Fia. 72. Girl, Jewish, age 4-11, pre-school. Credits, 1, 2, $4 a$, $4 b, 7 a, 7 b, 7 c, 16 b$. Total score 8. M.A. b-0. IQ 102 . Compare the drawing of the pupil of the eye with the preceding figure. Note that here it is entirely distinct from the outline of the eye in one case and well separated from the outline in the other. The inner square represents the face.

Fro. 78. Girl, Italian, age 6-9, kindergarten. Credits, $1,2,3,4 a$, C $a, 6 a, 7 a, 7 b, 7 c, 7 d, 10 a, 12 c, 12 e$. Total score 13. M.A. 6-3. IQ 93. The circle around the features signifies the face. The small circle within the trunk is the stomach. 


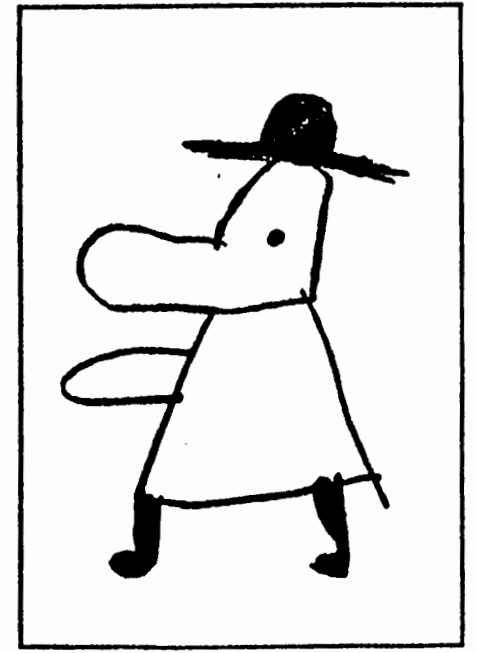

Fia. 74

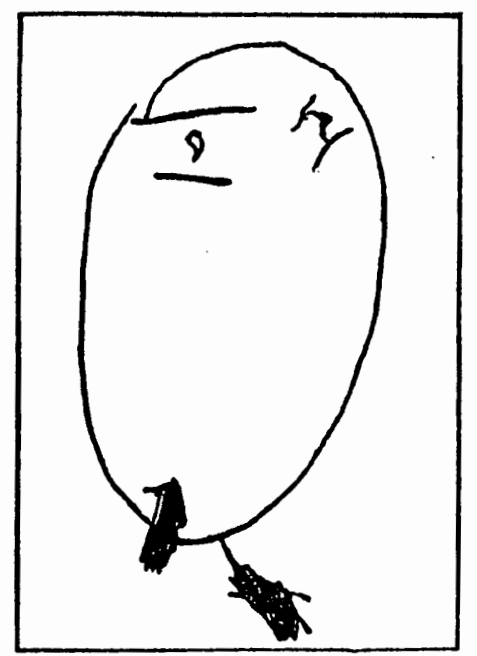

Fia. 76

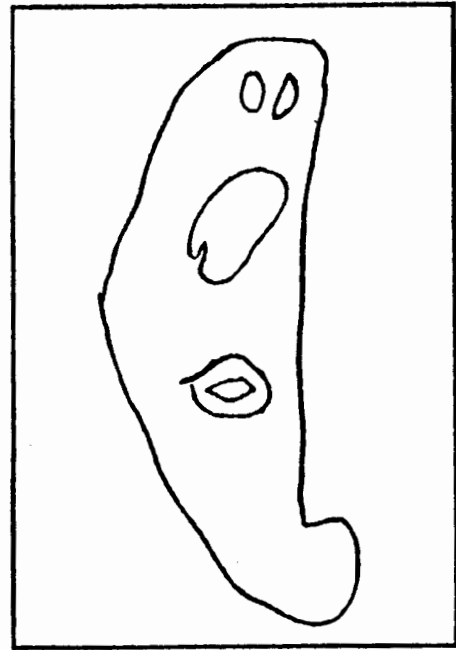

Fra. 75

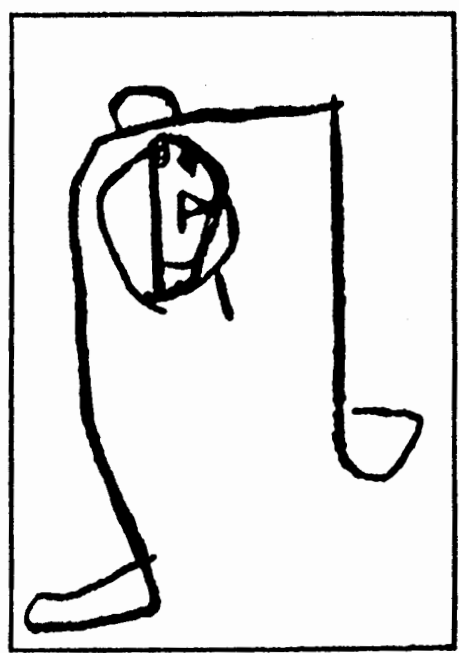

Fia. 77
F1a. 74. Girl, Italian, age 6-11, low first grade. Credits, 1, 2, 3, $4 a, 5 a, 7 a, 7 b, 8 a, 12 e$. Total score 9. M.A. 5-3. IQ 76. The enormous protuberance extending out from the head was said by the child to be the nose. Ordinarily it would be safe to interpret such a feature as the other arm. There was nothing in the child's manner or behavior to indicate that a caricature had been intended; she seemed very complacent about her work.

Fra. 75. Girl, Japanese, age 5-3, kindergarten. Credits, 1, 7 a, 7 b, 7 c. Total score 4. M.A. 4-0. IQ 76.

Fia. 76. Boy, Italian, age 4-4, pre-school. Credits, 1, 2, 7 a, 16 a. Total score 4. M.A. 4-0. IQ 82.

Fig. 77. Girl, racial stock unknown, age 5-10, low first grade. Credits, 1, 2, 7a,7 b, 7c, 9 a. Total score 6. M.A. 4-6. IQ 77. Through a mistake, crayon was used for this drawing in place of pencil, but it is unlikely that its use has affected the results, since the drawing is of so primitive a type. 


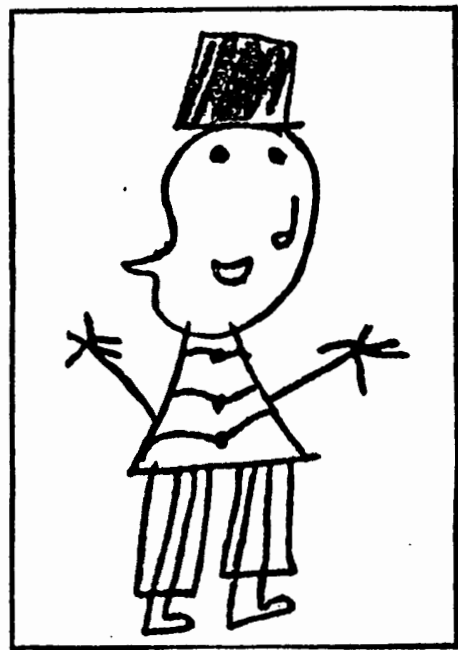

Fia. 78

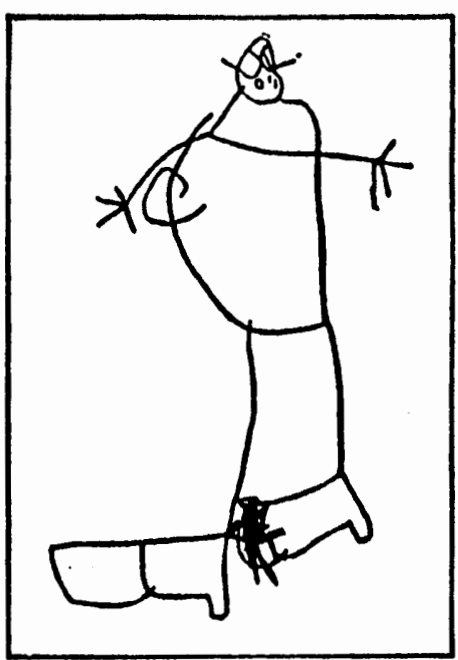

Fra. 80

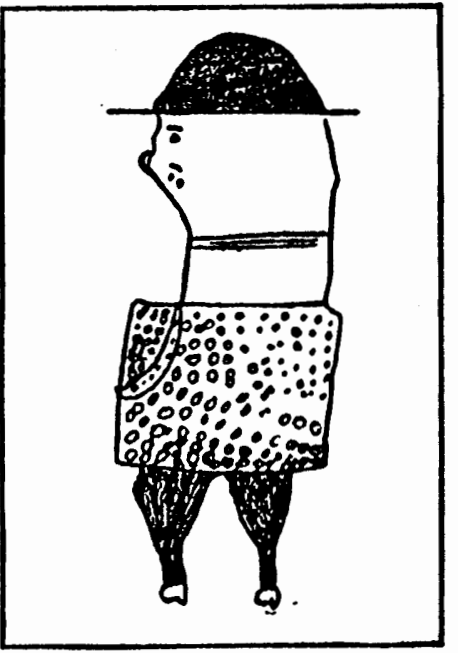

Fra. 79

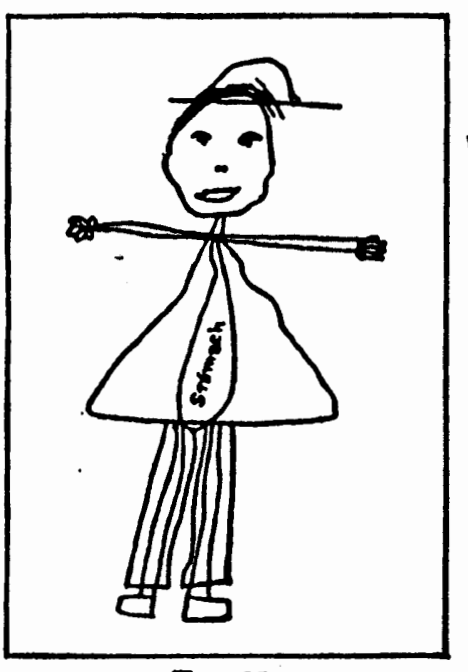

Fig. 81
Fia. 78. Boy, American, age 9-8, low fourth grade. Credits, $1,2,3,4 a, 5 a, 7 a, 7 b, 7 c, 8 a, 10 a, 10 b, 12 b, 12 c, 12 d, 14 a$, 15 a. Total score 16. M.A. 7-0. IQ 76. A delinquent; steals, lies, sex misconduct.

Fra 79. Girl, Jewish, age 9-3, low third grade. Credits, 1, \&, 3, $4 a, 5 a, 6 a, 6 b, 7 a, 7 b, 7 e, 8 a, 9 b, 9 d, 11 a, 11 b, 12 e, 13$, 14a, 16 a. Total score 18. M.A. 7-8. IQ 84.

Fro. 80. Boy, Indian, age 7-3, first grade. Credits, 1, 2, 3, $4 a$, $4 b, 5 a, 7 a, 8 a, 10 a, 12 c, 13$. Total score 11. M.A. 5-8. IQ79.

Fra. 81. Girl, American, age 9-5, low fourth grade. Credits, 1, $2,3,4 a, 5 a, 6 a, 7 a, 7 b, 7 c, 7 e, 8 a, 8 a, 10 a, 10 b, 12 a, 12 c$, 12d. 12 e, $14 a, 16 a, 17 a$. Total score 21 . M.A. 8-3. IQ 88. 


\section{APPENDIX F \\ GOODENOUGH DRAW-A-MAN TEST: \\ TABLE OF MENTAL AGE EQUTVALENTS OF SCORES}

Goodenough, F. L. (1926). Measurement of intelligence by drawing.

Chicago: World Book Company. 
TABLE OF MENTAL AGE EQUTVALENTS OF SCORES:

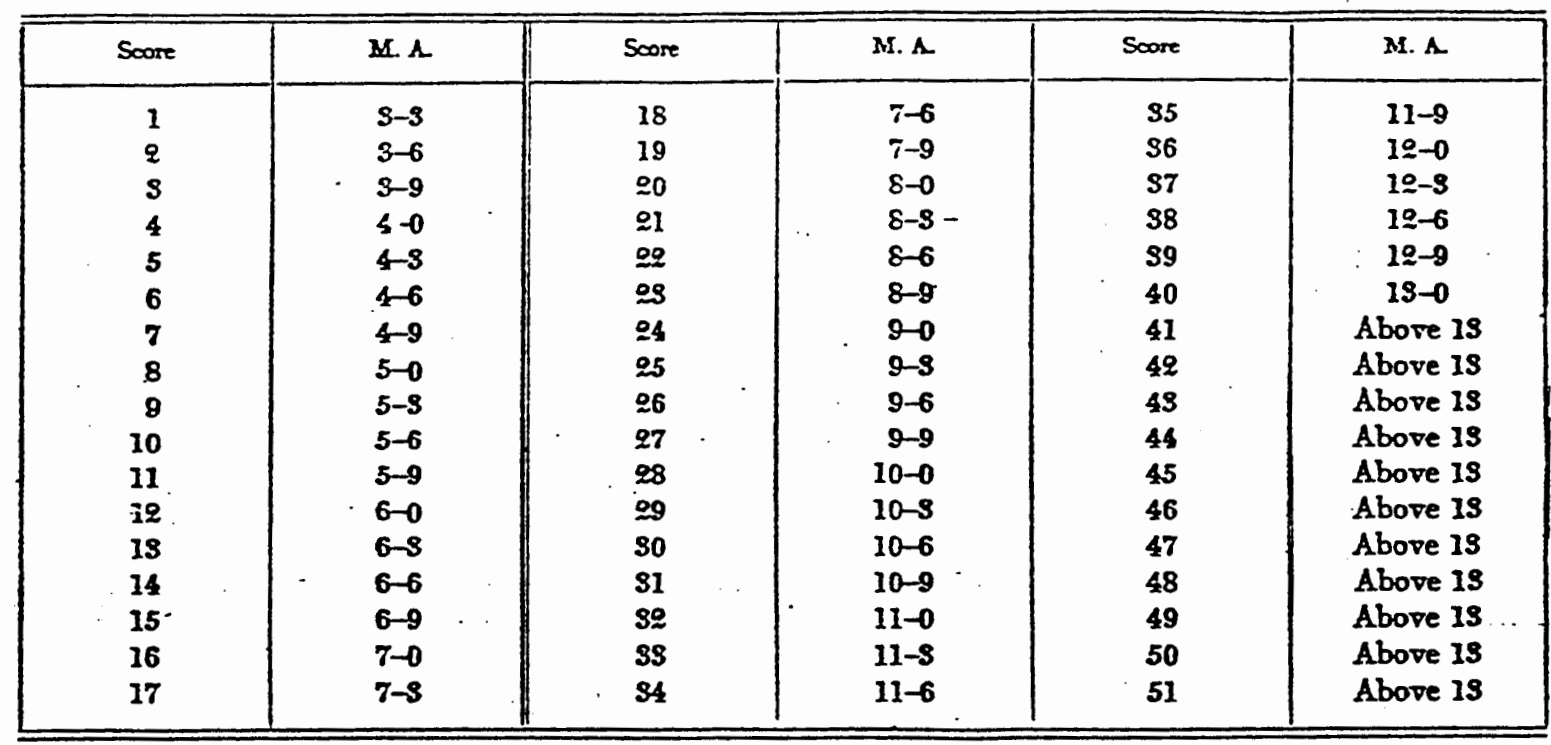

It bas not seemed wise to attempt to derive mental age equinzleats above age 13. In finding the IQ's of retarded children who are more than thirteen years old the chropologieal age sbould be trested as thirteen oaly, and the IQ recorded as "or below." In the case of children who " curn scores above 40 , the mental age should be reconded as " 18 or abooe" and the IQ as " or abooc" 


\section{APPENDIX G}

\section{MCCARTHY SCALES OF CHILDRENS ABILITIES}

McCarthy, D. (1972). McCarthy scales of children's abilities. Cleveland: The Psychological Corporation. 


\section{MCCARTHY SCALES OF CHILDREN'S ABILITIES Record Form}

NAME

AGE

SEX

HOME ADDRESS

NAMES OF PARENTS OR GUARDIAN

SCHOOL

GRADE

PLACE OF TESTING

TESTED BY

REFERRED BY

\section{MSCA PROFILE}

Enter the 6 Scale indexes on the appropriate lines below. Then circle the mark repre senting the Index for each Scale. Draw a line connecting the circles. Note that the values for GC are different from those for the other Scales.

SCALE
INDEX

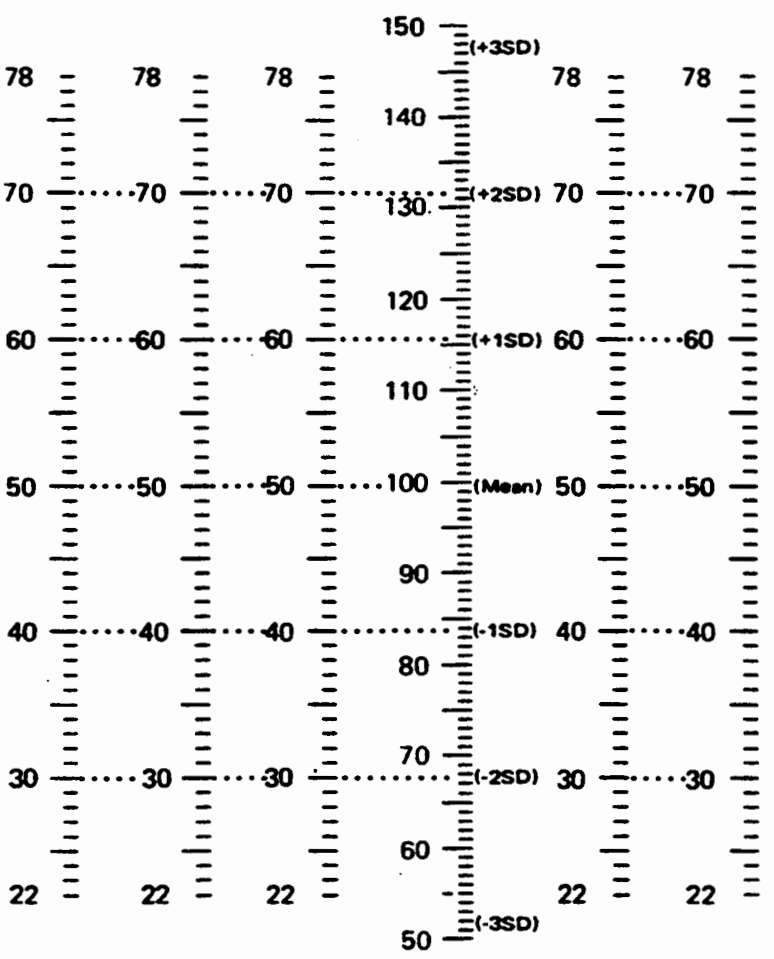

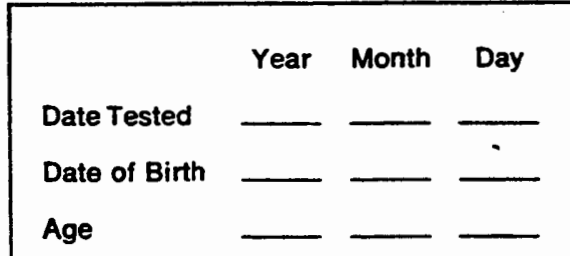

COMPOSITE RAW SCORES AND SCALE INDEXES

Enter the composite raw scores from the back cover. Obtain the composite raw score for GC by adding $\boldsymbol{V}+\boldsymbol{P}+\boldsymbol{Q}$. Determine the corresponding Scale indexes from Table 16. (See page 151 of manual for detailed directions.)

Scale

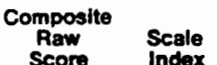

Verbal (V)

Perceptual-

Performance (P)

Quantitative (Q)

General Cognitive:

Add composite raw

scores $V+P+O$

Score Index

Memory (Mem)

Motor (Mot)

\section{LATERALITY}

(Enter information from Laterality Summary on page 5.)

Hand

Eye 


\begin{tabular}{|c|c|c|c|}
\hline \multicolumn{4}{|c|}{$\begin{array}{l}\text { 1. BLOCK BUILDING Discontinue anter } \\
\text { taiture on both trials of } 2 \text { consecutive items. }\end{array}$} \\
\hline & \multicolumn{2}{|c|}{ Score } & \multirow{2}{*}{$\begin{array}{l}\text { Best } \\
\text { Score } \\
\frac{(0-3)}{(0.5)}\end{array}$} \\
\hline & Trial1 & Trial 2 & \\
\hline 1. Tower & $(0-3)$ & $(0-3)$ & \\
\hline 2. Chair & $(0-2)$ & $(0-2)$ & $(0-2)$ \\
\hline $\begin{array}{l}\text { 3. Building } \\
\text { stert }\end{array}$ & $(0-2)$ & $(0-2)$ & $(0-2)$ \\
\hline & $(0-3)$ & $(0-3)$ & $(0-3)$ \\
\hline & & Total & $\begin{array}{c}\text { Mex.-10 } \\
\\
\end{array}$ \\
\hline
\end{tabular}

\begin{tabular}{|c|c|c|c|c|c|}
\hline \\
\hline \multicolumn{5}{|c|}{\begin{tabular}{|c|c|} 
3. PICTORIAL MEMORY \\
$\begin{array}{c}\text { Exposure } \\
\text { Time }\end{array}$ & $\begin{array}{c}\text { Response } \\
\text { Time }\end{array}$ \\
\end{tabular}} & Score \\
\hline \begin{tabular}{|c|}
$\begin{array}{c}\text { Exposure } \\
\text { Time }\end{array}$ \\
Allow 10"
\end{tabular} & Allow 90 & $\begin{array}{l}\text { Butron } \\
\text { Horse }\end{array}$ & $\begin{array}{l}\text { Fork } \\
\text { Padlock }\end{array}$ & $\begin{array}{l}\text { Paper Clip D } \\
\text { Pencil }\end{array}$ & $s^{(0-6)}$ \\
\hline
\end{tabular}

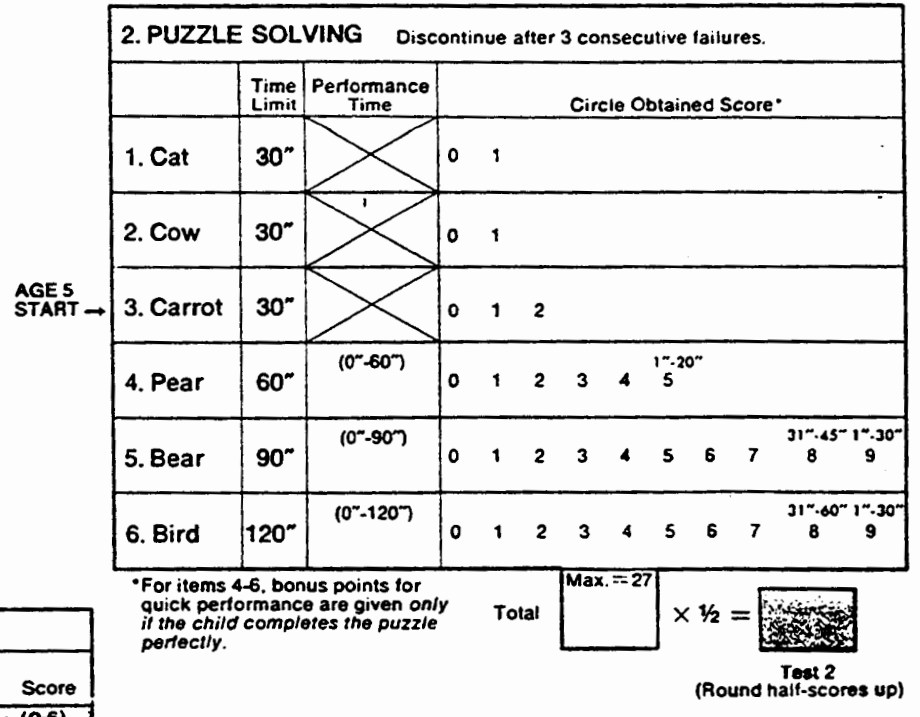

\begin{tabular}{|c|c|}
\hline \multicolumn{2}{|c|}{$\begin{array}{l}\text { 4. WORD KNOWLEDGE Discontinue it score on Part } 1 \text { is } \\
\text { loss than } 6 \text {. Discontinue Pant II after } 4 \text { consecutive tailures on that } \\
\text { part. }\end{array}$} \\
\hline $\begin{array}{l}\text { PART I. PICTURE VOCABULARY Response } \\
\text { Card }\end{array}$ & Score \\
\hline 1. Apple $\square$ Tree $\square$ House $\square$ Woman $\square$ Cow $\square$ & $(0.5)$ \\
\hline 2. Clock & $(0.11$ \\
\hline 3. Sailboat & $(0.1)$ \\
\hline 4. Flower & $(0.1)$ \\
\hline 5. Purse & $(0-1)$ \\
\hline Total (Part i) & $\max =9$ \\
\hline
\end{tabular}

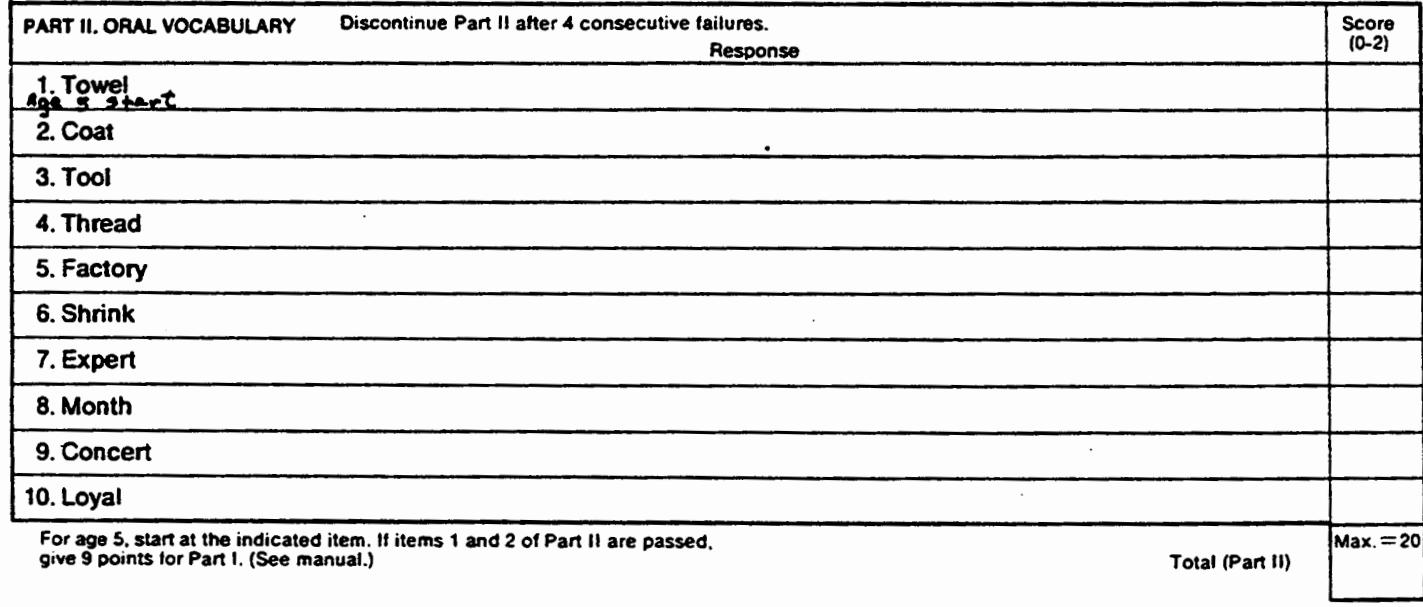

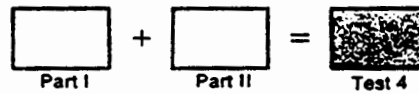




\begin{tabular}{|l|l|l|l|}
\hline \multicolumn{4}{|c|}{$\begin{array}{l}\text { 5. NUMBER QUESTIONS Discontinue } \\
\text { atter } 4 \text { consecutive failures. }\end{array}$} \\
\hline & $\begin{array}{c}\text { Right } \\
\text { Answer }\end{array}$ & Response & $\begin{array}{c}\text { Score } \\
\text { (0-1) }\end{array}$ \\
\hline 1. Ears & Two & & \\
\hline 2. Noses & One & & \\
\hline 3. Heads & One & & \\
\hline 4. Toys & Three & & \\
\hline 5. Balloons & Two & & \\
\hline 6. Candy & Six & & \\
\hline 7. Pennies & Seven & & \\
\hline 8. Apples & Twolve & & \\
\hline 9. Crayons & Six & & \\
\hline 10. Ball & Eighty & & \\
\hline 11. Secret & Four & & \\
\hline 12. Cookies & Three & & \\
\hline & & & Max. $=12$ \\
& & Total & \\
\hline
\end{tabular}

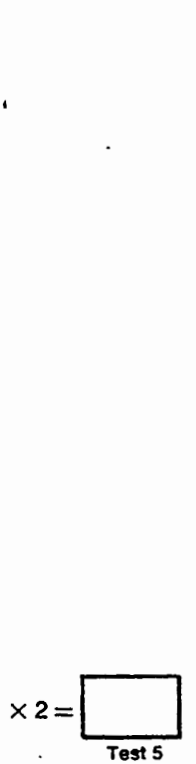

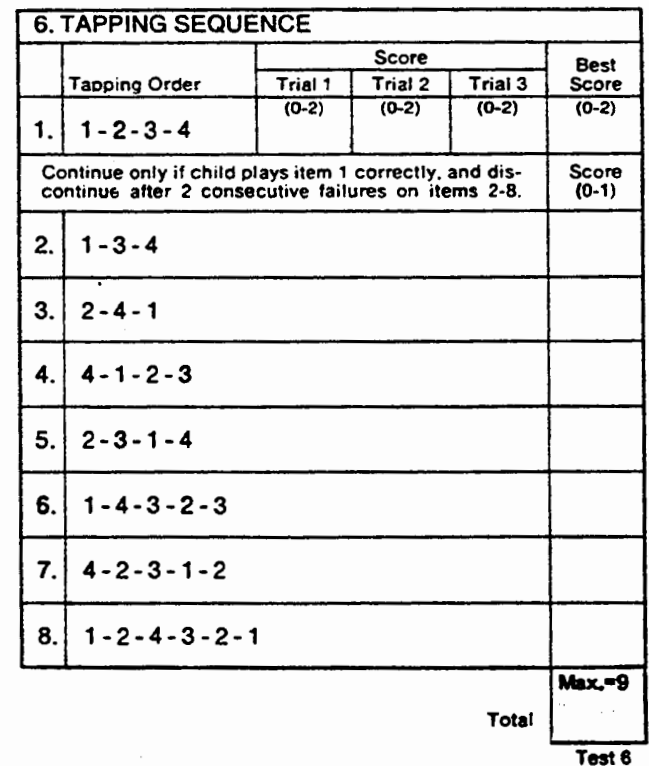

\begin{tabular}{|l|c|}
\hline $\begin{array}{l}\text { 7. VERBAL MEMORY Discontinue Part I atter } 3 \text { consecutive lailures. } \\
\text { more doints (out of 30) on Part I. give Part II. }\end{array}$ & Score \\
\hline PART I. WORDS AND SENTENCES & (0-3) \\
\hline 1. toy - chair - light & (0-3) \\
\hline 2. doll - dark - coat & (0-4) \\
\hline 3. after - color - funny - today & (0-4) \\
\hline 4. around - because - under - never & (0-7) \\
\hline Do NOT stress the underlined words in items 5 and 6. & $(0-9)$ \\
\hline 5. The boy said good-bye to his dog every moming before he went to school. & \\
\hline 6. The girl tied a pretty pink ribbon on her doll before she went out. & Max. $=30$ \\
\hline
\end{tabular}

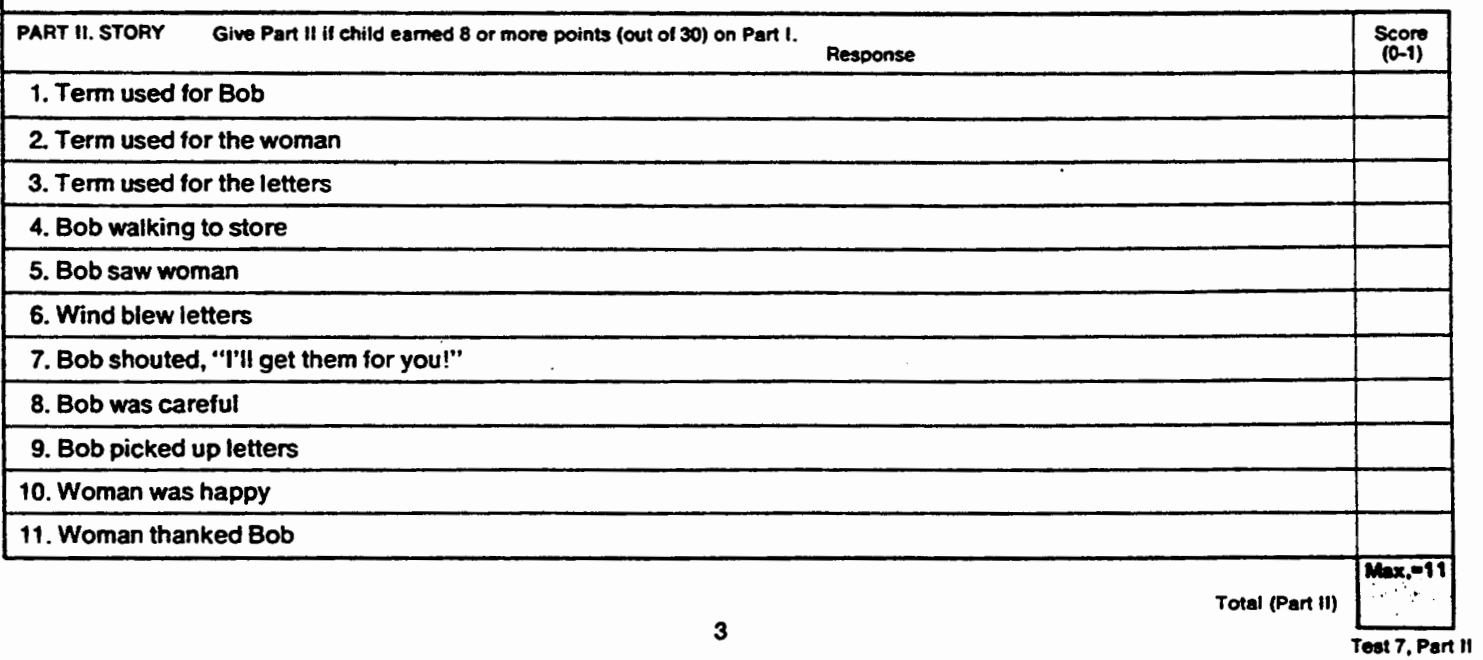




\begin{tabular}{|c|c|}
\hline \multicolumn{2}{|c|}{$\begin{array}{l}\text { 8. RIGHT-LEFT ORIENTATION Administer only to } \\
\text { children aged } 5 \text { and above. Discontinue after faiture on } 5 \\
\text { consecutive items. }\end{array}$} \\
\hline & $\begin{array}{c}\text { Score } \\
(0-1)\end{array}$ \\
\hline 1. Show me your right hand. & ‘ \\
\hline 2. Which is your left ear? & \\
\hline $\begin{array}{l}\text { 3. Touch your right eye } \\
\text { with your left hand. }\end{array}$ & \\
\hline 4. Put your chin in your left hand. & \\
\hline 5. Cross your left knee over your right one. & \\
\hline 6. Show me Roger's left knee. & \\
\hline 7. Show me Roger's right elbow. & \\
\hline $\begin{array}{l}\text {-8. Show me Roger's left foot } \\
\text { with your right hand. }\end{array}$ & \\
\hline $\begin{array}{l}\text {-9. Put your right hand } \\
\text { on Roger's right shoulder. }\end{array}$ & \\
\hline $\begin{array}{l}\text { - Enter score for each part separately. } \\
\text { Both parts must be failed for } \\
\text { the item to be considered a failure. }\end{array}$ & $\operatorname{Max}=12$ \\
\hline
\end{tabular}

\begin{tabular}{|l|c|c|c|c|}
\hline \multicolumn{4}{|c|}{$\begin{array}{l}\text { 9. LEG COORDINATION } \\
\text { items 1-5 are failed. }\end{array}$} & \multicolumn{2}{|c|}{ Discontinue after item 5 if both trais of } \\
\hline & Trial 1 & Trial 2 & $\begin{array}{c}\text { Best } \\
\text { Score }\end{array}$ & Notes \\
\hline $\begin{array}{l}\text { 1. Walking } \\
\text { backwards }\end{array}$ & $(0-2)$ & $(0-2)$ & $(0-2)$ & \\
\hline $\begin{array}{l}\text { 2. Walking on } \\
\text { tiptoe }\end{array}$ & $(0-2)$ & $(0-2)$ & $(0-2)$ & \\
\hline $\begin{array}{l}\text { 3. Walking a } \\
\text { straight line }\end{array}$ & $(0-2)$ & $(0-2)$ & $(0-2)$ & \\
\hline $\begin{array}{l}\text { 4. Standing on } \\
\text { one foot }\end{array}$ & $(0-2)$ & $(0-2)$ & $(0-2)$ & \\
\hline $\begin{array}{l}\text { 5. Standing on } \\
\text { other foot }\end{array}$ & $(0-2)$ & $(0-2)$ & $(0-2)$ & \\
\hline $\begin{array}{l}\text { 6. Skipping } \\
\text { Sking }\end{array}$ & $(0-3)$ & $(0-3)$ & $(0-3)$ & \\
\hline
\end{tabular}

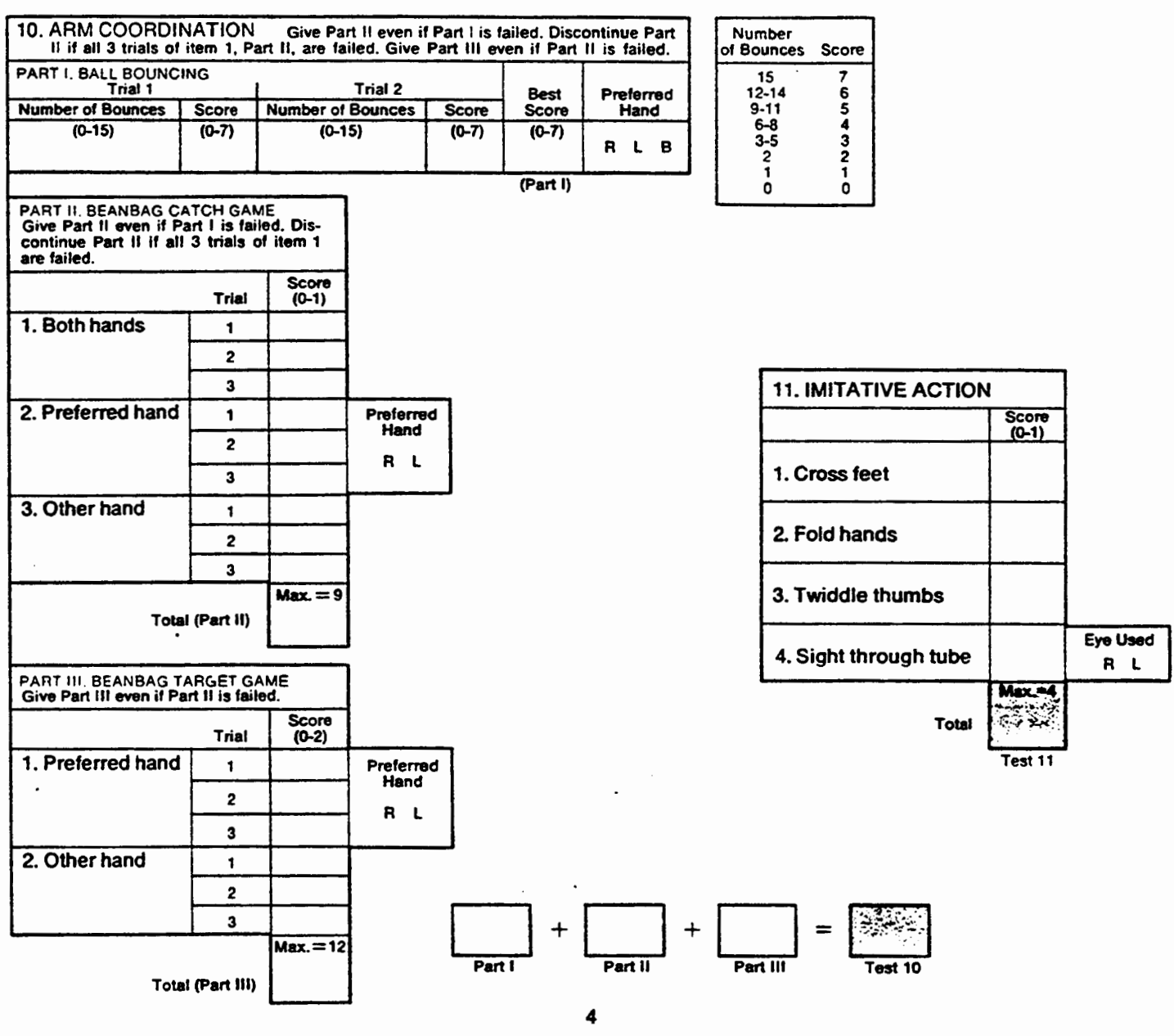




\begin{tabular}{|c|c|c|c|}
\hline \multicolumn{2}{|c|}{$\begin{array}{l}\text { 12. DRAW-A-DESIGN } \\
\text { consecutive failures. }\end{array}$} & \multicolumn{2}{|c|}{ Discontinue after 3} \\
\hline & Pass-Fail & Score & $\begin{array}{l}\text { Preferred } \\
\text { Hand }\end{array}$ \\
\hline 1. & & $(0-1)$ & R L B \\
\hline 2. & & $(0-1)$ & $R \quad L \quad B$ \\
\hline 3. - & & $(0-1)$ & $R<B$ \\
\hline 4. & & $(0-2)$ & $R \quad L \quad B$ \\
\hline 5. & & (a-2) & $A L B$ \\
\hline & & $(0-3)$ & $A<B$ \\
\hline 7. & & $(0-3)$ & $R \quad L \quad B$ \\
\hline & & $(0-3)$ & $R \quad B$ \\
\hline & & $(0-3)$ & R L B \\
\hline & Total & $\operatorname{Max}=19$ & \\
\hline & & Test 12 & \\
\hline
\end{tabular}

\begin{tabular}{|l|c|c|c|}
\hline 13. DRAW-A-CHILD & \multicolumn{2}{|c|}{ Administer only it child eamed 1 or more points on Test 12.} \\
\hline & $\begin{array}{c}\text { Score } \\
(0-2)\end{array}$ & $\begin{array}{c}\text { Preferred } \\
\text { Hand }\end{array}$ & Child's Comments \\
\hline 1. Head & & & \\
\hline 2. Hair & & \\
\hline 3. Eyes & & \\
\hline 4. Nose & & \\
\hline 5. Mouth & & \\
\hline 6. Neck & & \\
\hline 7. Trunk & & \\
\hline 8. Arms and hands & & \\
\hline 9. Attachment of arms & & \\
\hline 10. Legs and feet & & \\
\hline
\end{tabular}

\begin{tabular}{|c|c|c|c|c|}
\hline \multicolumn{5}{|c|}{ LATERALITY SUMMARY } \\
\hline \multicolumn{5}{|c|}{ HAND DOMINANCE } \\
\hline Test 10, Part I & Ball bouncing & $\mathbf{R}$ & $\mathbf{L}$ & $\mathbf{B}$ \\
\hline Test 10, Part II, item 2 & Beanbag catch & $\mathbf{R}$ & $\mathbf{L}$ & \\
\hline Test 10, Part III, item 1 & Beanbag throw & $\mathbf{R}$ & $L$ & \\
\hline Tests $12 \& 13$, all items & Drawing & $\mathbf{R}$ & $L$ & B \\
\hline & Totals & $\mathbf{R}$ & 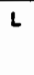 & B \\
\hline
\end{tabular}

HAND DOMINANCE

Check one: (See pages 148-149 of manual.)
$\square$ Dominance Established (Right-Handed)
$\square$ Dominance Established (Left-Handed)
$\square$ Dominance Not Established
$\square$ Not Scorable

EYE USED IN SIGHTING (Test 11, item 4)

Check one: (See page 149 of manual.)
$\square$ Right
$\square$ Left
$\square$ Not Scorable 


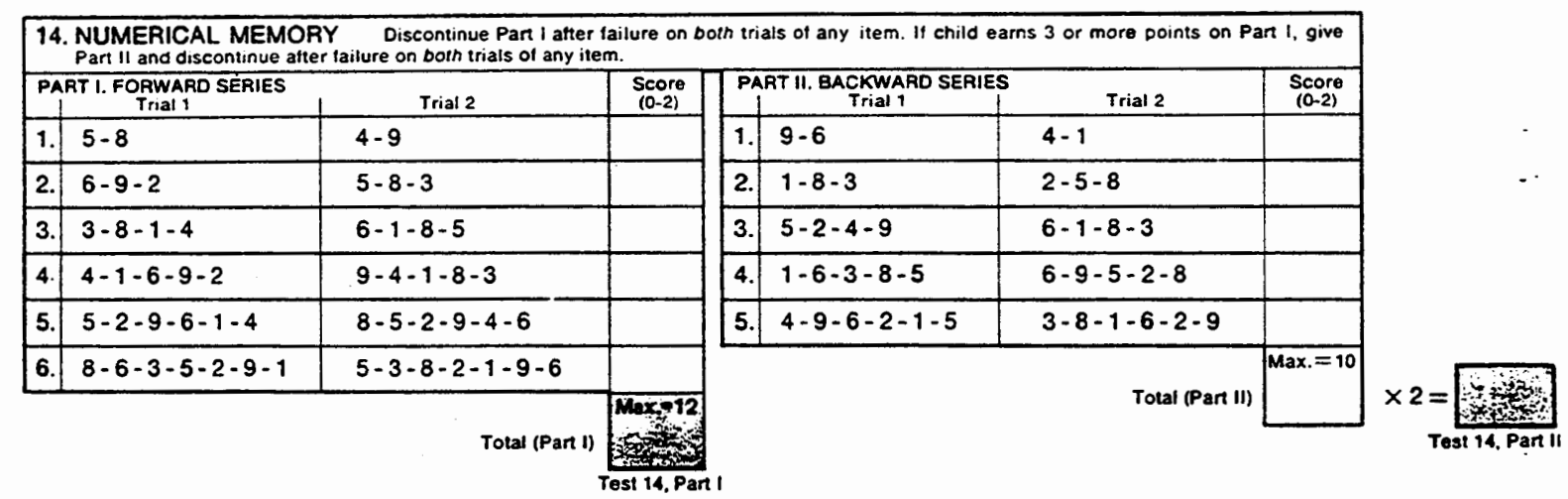

\begin{tabular}{|c|c|c|c|}
\hline \multicolumn{4}{|c|}{ 15. VERBAL FLUENCY } \\
\hline & $\underset{\text { Lime }}{\text { Timit }}$ & Record Responses Verbatim & $\begin{array}{l}\text { Score } \\
(0-9)\end{array}$ \\
\hline $\begin{array}{l}\text { 1. Things to eat } \\
\text { Examples: } \\
\text { bread } \\
\text { potatoes }\end{array}$ & $20^{\prime \prime}$ & & \\
\hline $\begin{array}{l}\text { 2. Animals } \\
\text { Examples: } \\
\text { cat } \\
\text { bear }\end{array}$ & $20^{\prime \prime}$ & & \\
\hline $\begin{array}{l}\text { 3. Things to wear } \\
\text { Example: } \\
\text { shoes }\end{array}$ & $20^{\prime \prime}$ & . & \\
\hline $\begin{array}{l}\text { 4. Things to ride } \\
\text { Example: } \\
\text { bus }\end{array}$ & $20^{\prime \prime}$ & & \\
\hline & & & 43 \\
\hline
\end{tabular}

\begin{tabular}{|c|c|}
\hline \multicolumn{2}{|c|}{$\begin{array}{l}\text { 16. COUNTING AND SORTING If child passed } \\
\text { g or more items on Test } 5 \text {, give full credit on Test } 16 . \\
\text { Otherwise. administer Test it and discontinue after } 4 \\
\text { consecutive failures. }\end{array}$} \\
\hline & $\begin{array}{c}\text { Score } \\
(0-1)\end{array}$ \\
\hline \multicolumn{2}{|l|}{ 1. Takes 2 blocks } \\
\hline \multicolumn{2}{|l|}{ 2. Takes 3 more blocks } \\
\hline \multicolumn{2}{|l|}{ 3. Answer: 5} \\
\hline \multicolumn{2}{|l|}{ 4. Puts 2 blocks on each card } \\
\hline \multicolumn{2}{|l|}{ 5. Answer: 2} \\
\hline \multicolumn{2}{|l|}{ 6. Puts 5 blocks on each card } \\
\hline \multicolumn{2}{|l|}{ 7. Answer: 5} \\
\hline \multicolumn{2}{|l|}{ 8. Point: 2nd block from left } \\
\hline \multicolumn{2}{|l|}{ 9. Point: 4th block from right } \\
\hline Total & Test 16 \\
\hline
\end{tabular}




\begin{tabular}{|l|l|}
\hline 17. OPPOSITE ANALOGIES & $\begin{array}{c}\text { Score } \\
(0-1)\end{array}$ \\
\hline 1. The sun is hot, and ice is . & \\
\hline 2. I throw the ball up, and then it comes & \\
\hline $\begin{array}{l}\text { Continue only it child answers at least one of items } 1 \text { and } 2 \text { cor- } \\
\text { rectly, and discontinue after } 3 \text { consecutive ailures on items 3-9. }\end{array}$ & \\
\hline 3. An elephant is big, and a mouse is & \\
\hline 4. Running is fast, and walking is & \\
\hline 5. Cotton is soft, and rocks are & \\
\hline 6. A lemon is sour, and candy is & \\
\hline 7. Feathers are light, and stones are & \\
\hline 8. Syrup is thick, and water is & \\
\hline 9. Sandpaper is rough, and glass is & \\
\hline
\end{tabular}

\begin{tabular}{|c|c|c|c|c|}
\hline \multicolumn{2}{|c|}{$\begin{array}{l}\text { 18. CONCEPTUAL GROUPING } \\
\text { consecutive tailures. }\end{array}$} & \multicolumn{3}{|c|}{ Discontinue atter 4} \\
\hline & & & & Score \\
\hline \multicolumn{4}{|l|}{ 1. Little, big } & $(0.1)$ \\
\hline \multicolumn{4}{|l|}{ 2. Red, yellow, blue } & $(0-1)$ \\
\hline \multicolumn{4}{|l|}{ 3. Square, round } & (0-1) \\
\hline & $\begin{array}{l}\text { Number } \\
\text { Right }\end{array}$ & $\begin{array}{l}\text { Number } \\
\text { Wrong }\end{array}$ & $\begin{array}{l}\text { Right } \\
\text { Minus } \\
\text { Wrong }\end{array}$ & \\
\hline 4. Square blocks & $(0-6)$ & $(0-6)$ & $(0-6)$ & $(0-2)$ \\
\hline 5. Big yellow blocks & $(0-2)$ & $(0-10)$ & $(0-2)$ & $(0-2)$ \\
\hline \multicolumn{4}{|l|}{ 6. Big round red block } & $(0-1)$ \\
\hline \multicolumn{4}{|l|}{ 7. Small blue square } & $(0-1)$ \\
\hline \multicolumn{4}{|l|}{ 8. Large blue square } & $(0-1)$ \\
\hline \multicolumn{4}{|c|}{ 9. Large yellow circle and small yellow square } & $(0-2)$ \\
\hline \multirow{2}{*}{\multicolumn{4}{|c|}{ Total }} & $\max -12$ \\
\hline & & & & $\frac{18+3}{\text { Test } 18}$ \\
\hline
\end{tabular}

NOTES: 


\section{COMPUTATION OF COMPOSITE RAW SCORES}

1. Enter the weighted raw scores which are in the shaded boxes on pages 2-7 of the record form. For each test, enter the score in the box(es) bearing that test's number. (For example, the score for Test 3 is entered in 2 boxes.)

2. Sum the scores in each of the 5 columns. Enter the totals in the composite raw score boxes at the foot of the page.

3. Transter the composite raw scores to the front cover. (Open the booklet and turn it over so that the front and back covers are side by side.) Enter the scores in the Composite Raw Score column in the box labeled "Composite Raw Scores and Scale Indexes."

(For more detailed directions on the completion of the record form, see Chapter 7 of manual.)

\section{Block Building \\ 2. Puzzle Solving \\ 3. Pictorial Memory}

4. Word Knowledge, $1+11$

5. Number Questions

6. Tapping Sequence

7. Verbal Memory, I

“ $", 11$

\section{Right-Left Orientation} (Ages 5 and over ONLY)

\section{Leg Coordination}

10. Arm Coordination, $1+11+111$

11. Imitative Action

12. Draw-A-Design

13. Draw-A-Child

14. Numerical Memory, I<smiles>[AlH2]</smiles>

15. Verbal Fluency

16. Counting and Sorting

17. Opposite Analogies

18. Conceptual Grouping

COMPOSITE RAW SCORE

WEIGHTED RAW SCORES

V

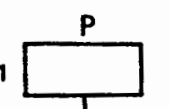

2

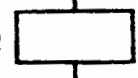

3

4
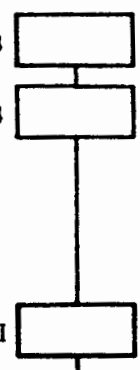

7II

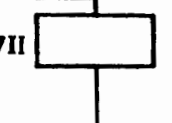

o

Mem

Mot 


\section{APPENDIX H \\ DEVELOPMENTAL SENTENCE SCORE: \\ SCORING CRITERIA}

Lee, L. L. (1974). Developmental sentence analysis. Evanston:

Northwestern University Press. 
Chart 8. The Developmental Sentence Scoring (DSS) Reweighted Scores

\begin{tabular}{|c|c|c|c|c|}
\hline SCORE & \begin{tabular}{|l|} 
INDEFINITE PRONOUNS \\
OR NOUN MODIFIERS \\
\end{tabular} & $\begin{array}{l}\text { PERSONAL } \\
\text { PRONOUNS } \\
\end{array}$ & MAIN VERBS & SECONDARY VERBS \\
\hline 1 & it, this, that & $\begin{array}{l}\text { 1st and 2nd person: I. } \\
\text { me, my, mine, you, } \\
\text { your(s) }\end{array}$ & 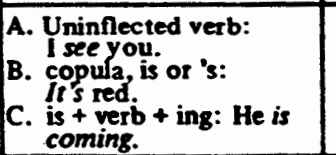 & \\
\hline 2 & & $\begin{array}{l}\text { 3rd person: he, him, his, } \\
\text { she, her, hers }\end{array}$ & $\begin{array}{l}\text { A. Sand ed: plays, } \\
\text { played } \\
\text { B. urtegular past: } \\
\text { ate. sow } \\
\text { c. Copula: am, are, } \\
\text { was, were , } \\
\text { D. Auxiliary am, are, } \\
\text { was, were }\end{array}$ & 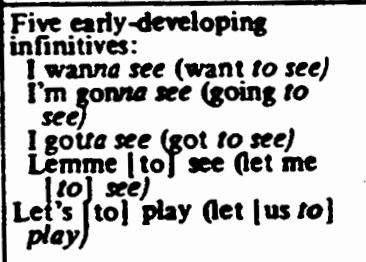 \\
\hline 3 & $\begin{array}{l}\text { A. no, some, more, all, } \\
\text { lot(s). one(s) two } \\
\text { (etc.).other(s). } \\
\text { 2nother } \\
\text { B. something, some- } \\
\text { body, someone }\end{array}$ & $\begin{array}{l}\text { A. Piurals we. us our (s). } \\
\text { B. they, them, their } \\
\text { Bese, those }\end{array}$ & & $\begin{array}{l}\text { Non-complementing } \\
\text { infinitives: } \\
\text { Istopped to ploy. } \\
\text { lmm arrad ro look. } \\
\text { It's hard fo do that. }\end{array}$ \\
\hline 4 & $\begin{array}{l}\text { nothing, nobody, none, } \\
\text { no one }\end{array}$ & & 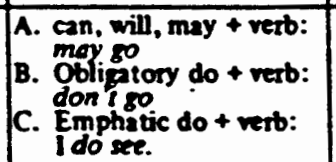 & $\begin{array}{l}\text { Participle, present of past: } \\
\text { I see a boy nunning. } \\
\text { I found the toy broker. }\end{array}$ \\
\hline 5 & & $\begin{array}{l}\text { Reflexives: myself, your- } \\
\text { sefs, himseif, hersed?. } \\
\text { itself, themsedves }\end{array}$ & tons & 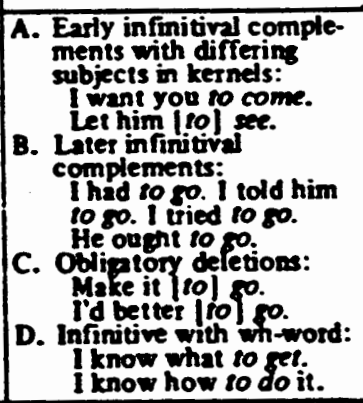 \\
\hline 6 & & 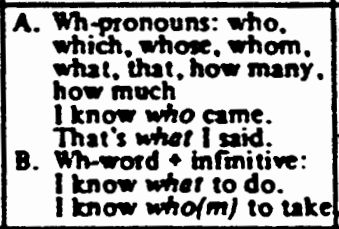 & 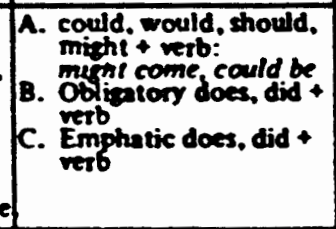 & \\
\hline 7 & 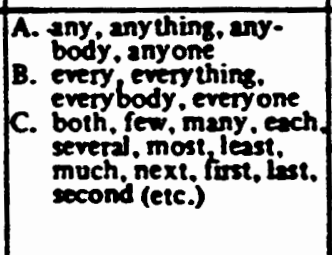 & $\begin{array}{l}\text { (his) own, one. oneself. } \\
\text { whichevet. whoeva. } \\
\text { watever } \\
\text { Take whatever you like. }\end{array}$ & 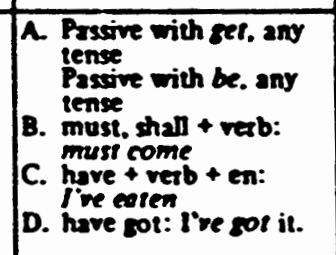 & $\begin{array}{l}\text { Passive infinitival } \\
\text { complement: } \\
\text { With get: } \\
\text { I have ro get dressed. } \\
\text { I don't want so get hurn. } \\
\text { With be: } \\
\text { I want ro be pulled. } \\
\text { lit's going to be locked. }\end{array}$ \\
\hline 8 & & & 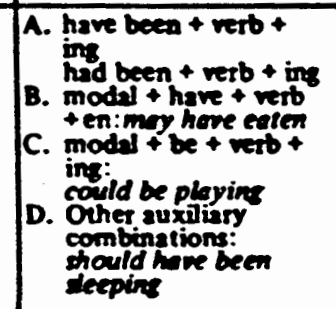 & $\begin{array}{l}\text { Gervund: } \\
\text { Swinsing is fon. } \\
\text { Illike fishing } \\
\text { He stanted louphing. }\end{array}$ \\
\hline
\end{tabular}




\begin{tabular}{|c|c|c|c|}
\hline NEGATIVES & CONIUNCTIONS & $\begin{array}{c}\text { INTERROGATIVE } \\
\text { REVERSALS }\end{array}$ & WH-QUESTIONS \\
\hline \multirow[t]{3}{*}{$\begin{array}{l}\text { it, this, that t copula or } \\
\text { auxiliary is, s, t not: } \\
\text { I!'s not mine. } \\
\text { This is not a dog. } \\
\text { That is not moning. }\end{array}$} & & $\begin{array}{l}\text { Reversal of copula: } \\
\text { Isn't it red? Were they } \\
\text { thete? }\end{array}$ & \\
\hline & & & 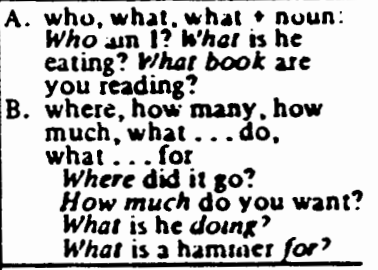 \\
\hline & and & & \\
\hline $\operatorname{cas}^{\prime} t$. don't & & $\begin{array}{l}\text { Reversal of auxiliary be: } \\
\text { is he cuming? Isn' he } \\
\text { coming? W'as he going? } \\
\text { Wasn't he soing? }\end{array}$ & \\
\hline \multirow[t]{2}{*}{ iss't, won't } & $\begin{array}{l}\text { A. but } \\
\text { B. so, and so, so that } \\
\text { C. or, if }\end{array}$ & & $\begin{array}{l}\text { when, how how }+ \text { adjective } \\
\text { When shall I come? } \\
\text { How do you do it? } \\
\text { How big is it? }\end{array}$ \\
\hline & because & 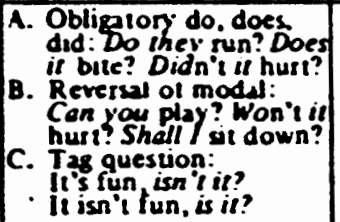 & \\
\hline \multirow[t]{2}{*}{$\begin{array}{l}\text { All Other negatives: } \\
\text { A. Uncontracted negatives: } \\
\text { I can not go. } \\
\text { He has nol gone. } \\
\text { B. Pronoun-auxiliary or } \\
\text { pronoun-copula } \\
\text { contraction: } \\
\text { I'm nol coming. } \\
\text { He's not here. } \\
\text { C. Auxiliary-negntive or } \\
\text { copula-ngsative } \\
\text { contraction: } \\
\text { He wasn't going. } \\
\text { He hasn't Been seen. } \\
\text { It couldn't be mine. } \\
\text { They aren't big. } \\
\end{array}$} & $\cdot$ & & $\begin{array}{l}\text { why what if, how come } \\
\text { how about t gerund } \\
\text { Why are you crying? } \\
\text { What if I won' do it? } \\
\text { How come he is crying? } \\
\text { How eboul coming with me? }\end{array}$ \\
\hline & 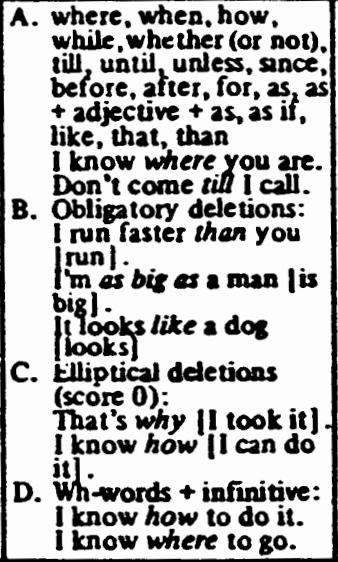 & $\begin{array}{l}\text { A. Reversal of auxiliary } \\
\text { have: } \\
\text { Has he seen you? } \\
\text { B. Reversal with two or } \\
\text { three auxiliaries: } \\
\text { Hes he been eating? } \\
\text { Couldn't he have } \\
\text { waited? } \\
\text { Could he hove been } \\
\text { crying? } \\
\text { Wound n't he heve been } \\
\text { going? }\end{array}$ & $\begin{array}{l}\text { whose, which, which + noun } \\
\text { Whose car is that? } \\
\text { Which book do you want? }\end{array}$ \\
\hline
\end{tabular}




\section{APPENDIX I}

\section{DEVELOPMENTAL SENTENCE SCORE: \\ NORMS}

Lee, L. L. (1974). Developmental sentence analysis. Evanston:

Northwestern University Press. 


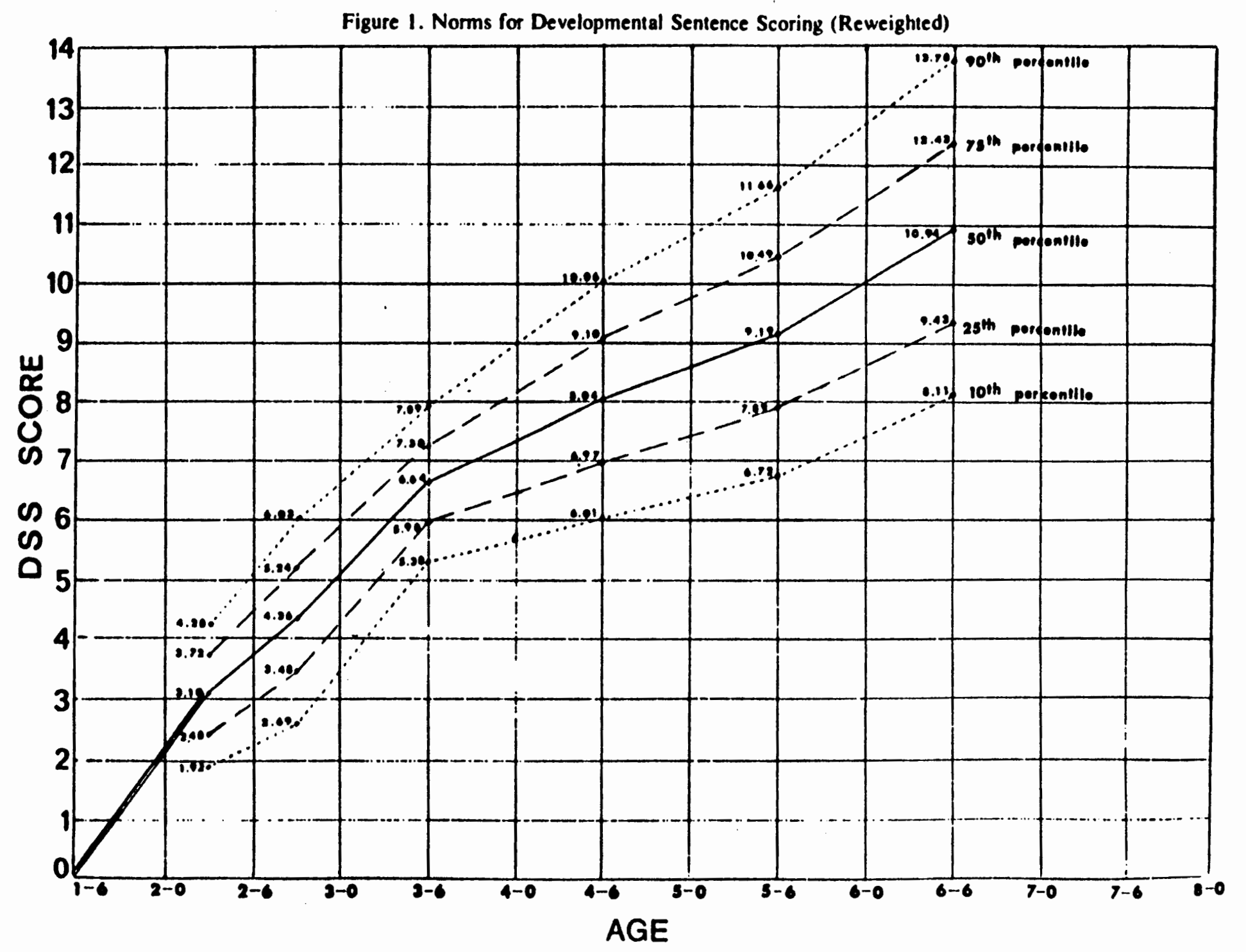




\section{APPENDDX J}

\section{VINELAND ADAPTIVE BEHAVIOR SCALES}

Sparrow, S. S., Balla, D. A., \& Ciccnetti, D. V. (1984). Vineland adaptive behavior scales. Circle Pines, MN: American Guidance Service. 


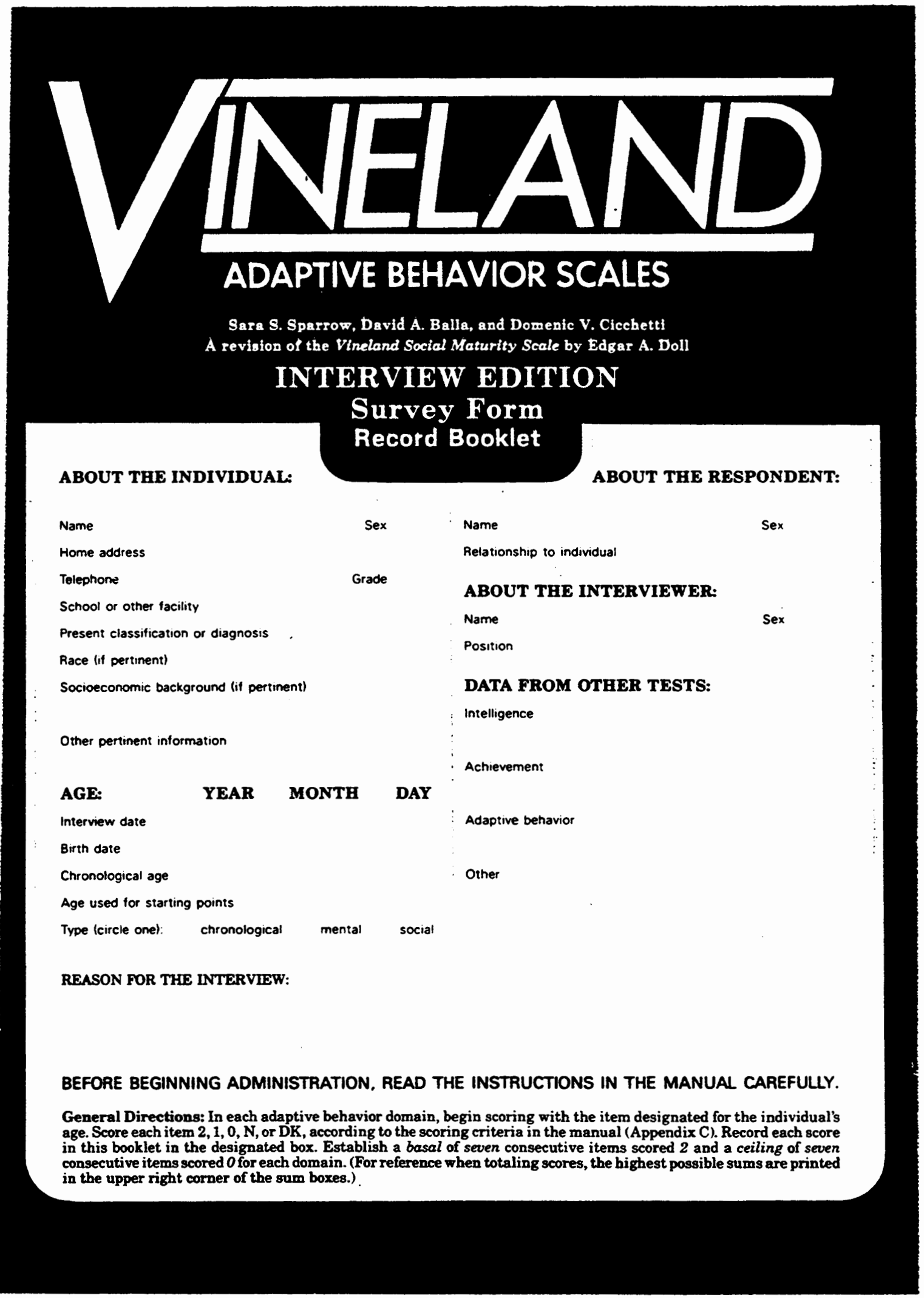




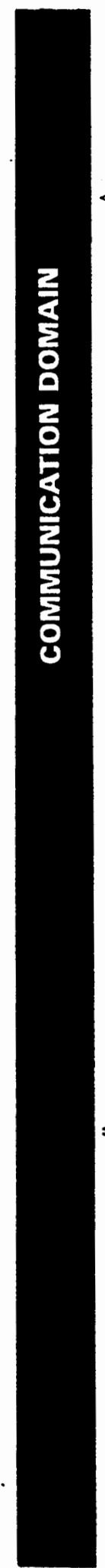
Yes. usually
Sometimes or partially
ITEM
DK Don opportunity

<1. Turns eyes and head toward sound

2. Listens at least momentarily when spoken to by caregiver

3. Smiles in response to presence of caregiver

4. Smiles in response to presence of familiar person other than caregiver.

5. Raises arms when caregiver says. "Come here" or "Up."

6. Demonstrates understanding of the meaning of "no.

7. Imitates sounds of adults immediatety after hearing them.

8. Demonstrates understanding of the meaning of at least 10 words

9. Gestures appropriately to indicate "yes." "no." and "I want."

10 Listens attentively to instructions.'

11. Demonstrates understanding of the meaning of "yes" of "okay."

12. Follows instructions requiting an action and an object.

13. Points accurately to at least one major body part when asked.

14. Uses first names or nicknames of siblings. friends. or peers, or states their names when asked.

15. Uses phrases containing a noun and a verb. or two nouns.

16. Names at least 20 familiar objects without being asked. DO NOT SCORE 1

17. Listens to a story for at least five minutes.

18. Indicates preference when offered a choice.

2 19. Says at least 50 recognizable words. DO NOT SCORE 1

20. Spontaneously relates experiences in simple terms.

21. Delivers a simple message

22. Uses sentences of four or more words.

23. Points accurately to all body parts when asked. DO NOT SCORE 1.

24. Says at least 100 recognizable words. DO NOT SCORE 1.

25. Speaks in full sentences

26. Uses " $a$ " and "the" in phrases or sentences.

27. Follows instructions in "if-then" form

28. States own first and last name when asked.

29. Asks questions beginning with "what," "where." "who." "why." and when." DO NOT SCORE 1 .

3.4 30. States which of two objects not present is bigger

31 Relates experiences in detail when asked

32. Uses either "behind" or "between" as a preposition in a phrase

33. Uses "around" as a preposition in a phrase.

Count items before basal as 2. items after ceiling as 0 


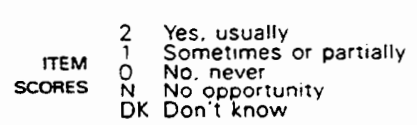

34. Uses phrases or sentences containing "but" and "or." 35. Articulates clearly. without sound substitutions 36. Tells popular story, fairy tale. lengthy joke. or television show piot

s 37. Recites all letters of the alchabet from memory. 38. Reads at least three common signs.

39. States month and day of birthday when asked. 40. Uses irregular plurals

- 41. Prints or writes own first and last name 42. States telephone number when asked. N MAY BE SCORED

43. States complete home address, including city and state. when asked 44. Reads at least 10 words silently or aloud 45. Prints or writes at least 10 words from memory.

46. Expresses ideas in more than one way. without assistance. 47. Reads simple stories aloud

7.8 48. Prints or writes simple sentences of three or four words 49. Attends to school or public lecture more than 15 minutes. 50. Reads on own initiative.

51. Reads books of at least second-grade level

52. Arranges items or words atphabetically by first letter

53. Prints or writes short notes or messages.

- 54. Gives complex directions to others.

55. Writes beginning letters. DO NOT SCORE 1

56. Reads books of at least fourth-grade level.

57. Writes in cursive most of the time. DO NOT SCORE 1

10 to 58 . Uses a dictionary.

59. Uses the table of contents in reading materials.

60. Writes reports or compositions. DO NOT SCORE 1

61. Addresses envelopes completely.

62. Uses the index in reading materials.

63. Reads adult newspaper stories. N MAY BE SCORED.

64. Has realistic long-range goals and describes in detail plans to achieve them

65. Writes advanced letters.

66. Reads adult newspaper or magazine stories each week. N MAY BE SCORED

67. Writes busıness letiers. DO NOT SCORE 1.

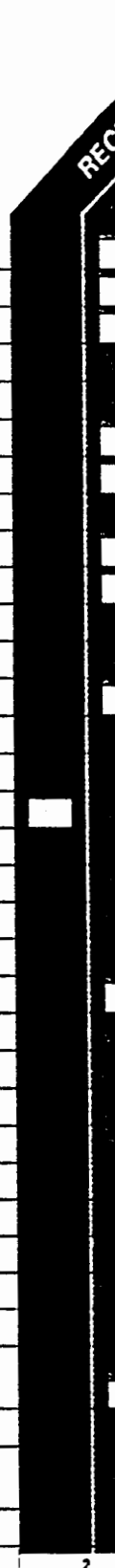

1.

2.

3.

4.
Sum of $2 \mathrm{~s}$, is. Os page 3 Sum of 2 s. 1s. Os page 2 Number of Ns pages 2 and 3 Number of DKs pages 2 and 3 SUBDOMAIN RAW SCORE (Add rows $1-4$ above)

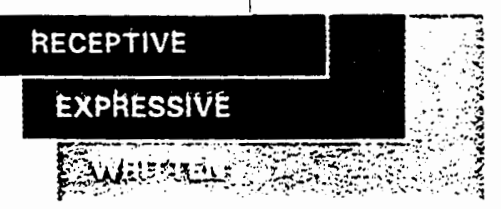


Vineland Adaptive Behavior Scales: INTERVIEW EDITION Survey Form

Individual's name.

Date of interviow.

Chronological oge
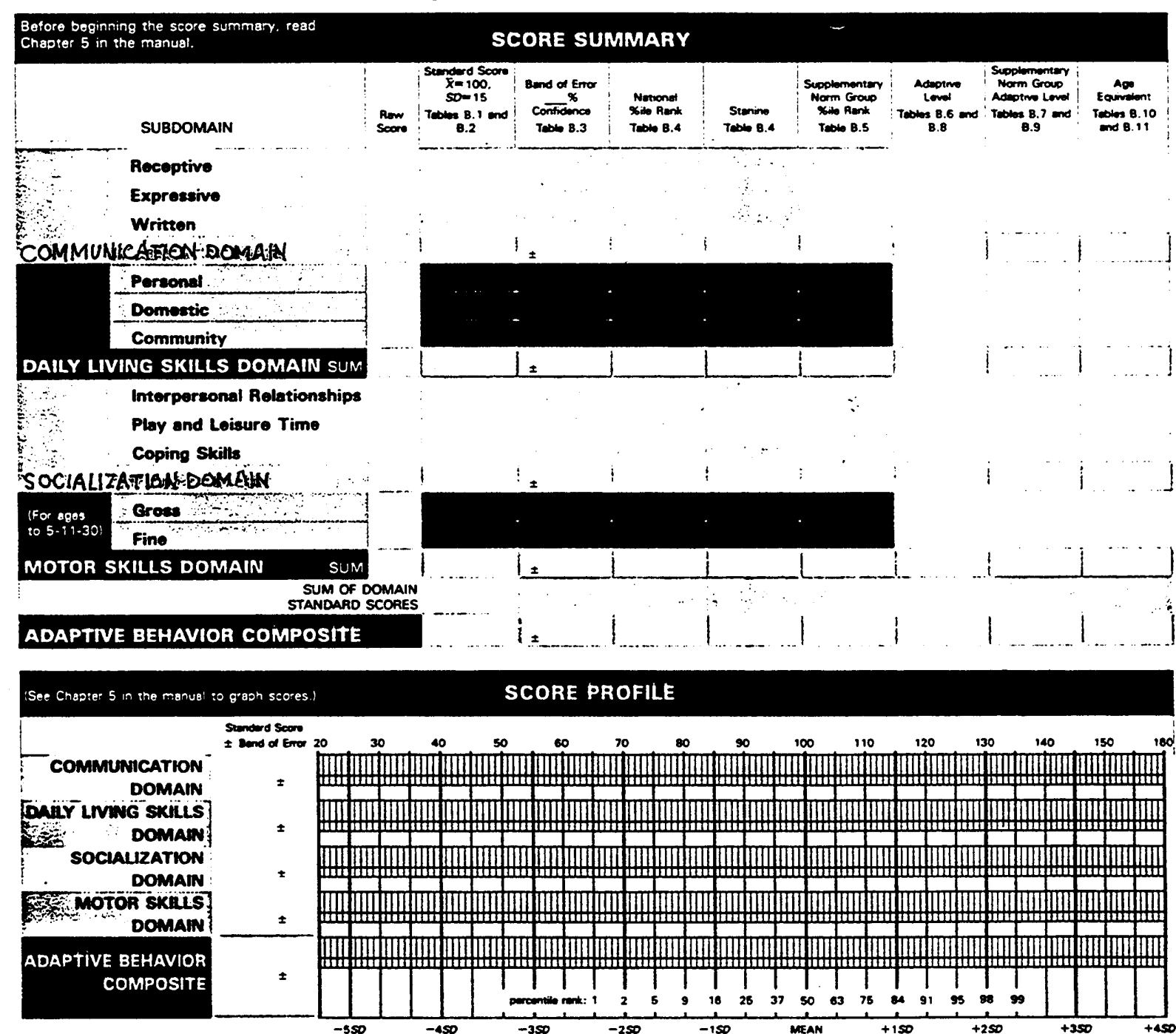

\section{OPTIONAL}

MALADAPTIVE BEHAVIOR DOMAIN

(Administer for ages 5-0-0 and older)

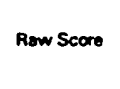

Maladeptive Level: Table B.12 Maledestive Level: Teblo B.13

Additional interpretive information (see Chapters 5 and 6 in the manual)

-.

Recommendations 
APPENDIX K

RAW DATA 
Raw Data Collected from Ǩindergarten Evvaluation: Controi Group

\begin{tabular}{|c|c|c|c|c|c|}
\hline $\begin{array}{c}\text { Subject } \\
\#\end{array}$ & $\frac{\text { MSCA }}{\text { PP** }^{* *}}$ & $\frac{\text { MSCA }}{\text { GCI* }}$ & $\frac{\text { DAM }}{*}$ & $\frac{\mathrm{DSS}}{* * *}$ & $\frac{\text { VABS }}{* *}$ \\
\hline 012 & 54 & 112 & 94 & 7.44 & 24 \\
\hline 014 & 64 & 116 & 114 & 7.54 & 24 \\
\hline 027 & 78 & 140 & 104 & 6.68 & 24 \\
\hline 032 & 47 & 98 & 109 & 6.55 & 24 \\
\hline 036 & 72 & 132 & 108 & 7.34 & 26 \\
\hline 039 & 77 & 132 & 140 & 7.41 & 24 \\
\hline 041 & 63 & 134 & 101 & 9.64 & 24 \\
\hline 050 & 42 & 101 & 89 & 6.92 & 25 \\
\hline 055 & 60 & 122 & 99 & 8.24 & 26 \\
\hline 058 & 52 & 123 & 119 & 10.62 & 24 \\
\hline 059 & 66 & 131 & 117 & 7.74 & 24 \\
\hline 063 & 62 & 121 & 99 & 11.35 & 24 \\
\hline 072 & 53 & 98 & 111 & 6.82 & 24 \\
\hline 078 & 60 & 104 & 113 & 7.09 & 24 \\
\hline 081 & 65 & 128 & 125 & 9.28 & 24 \\
\hline 095 & 58 & 111 & 97 & 6.38 & 24 \\
\hline 113 & 60 & 124 & 93 & 8.96 & 24 \\
\hline 129 & 49 & 102 & 79 & 7.46 & 25 \\
\hline 130 & 62 & 126 & 118 & 8.50 & 25 \\
\hline 131 & 57 & 130 & 133 & 8.42 & 26 \\
\hline 132 & 77 & 129 & 135 & 9.26 & 26 \\
\hline 138 & 50 & 105 & 103 & 7.48 & 24 \\
\hline 139 & 57 & 130 & 133 & 8.42 & 26 \\
\hline 141 & 56 & 116 & 112 & 6.36 & 26 \\
\hline 144 & 63 & 125 & 100 & 7.36 & 24 \\
\hline 150 & 64 & 120 & 148 & 7.32 & 25 \\
\hline
\end{tabular}

* Standard Scores ** Raw Scores *** Derived Scores 
Raw Data Collected from Kindergarten Evaluation: ELD Group

\begin{tabular}{|c|c|c|c|c|c|}
\hline $\begin{array}{c}\text { Subject } \\
\#\end{array}$ & $\frac{\text { MSCA }}{\text { PP** }}$ & $\frac{\text { MSCA }}{\text { GCI* }^{*}}$ & $\frac{\text { DAM }}{*}$ & $\frac{\mathrm{DSS}}{* * *}$ & $\frac{\text { VABS }}{* *}$ \\
\hline 006 & 38 & 83 & 86 & 5.94 & 24 \\
\hline 007 & 55 & 121 & 111 & 6.74 & 24 \\
\hline 015 & 33 & 70 & 92 & 5.13 & 25 \\
\hline 019 & 41 & 87 & 89 & 8.11 & 24 \\
\hline 029 & 45 & 87 & 136 & 6.62 & 24 \\
\hline 053 & 52 & 103 & 92 & 9.02 & 24 \\
\hline 057 & 56 & 103 & 124 & 6.82 & 24 \\
\hline 084 & 73 & 127 & 137 & 0.00 & 25 \\
\hline 085 & 56 & 92 & 131 & 5.82 & 24 \\
\hline 087 & 51 & 110 & 110 & 8.96 & 24 \\
\hline 092 & 71 & 133 & 129 & 7.38 & 24 \\
\hline 093 & 51 & 95 & 107 & 6.68 & 24 \\
\hline 094 & 66 & 116 & 104 & 6.06 & 24 \\
\hline 097 & 66 & 115 & 120 & 7.40 & 24 \\
\hline 100 & 52 & 109 & 96 & 6.23 & 24 \\
\hline 102 & 51 & 101 & 90 & 7.98 & 24 \\
\hline 103 & 58 & 115 & 120 & 7.40 & 24 \\
\hline 105 & 61 & 124 & 133 & 9.06 & 24 \\
\hline 107 & 78 & 127 & 165 & 8.50 & 24 \\
\hline 111 & 52 & 101 & 123 & 7.44 & 22 \\
\hline 114 & 49 & 104 & 93 & 11.16 & 24 \\
\hline 119 & 44 & 118 & 90 & 6.86 & 24 \\
\hline 142 & 56 & 113 & 93 & 6.30 & 24 \\
\hline
\end{tabular}

* Standard Scores ** Raw Scores *** Derived Scores 